NBSIR 81-2417(R)

\title{
Technical Activities 1981 Office of Recycled Materials
}

U.S. DEPARTMENT OF COMMERCE.

National Bureau of Standards

National Measurement Laboratory

Office of Recycled Materials

Washington, DC 20234

November 1981

Prepared for

National Bureau of Standards

QC Jepartment of Commerce

100 Nashington, DC 20234

456

$\$ 81.2417$

1981 

TECHNICAL ACTIVITIES 1981 OFFICE OF RECYCLED MATERIALS

Donald A. Becker, Joseph G. Berke, Eugene S. Domalski,

Rosalie T. Matthews, and Harvey Yakowitz, editors

U.S. DEPARTMENT OF COMMERCE

National Bureau of Standards

National Measurement Laboratory

Office of Recycled Materials

Washington, DC 20234

November 1981

Prepared for

National Bureau of Standards

Department of Commerce

Washington, DC 20234

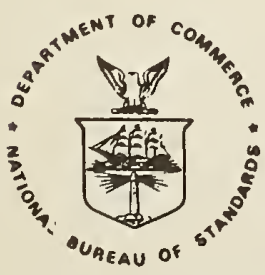

U.S. DEPARTMENT OF COMMERCE, Malcolm Baldrige, Secretary NATIONAL BUREAU OF STANDARDS, Ernest Ambler, Director 



\section{TABLE OF CONTENTS}

\section{Page}

Technical Activities

The Recycled 0il Progran 1

I. Introduction ............. 2

II. The NBS Role in Recyiled $0 i 1 \ldots . . . . .4$

III. The Current NBS Program . . . . . . . . 6

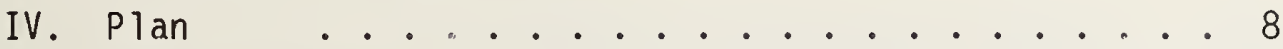

․ Implementation .............. 15

VI. Discussion ................... 23

The Resource Conservation Program 27

I. Goal and Objectives .............28

II. Introduction . . . . . . . . . . . 30

III. Needs . . . . . . . . . . 33

IV. Current Activities 34

A. Resource Recovery Program ........ . 35

B. Technical Advisory Center ......... 100

IV. Discussion . . . . . . . . . . 110

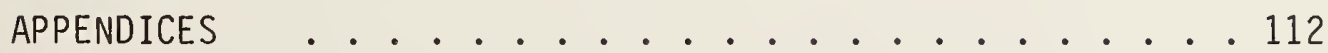




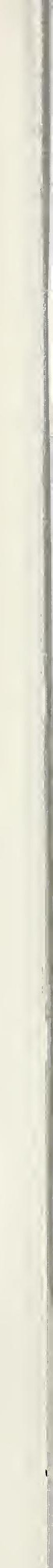


The NBS Recycled 0 il Program was established in 1976, in direct response to passage of the Energy Policy and Conservation Act of 1975 (EPCA, Public Law 94-163; 42 U.S.C. 6201 et seq.). Section 383(c) of this law requires NBS to "... develop test procedures for the determination of substantial equivalency of re-refined or otherwise processed used oil or blend of oil... with new oil for a particular end use."

This article is divided into five sections, and includes a description of the past problems and the current situation in the oil recycling industry as well as the past and present endeavors of the NBS Recycled 0 il Program itself.

The stated GOAL of the Recycled 0 il Program Program is: to provide the measurement methods and standards required for effective utilization of recycled petroleum products. This GOAL is being achieved through:

(1) establishng the scientific and technical basis for characterization of recycled petroleum products;

(2) developing and evaluating test procedures for establishing the substantial equivalency between recycled and virgin petroleum products; and

(3) providing technical information and support for the effective utilization of recycled petroleum products.

These goals are being implemented through research and development activities both within NBS and at several outside institutions. 


\section{Introduction}

$0 i 1$ recycling is not a new idea but in fact dates back to about 1920 . At that time lubricating oils had few or no additivies, (i.e., chemical compounds added to oils to improve lubrication characteristics such as wear, oxidation, corrosion) and recycling these oils required only limited processing which included heating (to remove volatile components), settling (to separate water, dirt and sludge), and finally centrifuging or filtering to remove most of the remaining insoluble contaminants. With this limited processing, lubricating oils could be brought back to essentially original oil quality. In the years following, the types of lubricating oils in the marketplace have expanded until they include a wide variety of different kinds and qualities of oils, many containing high levels of additives which can make recycling the used oils a much more difficult problem.

In 1980, new lubricating oil sales in the U.S. were estimated at $9.5 \times 10^{6}$ cubic meters $\left(2.5 \times 10^{9}\right.$ gallons $)$ per year. Of this, automotive lubricants represented $4.5 \times 10^{6}$ cubic meters $\left(1.2 \times 10^{9}\right.$ gallons), and industrial lubricants the remainder or approximately $5 \times 10^{6}$ cubic meters $\left(1.3 \times 10^{9}\right.$ gallons $)$. These industrial lubricants include hydraulic oils, quenching oils, cutting oils, metal working oils, electrical oils and process oils.

From the $9.5 \times 10^{6}$ cubic meters of lubricating oils sold, about onehalf or approximately $4.8 \times 10^{6}$ cubic meters of collectable used oil are generated annually in the U.S. It is estimated that, of the used $0 i 1$ which is collected each year, about $7 \%$ is re-refined into motor $011,17 \%$ is reclaimed into industrial 011 , approximately $50 \%$ burned for fuel or used in road oiling and dust control (often with little processing to remove contaminants), with the fate of the remaining $25 \%$ (approximately $1.2 \times 10^{6}$ cubic meters each year) unknown.

At the present time there are a relatively small number of $0 i 1$ recyclers in the U.S., with estimates ranging between 30 to 50 . Of these, only 10-20 are re-refiners, who produce a high quality lubricating $0 i 1$ basestock from the used oil. The individual companies involved in oil recycling usually are smal1, averaging only 10 - 15 employees. These recyclers fall into three categories: processors (processing used oil for reuse as a fuel, often only removing free-standing water and larger pieces of dirt or rust); reclaimers (generally applying a variety of relatively simple chemical and/or physical processes to the used oil for reuse as an industrial oil); and re-refiners (employing a number of different high technologies, generally with acid/clay or distillation/finishing treatment, to remove essentially all of the impurities and contaminants in the oil, yielding clean, high quality lubricating base oils). In many cases an oil recycler may be involved with more than one of these categories, and at times with all three. 
In the past there has been a number of regulatory obstacles to increased recycling of used oils in the U.S. Two of the most significant of these were: (1) a 1965 Federal Trade Commission (FTC) trade regulation rule, and (2) the exclusionary clauses in various Federal and military specifications. The first of these, the FTC trade regulation rule, required that all recycled motor oils contain the label "...made from previously used oils..." This requirement was harmful to the image of re-refined $\mathrm{Ci} / \mathrm{s}$, and was recently modified by the Used $0 i 1$ Recycling Act of 1980 (P. L. 96-463). This law now removes the FTC requirement of 1 abeling as to origin until future labeling standards directed by the Energy Policy and Conservation Act (P.L. 94-163, Section 383) become effective (i.e., NBS test procedures as provided to the FTC).

A seconc obstacle to increased recycling of used oils had been the specific prohibition on the use of recycled petroleum products found in a number of Federal and military specifications (e.g., burner fuels and engine oils), regardless of the quality of the recycled products. In response to requirements in the Resource Conservation and Recovery Act (P.L. 94-580) and after a substantial study ${ }^{1}$, the Department of Defense (DoD) has recently issued revised specifications for both burner fuel oil (Federal specification VV-F-815d) and engine oils used in administrative vehicles (passenger cars and light trucks; MIL-L-46152B). These revised DoD specifications now allow the use of recycled oils in products submitted for their use, provided these recycled products meet all other requirements.

Technically, recycled lu'ricating oil products appear to be potentially suitable for all end uses with proper clean-up and additive treatment, since the basic hydrocarbon structure is not significantly altered during use. While non-technical factors (such as economics and availability) will obviously determine whether all potential end uses for recycled oil can be made available on a realistic basis, the national goals of energy conservation, resource conservation, pollution control, and balance of payments certainly suggest that a strong effort should be made in persuing the goal of effective oil recycling in the United States. 
II. The NBS Role in Recycled $0 i 1$

There are three areas of legislation which provide the framework outlining NBS responsibilities in oil recycling. These include (1) the National Bureau of Standards (NBS) organic act and its amendments, (2) the Energy Policy and Conservation Act and (3) the Resource Conservation and Recovery Act. The model "States Used $0 i 1$ Recycling Act," while not a specific article of legislation, also has an influence on the NBS responsibilites, and will be discussed briefly.

The NBS organic act (particularly 15 U.S.C. 272) states that the NBS responsibilities include in part "...the development of methods for testing materials...cooperation with other governmental agencies and with private organizations in the establishment of standard practices...the preparation and distribution of standard samples... the development of methods of chemical analysis...". While these functions do not specifically consider the subject of recycled oil, they are consistent with the efforts required of the Recycled $0 i 1$ Program as described in Sections III and IV.

The Energy Policy and Conservation Act (EPCA, Public Law 94-163; 42 U.S.C. 6201 et seq.) was the primary force in establishing the Recycled $0 i 1$ Program at NBS in September 1976. Section 383 (c) of this 1 aw requires the National Bureau of Standards to "... develop test procedures for the determination of substantial equivalency of re-refined or otherwise processed used oil or blend of $011 \ldots$ with new oil for a particular end use." It also requires that after development of these test procedures they be reported to the FTC. The stated purposes of this legislation were (1) to encourage the recycling of used oil; (2) to promote the use of recycled $011 ;$ (3) to reduce the consumption of new oil; and (4) to reduce the environmental hazards associated with disposal of used oils. This law implies that all potential end uses of recycled oil should be addressed including reuse as fuel, motor oils, hydraulic and industrial oils.

The Resource Conservation and Recovery Act (Public Law 94-580, 42 U.S.C. 3251), in Section 6002, states that each Federal agency shall procure items with the highest percentage of recovered materials practicable. It further states that any decision not to procure such recycled material must be based on one or more of the following: unavailability; unreasonable price; or failure to meet NBS performance standards (when available). This Act includes recycled oils as well as other recycled materials, and when taken in combination with the EPCA, requires that NBS address the problem of performance standards for recycled oils. In addition, this law requires that exclusionary clauses in Federal and Military specifications be reviewed by the appropriate Federal agency, and revised to encourage the use of recycled materials.

Finally, a model state "Used $0 i 1$ Recycled Act" was sponsored by the Federal Agency Administration in 1976 and published in the Federal Register. This model Act was designed to assist individual states in establishing control over used oil disposal, and clearly encourages recycling as a superior method of disposal. This model Act refers 
directly to Section 383 of EPCA for the determination of substantial equivalency for recycled petroleum products. Used oil recycling laws at present have been passed by at least eight states, and in many cases these laws are similar to the model Act. Several additional states have also introduced legislation based on this model Act.

The NBS role was recently confirmed by passage of the "Used $0 i 1$ Recycling Act of 1980" (P.L. 96-163). This Act was passed late in 1980 to alleviate the problem oil recyclers were having as a result of the FTC labelling requirements, but is to be in effect only until the NBS test procedures become available. The U. S. Congress Committee report further statei" "...the Committee believes that the work of the Bureau (of Standards) should continue.... The Committee expects the Bureau to give this work a high priority." 2

An important reason why recycled lubricating products have not yet met with widespread consumer acceptance, both by the Federal Government as well as by the public, is the lack of reliable test procedures and standards on which realistic performance criteria can be based. In the above legislation, particularly EPCA, NBS is directed to develop such test procedures and standards, and these procedures will provide the basis for FTC trade regulation rules for industry-wide performance standards and labelling requirements for recycled oil.

The resolution of this problem by NBS is particularly appropriate because it involves both the development and evaluation of measurement methods and standards, and because it requires an independent third party role for acceptance by all concerned parties (virgin oil refining industry, oil recycling industry, user industries, and government regulators). The alternative to increased recycling of petroleum oils is the continued contamination of the environment and loss of a valuable resource. Recent published data indicate that, of all crude petroleum and petroleum products reaching the ocean, over 40 percent is due to used lubricating oils. 
III. The Current NBS Program

This section describes the current NBS Recycled $0 i 1$ Program, its goal, objectives, program plan, and progress made to date.

A. Goal

The Goal of the NBS Recycled 0il Program is: TO PROVIDE THE MEASUREMENT METHODS AND STANDARDS REQUIRED FOR EFFECTIVE UTILIZATION OF RECYCLED PETROLEUM PRODUCTS.

B. Objectives

In order to reach the above goal, the three following objectives should be met:

(1) ESTABLISH THE SCIENTIFIC AND TECHNICAL BASIS FOR CHARACTERIZATION OF RECYCLED PETROLEUM PRODUCTS.

(2) DEVELOP AND EVALUATE TEST PROCEDURES FOR ESTABLISHING THE SUBSTANTIAL EQUIVALENCY BETWEEN RECYCLED AND VIRGIN PETROLEUM PRODUCTS.

(3) PROVIDE TECHNICAL INFORMATION AND SUPPORT FOR THE EFFECTIVE UTILIZATION OF RECYCLED PETROLEUM PRODUCTS.

The first objective covers the research that is required to effectively utilize recycled lubricating oils. At the present time, there is a concern among user industries, especially the automotive industry, that the quality and batch-to-batch variability of recycled oils are not sufficiently well known to assure a continuous supply of high quality recycled oil. In addition, the various impurities and contaminants which can occur in a used or recycled petroleum product may have effects on the final product which are not well established. A sound scientific and technical data base is crucial for the test procedures developed by NBS to be widely accepted by industry. This basic understanding has not been completely developed at present.

The second objective, to develop and evaluate test procedures for substantial equivalency, is the basic requirements as set forth in EPCA. This requirement is complicated by the current testing methods used. These current tests (called "engine sequence tests") consist of automobile/truck engines and/or special test engines on laboratory dynamometer test stands, and are run in sequence with different loads, speeds, temperatures, controlled blowby (gases bypassing the piston rings), etc., usually requiring special fuels. The controlled variables must be within prescribed limits for acceptable test results to be reported. For the API SF classification (i.e., the oil quality currently necessary to maintain 1981 automobile warranties), four different engine tests must be passed. For military specifications for administrative vehicles (MIL-L-46152B, approximately equivalent to API classification $\mathrm{SF} / \mathrm{CC})$, five engine sequence tests are needed. The minimum cost of a set 
of these tests for a single oil is at least $\$ 30,000$. Since there is no alternative set of commonly accepted test procedures or specifications for physical and chemical laboratory tests on $0 i 1$ basestocks or formulated oils, the small re-refining companies have had a difficult time entering the quality lubricating oil market.

The third objective, to provide technical information and support for the effective utilization of recycled petroleum products, is important in accommodating recycled products for each end use. This objective includes providing technical support to the FTC as required for the NBS test procedures, as well as to disseminate the NBS research and evaluation results and other technical information on used and recycled petroleum products to the industry and the consumer public. Both the EPCA and RCRA legislation contain sectiors which emphasize the necessity for Federal agencies to encourage the utilization of recycled products, and to educate the public in the proper reuse and disposal of these products. 
IV. Plan

The initial emphasis of the NBS Program from 1976 to 1978 was on used oil recycled to be used as fuel. This choice was made for a number of reasons:

- As described in Section I, the primary fate of used oil at present is through burning for fuel, and is largely uncontrolled;

- There appear to be operational and environmental problems from uncontrolled burning of used and minimally processed recycled oils; and

- This end use could be addressed with the limited resources available at that time.

In November of 1978, the official report on Phase I of the Recycled 0il Program, "Test Procedures for Recycled 0il Used as Burner Fuel," was transmitted to the Federal Trade Commission (NBSIR 78-1453; 1 later issued as NBS Technical Note 1130). This report contains test procedures for the operational performance of recycled oils used as burner fuel oils. Simultaneously, Phase II of the NBS Program, "Test Procedures for Recycled $0 i 1$ Used as Motor $0 i 1 "$, was initiated.

There has been sufficient engine testing on re-refined oils to establish that: (1) a high quality re-refined lubricating oil which has been formulated with a high quality additive package can be comparable to a virgin oil similarly formulated, and (2) that both will provide adequate performance in most types of automotive service. The problem which exists at the present time is the lack of technical information and data to determine which tests are necessary and how often they should be applied in order to assure that the re-refined $0 i 1$ basestock is consistent inbetween the engine testing. The user industries have made it clear that they are concerned about the potential lack of consistency of re-refined oil products, and about the potential effects of unusual or unknown contaminants in the used oil feedstock to re-refineries. These potential problems are of particular concern when warranty questions are involved.

The most important requirement for assuring the quality of re-refined motor oil is development of a set of test procedures capable of monitoring the quality, consistency, and additive response of the oil basestock inbetween qualifications by means of the very expensive engine sequence tests. These evaluated test procedures are crucial in order to allow accommodation of the re-refined oils within the existing API-SAE-ASTM classification system. (Note: API = American Petroleum Institute; $S A E$ = Society of Automotive Engineers; ASTM = American Society for Testing and Materials.) Development and evaluation of these tests by NBS is significantly more difficult because no such set of test procedures exists for virgin lubricating oils. Historically, virgin oil producers were instead required to control the crude source and refining technology in order to assure a constant lubricating oil basestock, particularly for the U.S. military specifications. This option is not avilable to oil recyclers. 
The quastion of the consistency of re-refined oil has been addressed in the recently' completed cooperative ASTM/NBS study. In this one-year study, four virgin oil producers and six re-refined oil producers submitted monthly samples of their regular production basestock for analysis by a group of 14 laboratories, including NBS (Table 1). These laboratories analyzed the coded samples using over 40 different chemical, physical, and performance tests (Tables $2-4)^{3}, 4$. It is expected that the evaluated data from this study will provide much of the information necessary to indicate an appropriate set of test procedures to monitor rerefined basestock consistency. In addition to the consistency study described above, the NBS Program is currently evaluating the chemical and physical test procedures used on lubricating $0 i 1$ basestocks, as well as performing research and development on bench-scale performance tests for establishing basestock additive response. Development of effective and economical test(s) for additive response appears to be crucial to the success of our efforts.

Therefore, the strategy NBS has adopted for engine oils is to attempt to provide a set of test procedures capable of adequately monitoring the consistency and additive response characteristics of the re-refined petroleum lubricating oil basestocks. A diagram of this strategy is shown in Figure 1. This set of basestock tests will then be coupled to the appropriate engine sequence testing as shown. Subsequent samples can then be monitored using the NBS tests, without the engine testing, for some period of time yet to be established. If successful and implemented, this strategy should provide the methodology to assure a consistently high quality product with a minimum of subsequent engine testing. 


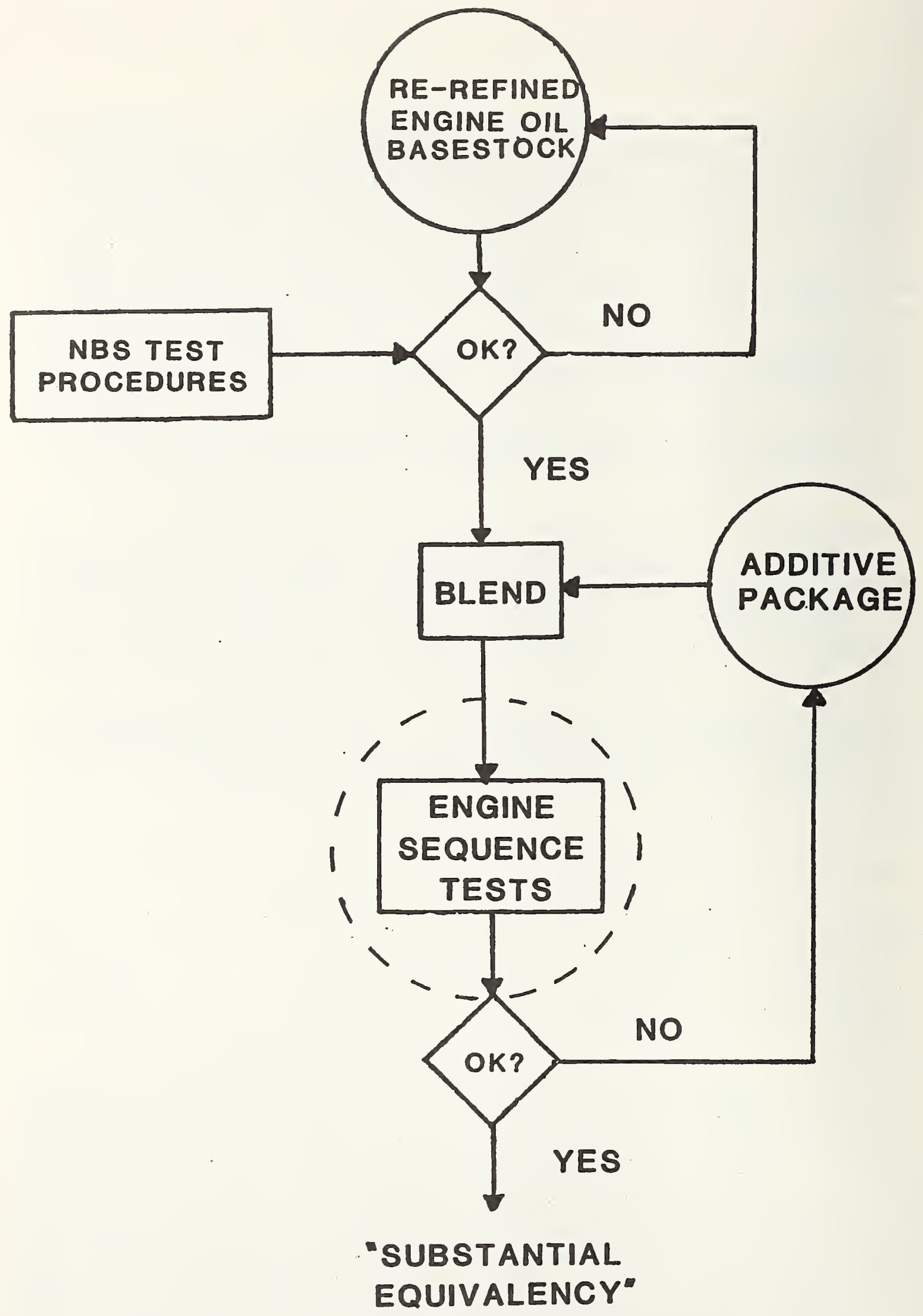

FIGURE 1. DIAGRAM OF EQUIVALENCY TEST STRATEGY 


\section{Table 1 \\ Laboratories Cooperating in the ASTM/NBS \\ Basestock Consistency Study}

Bartlesville Energy Technology Center

National Research Council of Canada

Motor 0ils Refining Co.

Mobil 0il Corporation

U.S. Army MERADCOM

National Bureau of Standards

Shel1 Research/Thornton (U.K.)
Chevron, USA

Suntech, Inc.

SAVANT, Inc.

Texaco

Lubrizol

Gulf $R$ \& D

Filmite 
Table 2

Physical Property Tests

Test

API Gravity

Aromatics

Boiling Point Range

Brookfield Viscosities

co $0^{\circ}$ to $-40^{\circ} \mathrm{F}$

Carbon residue

Color

Demulsibility

Filterability

Foam

oxidation

Pour Point

Refractive Index

Sulfated Ash

Viscosities $840^{\circ} \mathrm{C}$ and $100^{\circ} \mathrm{C}$

Viscosity Index
Method

ASTM 0287

Low Resolution Mass Spec UV

ASTM D2287 (GC)

ASTM 02983

ASTM D524

ASTM D1500

ASTM D1401

(1)

ASTM 0892

(1)

ASTM 097

ASTM D1218

ASTM 0874

ASTM 0445

ASTM 02270

(1) Proprietary 
Table 3

Chemical Property Tests
Method

ASTM 0664

Neutron Activation

Neutron Activation

(1)

Emission Spectrograph

Chemi luminescent

Modified UOP

Neutron Activation

ASTM D94

Neutron Activation

ASTM 01551

ASTM 01744

Water

Carbon-13 NMR Analysis

Polycyclic Aromatics by DMSO Extraction

Hydrocarbon Types by TLC/FID

High Resolution Mass Spectrometry

(1) Proprietary
IP 346

\section{(1)}




\section{Table 4}

Bench Tests

\section{Test}

Anti-0xidant Response

Cold Crank Simulator a $0^{\circ}$ to $-40^{\circ} \mathrm{C}$

Differential Scanning Calorimeter

Ford Anti-0xidant Capacity

Load Wear Index

Mini-Rotary Viscometry

RBOT

Rust Tendency

Sequence III Simulator

Stability in Sunlight plus

Various Temperatures

TOST

(1) Proprietary
Method

(1)

ASTM D2602

ASTM D2783

ASTM D3829

ASTM D2272

ASTM D665

(1)

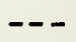

ASTM 0943 


\section{Implement ation}

In the past year, there has been significant progress in the NBS Program. The ASTM/NBS Basestock Consistency Study has already been discussed, and the data from this study have already proved immensely helpful to us in our efforts. Further evaluation and correlation of the very large amount of data generated in this study will provide even greater rewards in our understanding of lubricating base oil in general and, in particular, re-refined oils.

Progress in the evaluation of chemical and physical test procedures has also been steady. It is felt that the most important of these tests for re-refined oil will include the following: (1) visual inspection, (2) viscosity/VI, (3) density (API gravity), (4) flash point, (5) pour point, (6) sulfated ash (modified), (7) total acid number,

(8) saponification number, and (9) copper corrosion. Additional tests of great interest at this time, although no decision has been made at present about their need, include boiling point distribution, metals analysis, differential IR, chlorine, hydrocarbon types by clay-gel chromatography, and a corrosion/rust test. Of course, it must be understood that the above lists are preliminary, and additional information from the Basestock Consistency Study will be utilized before completing these evaluations.

Significant progress has also been made in research on test procedures for additive response, and some of this work will be briefly described. Dr. Stephen Hsu and other members of the Tribochemistry Group at NBS have modified and evaluated several tests which, at this time, suggest they may be capable of monitoring the additive response of lubricating basestocks, yet are simple enough to be run on a routine basis.

The first test to be described is a modification of a bench test for oxidation stability named the Rotating Bomb Oxidation Test, or RBOT (ASTM D2272). While this test was originally developed to estimate the oxidation stability of steam turbine oils, it has also been used with varying success with many types of oils. Modifications to this test include: (1) use of a high accuracy pressure gauge in the initial oxygen charge; (2) use of an aluminum insert and modified sample beaker to acommodate a $1.5 \mathrm{gram}$ oil sample vs. $50 \mathrm{grams}$ in the original procedure; (3) use of both steel and copper wire catalysts; (4) addition of on ly $2 \%$ water to the 011 ; and (5) operation at $160^{\circ} \mathrm{C}$. The results from this modified RBOT on six engine oils with substantial enqine test data are shown in Table 5. Additional development of this test using a soluble metal catalyst package ( $\mathrm{Fe}, \mathrm{Pb}, \mathrm{Cu}, \mathrm{Mn}, \mathrm{Sn}$ ) along with a synthetic fuel blow-by catalyst provided the improved results shown in Table 6 . These results indicate the test is capable of good separation between differing performance levels of the total set of III-D ASTM Reference Engine 0ils, and in addition averaged on $1 y$. $4 \%$ standard deviation between duplicate runs on each sample.

This test was also run on samples of re-refined and virgin oil from the Environment Canada/RCMP Fleet Test, and results from engine test data and the modified RBOT test are shown in Table 7 . Since tilese two oils were formulated with exactly the same additive package at the identical treat level, these results sugqest that this modified RBOT test may be 


\section{Table 5}

Results from the Modified RBOT Test Using Wire Catalystsa

$\begin{array}{ccccc}\text { Reference 0il }_{\text {A }} & \text { Engine Test Results (hours) } \\ \text { B } & \text { Pass }(64) & \text { RBOT Break Point (min) } \\ \text { C } & \text { Pass }(56) & 390, & 590 \\ \text { Pass }(40) & 250, & 258 \\ \text { D } & \text { Fail }(24) & & \\ \text { E } & \text { Fail }(16) & 240, & 250 \\ \text { F } & \text { Fail }(16) & 193, & 168\end{array}$

aFor a description of modifications, see test.

b hours $=$ no. of hours to $375 \%$ viscosity increase in the III-D Test. 
Table 6

Results from the Modified RBOT Test Using

Soluble/Synthetic Catalystsa

$\begin{array}{cccc}\text { Reference 0i1 } & \text { Engine Test Results (hours) } \\ \text { A } & \text { Pass }(64) & \text { RBOT Break Point (min) } \\ \text { B } & \text { Pass (56) } & 268, & 278 \\ \text { C } & \text { Pass (40) } & 154, & 150 \\ \text { D } & \text { Fail (24) } & 58, & 60 \\ \text { E } & \text { Fail }(16) & 43, & 45 \\ \text { F } & \text { Fail (16) } & 40, & 38\end{array}$

afor a description of modifications, see test.

bHours $=$ no. of hours to $375 \%$ viscosity increase in the III-D Test. 
Table 7

Results from the Modified RBOT on 0il Samples from the Environment Canada/RCMP Fleet Test ${ }^{\mathrm{a}}$

0il Identification

FLO 79034 (Re-refined)

FLO 79038 (Virgin)
Engine Test Results

(hours) $^{b}$

Pass (40); Fail (64)

Pass (40); Fail (64)

Pass (40); Pass (64)
RBOT Break Point

$\underline{(\min )}$

186

222

aboth oils performed satisfactorily in the fleet test.

bBoth oils satisfactorily met the design criteria for that additive package (MIL-L-46152A; pass at 40 hours). 
capable of discriminating between different lubricating oil basestocks, and possibly, between differing quality levels of the same basestock.

Another bench test being evaluated with respect to lubricating oil additive response characteristics is a test for metallic wear. After substantial research, a step loading seizure test (SLST) using a 4-ball wear test rig has been developed which successfully discriminated between the six high/low wear III-D Reference Engine $0 i l s$. This test is run at slow speed (200 RPM), with 9 kilogram (20 pound) increments every 5 minutes until seizure. The results from this test are shown in Table 8 , and suggest the SLST can successfully differentiate between the III-D high wear and low wear reference oils.

In addition, a variation of this test was developed which uses very small oil samples (6 microliters), which is called the micro-sample SLST. When applied to the set of III-D reference oils, this test also was able to successfully differentiate between the high/low wear reference oils. When both of these tests were used to look at the Environment Canada/RCMP fleet test oils, they could see no difference between the virgin and rerefined oils while indicating good wear characteristics for these two oils. These results agree with the fleet test and engine test results for these oils, which showed no significant differences between them for wear characteristics. 
Table 8

Results from the 4-Ball Step Loading Seizure Test

\begin{tabular}{|c|c|c|c|}
\hline \multirow[b]{2}{*}{ Reference 0 il } & Engine Test & \multicolumn{2}{|c|}{ 4-Ball Test Results } \\
\hline & Wear Rating (Wear) ${ }^{a}$ & Seizure Load $(\mathrm{Kg})$ & Average $(\mathrm{Kg})$ \\
\hline A & Low (48) & 200,200 & 200 \\
\hline B & Low (46) & $227,191,209,209$ & 209 \\
\hline c & Low (48) & 218,218 & 218 \\
\hline D & High (287) & $\begin{array}{l}145,163,181,172, \\
172,172,163\end{array}$ & 168 \\
\hline$E$ & High (277) & 127,136 & 132 \\
\hline $\mathrm{F}$ & High (256) & 127,136 & 132 \\
\hline
\end{tabular}

aWear values $=$ Average $\mathrm{cam}$ and lifter wear $\left(\mathrm{cm} \times 10^{-4}\right)$ 
Additional research projects which were funded by the Recycled $0 i 1$ Program during FY-1981 include the following:

- Bench Test for Wear (Metallurgy Division/CMS) This test utilized the Sun Tech modification of the Timkin ring and block test. While the results were able to discriminate between various ASTM reference oils, the test procedure was judged more difficult to quantitate than the 4-ball SLST test, and also required numerous test runs to evaluate a single oil. Funding for this project had been decreasing and was dropped at the end of FY-1981.

- Ford Anti-oxidant Titration (Chemical Thermodynamics Division/CCP) White found to be highty reproducible and useful for the evaluation of formulated products, this test was judged not suitable for the routine evaluation of lubricating oil basestocks. Funding for this project was terminated after comletion of the ASTM/NBS Basestock Consistency Study (BCS) samples, about 3/4 through the FY-1981 year. However, the equipment was transferred to the Tribochemistry Group, and some use is being made of the test in their on-going research program.

- Differential Scanning Calorimetry (Chemical Kinetics Division/CCP) This technique is felt to be extremely useful in the investigation of lubricants and basestock-additive interactions, but was judged too difficult for routine use, especially since the modified RBOT test was developed. The project is being funded again in FY-1982 at a somewhat reduced level, primarily for research on the technique and for evaluation of research samples generated by the Tribochemistry Group.

- Polychlorinated Biphenyls (Organic Analytical Research Division/CAC) A reliable method for the determination of PCBs in Tubricating oil was developed, and a PCB in $0 i 1$ Standard Reference Material (SRM) is being produced. The SRM should be available early in 1982. This group is also cooperating in the production of samples for an ASTM/NBS round-robin on the analysis of PCBs in oils.

- Halogen Analysis by Neutron Activation (Inorganic Analytical Research Division/CAC) The neutron activation analysis (NAA) technique is very sensitive and highly reliable for the determination of chlorine and bromine in petroleum oils. This method provided excellent results for the BCS samples, and is of continuing benefit in the on-going research program of the Tribochemistry Group. Additional efforts in FY-1982 will concentrate on speciation studies of the chlorine-containing compounds, in order to better understand their source(s) and effects on lubrication performance.

- Pennsylvania State University Micro-0xidation Test Research on this test for oxidation stability is rapidly concluding, and they are now running a variety of lubricating oil samples to establish 
the limits of the technique. This project will be completed in mid-1982.

- U.S. Army MERADCOM Deposits Study In a cooperative research effort, the U.S. Army lubrication laboratory at Southwest Research Institute (SWRI) has been evaluating virgin and re-refined oils for their comparative sludge and deposits tendencies. This work is essentially completed and a report on this two year project will be forthcoming shortly.

- U.S. Army MERADCOM/Franklin Research Center/NBS Bench Engine Screening Test Development A cooperative agreement on this development project was signed near the end of FY-1981. The purpose of this project is attempt to develop an apparatus utilizing bench scale hardware to simulate the $V-D$ engine sequence test. This apparatus will utilize actual engine hardware along with an auxiliary power source and blowby generator. It is expected that a decision on the success of this approach can be made by mid-FY 1982 .

In conclusion, the program described above is felt to be a comprehensive and responsible effort by NBS to address a challenging and technically very difficult legislative mandate. At this point in time, we perceive a very real possibility of success in this endeavor, with approximately two more years required for completion. 


\section{Discussion}

In the past five years, the Recycled $0 i 1$ Program has made substantal progress towards fulfilling its responsibilities under the Energy Policy and Conservation Act. In addition, it has established itself as one of the leading laboratories in the country in the area of test procedures and evaluation of recycled petroleum products and lubricating oils. Specific items indicating progress in the Recycled 0il Program are:

- Organized and held the first conference on Measurements and Standards for Recycled 0il (November 1976). Proceedings published as SP 488 (149 pages).

- Established an extensive oil characterization laboratory.

- Was instrumental in creating the nEw ASTM Technical Division P, on Recycled Petroleum Products and Lubricants. ROP senior staff member was appointed divisional vice-chairman, and chairman of one of the sections.

- Organized and held the second conference on Measurements and Standards for Recycled 0il (November 1977). Had over 170 attendees representing al1 aspects of industry and government. Proceedings published as SP 556 (225 pages).

- Obtained an Industrial Research Associate from the Association of Petroleum Re-refiners (APR) to work at NBS on recycled oil test procedures (1977-79). Person selected was the chief chemist of the largest re-refiner in the U.S.

- Completed Phase I of the NBS Recycled 0il Program on the test procedures for the operational performance of recycled oils used as burner fuel. Report transmitted to the FTC in November 1978, and published as NBSIR 78:1453 and NBS Tech. Note 1130 .

- Received FY 1978 supplemental appropriation in September of 1978, initiating the appropriated funding for recycled oil. Funding plan included amounts for facilities modifications, equipment, and certification of related Standard Reference Materials.

- Initiated Phase II of the NBS Program, on motor oils (November 1978).

- Obtained a senior staff member from a large additive company to head projects on performance testing. Became Group Leader of the Tribochemistry Group, formerly the Recycled 0il Laboratory.

- Established a lubricated wear laboratory for development and Evaluation of test procedures on friction and wear.

- Obtained space and initiated required modifications for a storage area and blending facility for producing formulated re-refined oils for testing and evaluation. 
- Established an extensive oxidation/deposit performance testing laboratory.

- Successfully completed the sampling and analyses phases of a cooperative ASTM/NBS re-refined oil basestock consistency study. This study utilized monthly oil samples from six re-refiners plus four virgin oil refiners, and after subsampling and coding at NBS, these samples were analyzed for 43 different characteristics by 14 laboratories. After final data reduction and correlations are comleted, this study is expected to provide the data necessary to determine which characteristics should be monitored for re-refined oil basestocks, a crucial question.

- Testified as an expert witness at three Congressional Hearings on 0 il Recycling.

- Provided cooperative efforts in support of two important non-NBS recycled oil programs:

-- U.S. Army MERADCOM's development of the MIL-L-46152A revised specification, which now allows use of re-refined basestock.

-- Environment/Canada's fleet test evaluation of re-refined oil in Royal Canadian Mounted Police vehicles.

- In addition to the above, the Program Manager has been an invited speaker at national and/or international meetings of the Association of Petroleum Re-refiners, the Society for Automotive Engineers, the American Society of Lubrication Engineers, the American Petroleum Institute, the National Petroleum Refiners Association, the Independent $0 i 1$ Compounders Association, the AllIndia Re-refining Conference, the Second European Congress on Recycling of Used $0 i 1$, and others.

The above specific items of efforts within the Recycled 0il Program indicate to some extent the activity which has occurred in this program during the past years. At the present time, the Recycled 0il Program funds efforts consisting of approximately 15 staff-years within the NBS technical divisions, plus three projects located outside NBS. These efforts have contributed greatly to the recent advances in oil recycling. 


\section{The Future}

The future of the Recycled 0il Program during FY-1982 and beyond is difficult to predict. We currently estimate that the test procedures for re-refined engine oil, if current progress can be successfully maintained, can be completed by the end of FY-1983. Additional work on re-refined automotive transmission oils, re-refined hydraulic oils and re-refined or reclaimed industrial oils would require additional time, probably ranging from 1-3 years all told.

On the other hand, current contractions in government funding may seriously affect the Recycled 0il Program in the future, requiring curtailment and/or cessation of these activities. At present, FY-1982 funding appears to be firm, and we are continuing our efforts on completion of the tests for engine oils. 


\section{References}

1. E. A. Frame and T.C. Bowern, Jr., "U.S. Army/Environmental Protection Agency Re-refined 0il Program," AFLRL Report No. 98, May 1978 (Available from Defense Documentation Center, Cameron Station, Alexandria, VA 22314).

2. House of Representatives, "Used 0il Recycling Act of 1980," Report No. 96-1415, 96th Congress, Government Printing Office, Washington, D.C.

3. K. Frassa, "ASTM/NBS Base Stock Consistency Study," in Proceedings, Joint Conference on Measurements and Standards for Recycled 0il/Systems Performance and Durability, edited by D. A. Becker, NBS Spec. Pub1. 584, U. S. Department of Commerce (Nov. 1980).

4. W. C. Starr, "Consistency of Base Stock Production - An ASTM/NBS Study, " to be published in Proceedings, 4th International Conference on Used 0il Recovery and Reuse, Association of Petroleum Re-refiners, Washington, D.C. (In Press). 
THE RESOURCE CONSERVATION AND RECOVERY PROGRAM 


\section{Goal and Objectives:}

NBS involvement with recycled materials spans several decades. However, the program described here dates from 1973 when data concerning reactions from incineration of municipal solid waste were obtained by the Physical Chemistry Division. In 1976, the Congress via the Resource Conservation and Recovery Act (RCRA), assigned DoC and NBS direct responsibilities for research concerning recycling. The Office of Recycled Materials within NBS is the Departmental focal point for fulfilling these legal mandates. The goals and objectives of the RCRA program are as follows:

Goal:

To improve the Nation's productivity and innovation by providing a framework for fostering the advances required to optimize the mix of economic and environmental factors associated with the disposal and subsequent recovery and/or reuse of resources contained in municipal, industrial, commercial and hazardous solid wastes.

\section{Objectives:}

(1) To develop methodologies for the economic assessment of current and potential technologies, market potentials, and institutional barriers relative to resource conservation and recovery, and to assist public and private sectors to fully utilize both the methodologies and information derived therefrom; (2) to evaluate current and innovative technologies for the conservation of materials, as well as the recovery, reuse, and recycling of waste materials from all potential sources including industrial processes; (3) to provide for the economic retention and development of businesses and industries through mitigation of the impact of federal regulatory policies, particularly environmental actions, and by utilizing the potential for new business opportunities and growth.

Sections 5002 and 6002 of RCRA mandate NBS actions concerning guidelines for specifications for recovered materials and governmental procurement of recycled goods. Note that NBS will be the only federal laboratory carrying out research involving resource recovery after $F Y$ 1981. The Environmental Protection Agency (EPA) announced in April 1980 that it would have to devote all of its research resources to hazardous waste problems in FY 1981 and thereafter. The Department of Energy has effectively left the field as well.

The NBS efforts fall into three main categories:

(1) Direct laboratory-based research aimed at achieving the goals of RCRA;

(2) Examination of governmental policies with respect to procurement of products containing recovered materials; and 
(3) Identification and assessment of the need for uniform physical and chemical measurements which derive from laws, regulations and policies at the state and local level. (Note that the Resource Recovery portion of this effort is part of a larger NBS effort to define state measurement needs in detail.) Current activities and some plans for the future in each of these categories are discussed in detail.

The Technical Advisory Center (TAC) works to improve the Nation's productivity and innovation by providing a framework for fostering the advances required to optimize the mix of economic and environmental factors associated with the disposal and subsequent recovery and/or reuse of resources contained in municipal, industrial, commercial and hazardous solid wastes. The TAC accomplishes these goals by developing methodologies for the economic assessment of current and potential technologies, market potentials, and institutional barriers to resource conservation and recovery; to assist public and private sectors to utilize fully the methodologies and information; and, by identifying the potential for new business opportunities and growth. In short, TAC's primary function is to assure implementation of RCRA responsibilities of the Department, which are (i) encouragement of the commercialization of proven technology; (ii) stimulation of the development of markets for recovered materials, and (iii) evaluation of the commercial feasibility of resource recovery facilities as well as the development of an information base to assist communities and other entities in selection of a recovery system.

The TAC currently interacts with a wide variety of parties affected by RCRA including private industry, intergovernmental entities such as the Great Lakes Basin Commission, state and local government, universities, public interest groups, other federal agencies, and interested entities within DoC. 


\section{RESOURCE CONSERVATION AND RECOVERY PROGRAM}

\section{Introduction}

The Resource Conservation and Recovery Act of 1976 (P.L. 94-580) enacted October 21, 1976, directs the Secretary of Commerce, acting through NBS, to hold public hearings and publish guidelines for the development of specifications. These specifications are needed for the classification of materials which can be recovered from waste now destined for disposal. NBS is authorized to undertake work of this nature by 15 USC 272 which describes functions of the Secretary of Commerce to include "the determination of physical constants and properties of materials when such data are of great importance to scientific or manufacturing interests and are not to be obtained of sufficient accuracy elsewhere."

The Nation generates about 145 million tons of municipal solid waste per year. Currently, over 93 percent of this waste is disposed by open dumping, "sanitary" landfilling, incineration or ocean dumping, all environmentally unsound methods. Alternatives to land disposal methods must be found since many cities in the U.S. may run out of suitable solid waste disposal sites in the near future. A method to do this is to separate metals, glass and the organic fraction of this refuse from one another thus providing a potentially marketable set of commodities.

Large quantities of potential resources are being discarded in the waste. According to figures compiled by EPA, we annually discard about 20 percent of the Nation's tin and aluminum requirements, 10 percent of its ferrous metal requirements, enough glass to replace a year's needs for glass containers, and enough organic material, which if converted to energy could provide up to 2 percent of current energy needs.

In enacting P.L. 94-580, the Congress stated that:

(1) Millions of tons of recoverable material which could be used are needlessly buried each year.

(2) Methods are available to separate usable materials from solid waste.

(3) The recovery and conservation of such materials can reduce the dependence of the United States on foreign resources and reduce the deficit in its balance of programs.

In order to reclaim materials and energy from municipal solid waste in an economically acceptable way, markets for these commodities must exist. Energy can be reclaimed from the organic fraction of the refuse (80 percent), but, unless a stable long-term market for this energy is found, large scale reclamation of energy and materials is not financially feasible. The organic fraction is usually converted to refuse derived 
fuels (RDF) which can take several physical forms: fluff, pellets, powder, gas, liquid, or solid char. In the absence of characterization and specifications for all of these forms of RDF, marketing of this commodity has proven very difficult. Hence, a necessary first step is selecting the form of RDF best matched to the market in the region of the resource recovery facility. For example, in a 40,000 square mile tri-state region in the midwestern U.S., a market was found to exist if RDF meeting a certain specification could be produced. This market would enable 82 percent of the region's waste to go to resource recovery. Otherwise, in the absence of the market, virtually all of the waste would be landfilled. The NBS program under P.L. 94-580 will place heavy emphasis on the characterization of RDF in order to have a firm basis (specification) for marketing.

Once the crucial energy marketing step is completed, it becomes economically feasible to recover other materials such as metals and glass. Again, specifications will tend to dictate whether the materials emerging from the resource recovery facility can be sold at a suitable price.

Since the beginning of 1981, ORM has been dealing in far greater detail with problems faced by the private sector, i.e., non-hazardous industrial wastes. In calendar year 1981, ORM has taken the following actions with regard to industrial wastes:

- A major study in the Great Lakes Region concerning business response to hazardous waste regulations.

- Agreement to cooperate with the tanning industry on recovery of chromium and reduction of waste from tanning processes.

- Close cooperation with the petroleum industry concerning uses for waste oils.

- Agreement to work with the steel industry concerning recycling or reuse of mill sludges and pickle liquors.

In addition, ORM has become increasingly involved with characterization of discards which may be deemed hazardous. With cooperation from the Department of Energy (DoE), the Environmental Protection Agency (EPA), the Department of Defense (DoD), and the American Iron and Steel Institute (AISI), ORM has begun to characterize such materials. Among the reasons for doing so are that some 50 million metric tons of potentially hazardous wastes are produced annually in the United States. That amount grows at a projected rate of about 3.5 percent a year. And less than 10 percent is probably being disposed of in an environmentally sound manner. Furthermore, the number of actors who are involved with hazardous waste is immense:

- Over 750,000 businesses generate some amount of hazardous waste.

- Over 10,000 transporters are involved in shipping it.

- Over 30,000 sites are used for treatment, disposal, or storage-some on the premises of the generator, others located elsewhere. 
Hazardous wastes--whether from a chemical plant, battery producer, or electroplater, to cite three examples--are either disposed of at the factory or off-site. In either case, the disposal options are nearly identical:

- Disposal on the land

- Incineration

- Placement in lagoons

- Injection wells

- Recycling or reclaiming

If wastes are not retained on-site, they are transported elsewhere by truck, barge, or rail.

Safe waste management should embody the best technologies that can be developed. Yet without rules and regulations to ensure protection of public health and the environment, the costs of disposal have been low. As a result, industry has had little incentive to apply resources or brainpower to developing better, safer technologies for managing wastes.

Waste storers, treaters and disposers will seek out more sophisticated technological processes to properly handle their wastes. And the costs of environmentally sound waste management will rise, producing a powerful incentive for generators to change methods of production so as to minimize their output of hazardous wastes. 
III. Needs

The duties of the Secretary of Commerce are set forth in Sections 5001 to 5004 (42 U.S.C. 6951 et. seq.) of P.L. 94-580.

Section 5001 (42 U.S.C. 6951) requires the Secretary to encourage greater commercialization of proven resource recovery technology. Four specific tasks are indicated:

(1) Provision of accurate specifications for recovered materials;

(2) Market development stimulation for these materials;

(3) Promotion of proven technology; and

(4) A forum for the exchange of both technical and economic data relating to resource recovery facilities--presumably high technology $\mathrm{plants}$ designed to recover materials and/or energy from municipal waste.

Section 5002 (42 U.S.C. 6952) specifically directs the Secretary, acting through NBS, "to publish guidelines for the development of specifications for the classification of materials recovered from waste which were destined for disposal. The specifications shall pertain to the physical and chemical properties and characteristics of such materials in various industrial, commercial and governmental uses." In addition, P.L. 94-580 directs NBS to hold public hearings on these guidelines and to publish the guidelines. These guidelines will: (1) Aid in conserving valuable material and energy resources, (2) increase the rate at which resource recovery from municipal solid waste will occur in the U.S., and (3) serve in the settlement of possible disputes involving the use of recyclables in items purchased by the Federal Government (Section 6002 (42 U.S.C. 6962) of P.L. 94-580. 
IV. Current Activities

Several projects were completed since the Panel meeting last May. Appendix $I$ is the Executive Summary of the final report concerning procurement of products containing recovered materials. The State Measurement Needs Study was also completed, and Appendix II contains the title page and Executive Summary of this report. A number of directly supported research projects also issued reports. These are included in Appendices III - IX. Finally, what follows is a summary of ongoing research which is being carried out in fulfillment of the mandates of the Resource Conservation and Recovery Act. 
A. RESOURCE RECOVERY PROGRAM 
Project Title: Combustion Calorimetry of Refuse and Refuse-DerivedFuel (RDF)

Goal: (1) To provide a consensus test method for determining the heating value of minimally processed refuse so that engineers can evaluate the performance and design specifications of an incinerator or boiler with enhanced confidence.

(2) To provide test methods for determining the heating value of RDF so that it can be established as an article of commerce.

Technical Center for Chemical Physics

Areas at Chemical Thermodynamics Division

NBS:

Personnel: E. S. Domalski, D. R. Kirklin, J. Colbert, K L. Churney, M. L. Reilly,* A. E Ledford, R. Kelly, S. Abramowitz, and R.V. Ryan.

Other U. S. Department of Energy

Agency Office of Energy from Municipal Waste

Support: D. Walter, B. Greenglass, C. Kouts, and L. Lehr

Compatible with the Resource Conservation and Recovery Act of 1976 is the national aim to expand our technology to produce useable energy from solid waste. One of the greatest needs is to develop test methods for the determination of the heat of combustion of refuse and refuse-derived-fuels (RDF). Evaluating the design specifications of an incinerator or a boiler and the buying and selling of RDF will be done on the basis of the heats of combustion of RDF samples. At present, commercial laboratories use conventional bomb calorimetric techniques on gram-size samples. There is a dispute about the reliabiity of the current techniques for measuring the heat of combustion of the input waste stream. Many combustion engineers believe that the input waste stream to an incinerator installation cannot be sampled and processed to produce gram-size amounts of material whose heating value is representative of the original waste. Those engineers argue that the original heterogeneity of the waste stream and changes in composition caused by processing to gram-size samples dictate that the test sample should be minimally processed and of kilogram size. At present, insufficient quantitative data exist to resolve the problem. Establishment of a consensus method requires calorimetric measurements of grams to kilogram-size samples.

The NBS effort in the development of test methods to determine heats of combustion of refuse and refuse-derived-fuel dates back to April 1977, shortly after Congress passed the Resource Conservation and Recovery Act of 1976. The initial effort involved the determination of whether a 25gram capacity bomb calorimeter could provide heats of combustion which more accurately represented a gross RDF sample than did the heat of combustion determined in the conventional-size (2.5 gram capacity) bomb

* Center for Absolute Physical Quantities

Temperature and Pressure Measurements and Standard Division 
calorimeter.

Comparative studies involving calorimeters with sample capacities of $2.5 \mathrm{gram}, 25 \mathrm{grams}$ and $2.5 \mathrm{kilogram}$ are being carried out to determine the sample size necessary to produce heats of combustion that accurately represent a gross RDF sample. From April 1977 to the present time, more than 20 different RDF samples have been studied in the NBS calorimeters.

Accomplishments in FY 1981

Five lines of work have been emphasized during the past year:

(A) Oxygen flow calorimetry of solids, (B) 0xygen bomb calorimetry of solids, (C) Metals in RDF, (D) Variability of municipal solid waste, (E) Ash content of RDF, coal, and RDF/coal mixtures as a function of temperature.

\section{A. Oxygen Flow Calorimetry of Solids}

A 2.5 kilogram-capacity flow calorimeter, shown in figure 1 , has been designed for burning pellets of minimally processed municipal solid waste (MSW). The calorimeter vessel is 3 feet in diameter, 8 feet high, and will contain 983 liters of water (1 ton). The calorimeter design was based on the results obtained using a trial combustor, 30 inches in diameter and 6 feet high. Eighteen trial combustions were carried out using various sample and oxygen supply configurations. Pellets of up to $2.2 \mathrm{~kg}$ of minimally processed RDF were successfully burned at rates of 15 minutes per kilogram with $\mathrm{CO} / \mathrm{CO}_{2}$ ratios of less than $0.1 \%$. The component parts of the $2.5 \mathrm{~kg}$ capacity flow calorimeter are being fabricated by various vendors. We expect calorimeter assembly to begin before the end of FY 1981.

B. Oxygen Bomb Calorimetry of Solids

\section{(1) ASTM Round Robin Testing of RDF-3}

RDF-3 is defined as a shredded fuel derived from municipal solid waste processed for the removal of metal, glass, and other entrained inorganic materials. This matrial has a particle size such that 95 weight percent passes through a 2 inch square mesh screen.

A round robin was conducted to compare two ash content procedures being drafted by ASTM Subcommittee E38.01. Five laboratories

participated. One procedure is the ash furnace method and is similar to that used for coal and coke (ASTM D-3174-73). The other is based upon the ash residue remaining in the combustion bomb after a calorimetric determination has been carried out. The assumption that ash-content data on a twin or equivalent analysis sample which has been determined using ASTM D-3174-73 is applicable to combustion bomb calorimetric data is not completely valid. Ash was measured in a furnace at $575^{\circ} \mathrm{C}$ and $725^{\circ} \mathrm{C}$. Ash was also determined as the bomb residue of a combustion experiment where temperatures are in excess of $1500^{\circ} \mathrm{C}$. The ash content is an important parameter since it is used with calorimetric data to calculate higher heating values on a moisture and ash-free basis. The teriperatures $575^{\circ} \mathrm{C}$ and $725^{\circ} \mathrm{C}$ were selected because they are the ASTM ashing temperatures for cellulose and coal, respectively. The bomb residue method is important 


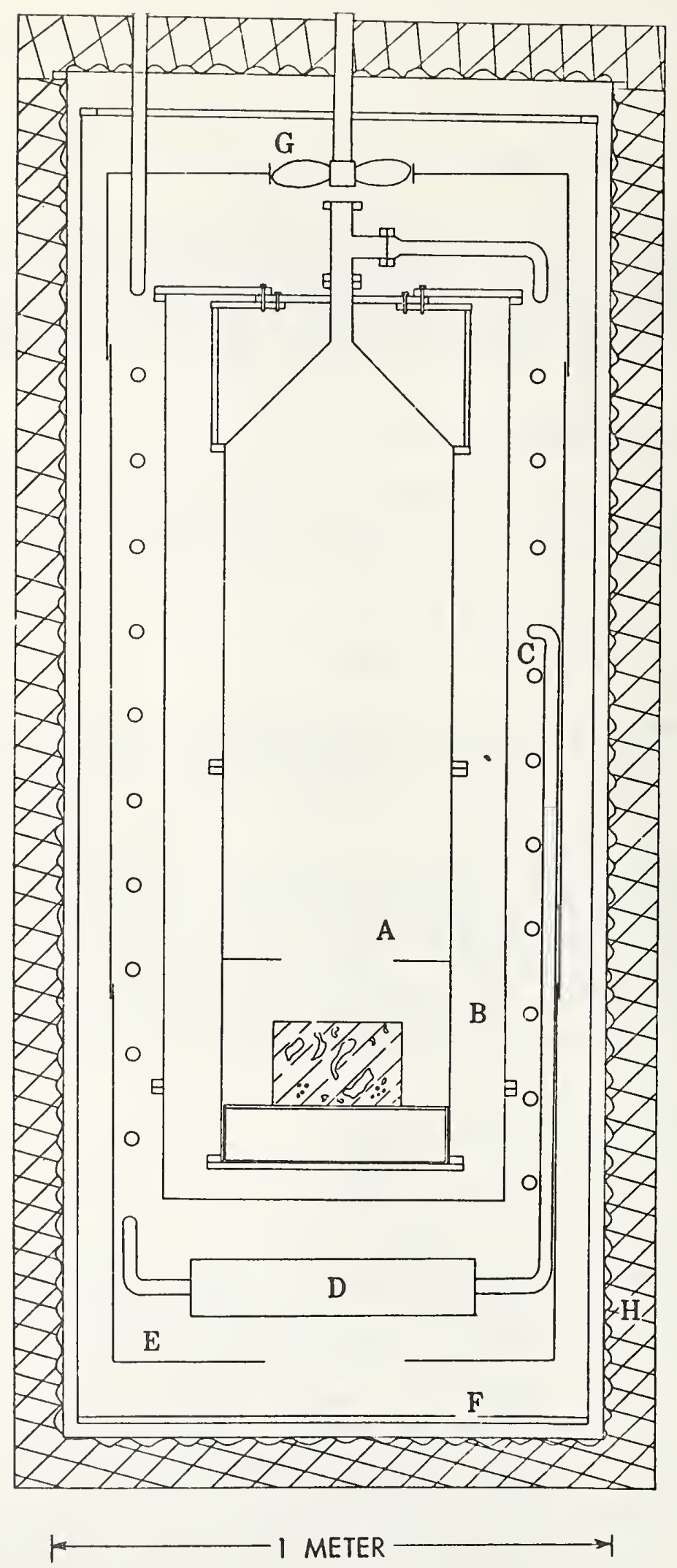

Figure 1. The 2.5 Kilogram Capacity Flow Calorimeter.
A. Combustor
B. Combustor enclosure
C. Exhaust cooling coils
D. Exhaust condenser 38
E. Flow shied
F. Calorimeter vessel
G. Stirrer
H. Water-wall jacket 
because it relates directly with the calorimetric data obtained in the RDF-3 combustion measurement. Within experimental uncertainties, as determined from the standard deviation of a measurement, the ash contents compared well between the laboratories. However, in four out of the five laboratories, the bomb ash method had the highest precision. Although fuel ashing methods are traditionally carried out in combustion furnaces, we have written an ASTM subcommittee E38.01 draft standard using the bomb ashing technique as an alternate ashing method because of its higher precision and its direct traceability to the actual combustion data. This draft standard has been reviewed by subcommittee E38.01 members and is ready for balloting for acceptance as an ASTM standard.

(2) Interlaboratory Tests on RDF-3

The ASTM round robin testing of RDF-3 began in June 1978 and ended in September 1980. Concern over the apparent dispersion of test data on the residual moisture, ash content, and higher heating values led to the redetermination of these properties at NBS using ASTM processed RDF-3 samples which were obtained from some of the participating laboratories. During the ASTM testing program from June 1978 to September 1980, the interlaboratory reproducibility for RDF-3-samples was two to three times lower than the interlaboratory reproducibility for test on coal samples. To determine if the variability was due to the sample or to the individual laboratory procedures, NBS obtained eight previous round robin samples from four of the participating laboratories. Higher heating values, moisture contents and ash contents were measured in the NBS laboratory and were compared to the previous results that were submitted by the participating laboratories during the round robin testing studies. The new results differed only slightly from the previous reported ASTM round robin results.

\section{(3) Processing Effects in RDF-3}

A study was designed to determine the effect of sample processing on the higher heating values and ash contents of RDF-3 samples. Teledyne National RDF-3 before (RDF-3 Fluff) and after (RDF-3 extrusion) pelletizing were obtained for this study. The samples were coned and quartered with quarters I and III to be milled to pass a $1.6 \mathrm{~mm}$ (1/16 inch) screen and quarters II and IV to be studied as received. The RDF-3 fluff was pressed into pellets for measurement of the heating value. The heating values are being measured in the 25 gram-capacity bomb

calorimeter. At the conclusion of this study (1 September 1981), data will be compared for RDF-3 fluff and RDF-3 extrusion which will provide information on the effect of pelletizing samples at the Teledyne National Resource Recovery Facility. Data will also be available on the RDF-3 fluff and RDF-3 extrusions after these materials have been milled to provide information on the effect of laboratory processing of RDF-3 samples. In both the extrusion and milling processes, significant quantities of heat are liberated and this study will identify if any sample degradation has occurred during these processes. Together with the moisture and ash data, heating values can be compared on an as-received, moisture-free, and moisture and ash-free basis. 
The Aluminum ( $A 1$ ) and iron (Fe) content of RDF-3 has been found to be of the order of 0.5 percent each. Conventional heating value measurements are made on milled samples where finely divided Al and Fe may burn and conribute to the measured heating value. In a preliminary study during fiscal year 1980, a synthetic RDF was prepared containing $80 \%$ cellulose and $20 \%$ non-combustible (silica, alumina, and iron oxide) and was doped with $3 \% \mathrm{AT}$ or $3 \% \mathrm{Fe}$. Based on known heats of combustion of the starting materials, it was found that $60 \%$ of the $A 1$ and none of the Fe burned. This may have been due to the particle size of the metals and therfore a study was planned to investigate the effect of metals in RDF further. A synthetic RDF of the previous composition was prepared. Al and Fe powders of 40,150 , and 350 micrometers were obtained to dope the synthetic RDF so that it would have a metal content of $0.5 \%$ separately and $1.0 \%$ combined. Heating values, moisture content, and ash contents have been measured for the undoped synthetic RDF and the synthetic RDF which has been doped with the 40 and 150 micrometer metals. Values are presently being measured for samples doped with 350 micrometer particle size metals. At the completion of this study (1 September 1981), the data will be compared to the theoretical heats of combustion which are based on the heats of combustion of the starting materials. Theoretically, the heat of combustion will be significantly lowered if none of the metal burns, moderately lowered if the Fe burn to either $\mathrm{FeO}, \mathrm{Fe}_{2} \mathrm{O}_{3}$, or $\mathrm{Fe}_{3} \mathrm{O}_{4}$ and significantly higher if the Al burns to $\mathrm{Al}_{2} \mathrm{O}_{3}$.

\section{Variability of Municipal Solid Waste}

During fiscal year 1980, a study was carried out to determine the variability of municipal solid waste (MSW) examined over a two-week period at the Baltimore County Resource Recovery Facility in Cockeysville, MD. Municipal solid waste was processed through a primary shredder and samples were collected daily for two weeks. After the total moisture content was determined, the samples were reduced in particle size to $2 \mathrm{~mm}$ or less. A total of 40 samples were prepared for measurements. Testing was carried out for residual moisture, furnace ash, bomb ash, and higher heating value (HHV).

During fiscal year 1981, the results were analyzed and showed that the daily variability of MSW is large and is demonstrated by the data obtained for moisture, ash, and HHV determinations. Statistical analysis of the data suggests that the day to day variability of MSW constitutes 70 to 80 percent of the overall variability, with the other variables being errors in measurement techniques, sampling, and systematic errors.

The study was performed to determine the merits of making measurements on RDF samples of the order of 2.5 kilograms in order to increase the confidence for a higher heating value of a fuel derived from the variable municipal solid waste (MSW). The development of a $2.5 \mathrm{~kg}$ capacity combustion calorimeter is not expected to reduce the overall variability (precision) of data on HHV beyond what is currently available from conventional combustion calorimeters which accommodate gram-size samples. Unfortunately, test procedures which require gram-size samples of MSW or 
RDF introduce uncertainties into the measurement results because they so poorly represent the large multi-ton array of refuse. This representation maybe poor not only because of the high heterogeneity of refuse but also because of the large amount of processing necessary to produce an analysis sample.

One can expect to have more confidence in data on HHV's which are determined in a $2.5 \mathrm{~kg}$ capacity combustion calorimeter because a larger sample is being used. The use of a larger sample should lead to an average HHV which is closer to the true mean of the refuse population than one would o'tain from using gram-size samples. Such HHV's should be more accurate, but may not be any more precise.

\section{E. Ash Content of RDF, Coal and RDF/Coal Mixtures as a Function of Temperature}

The purpose of the study was to find out whether recommended ashing temperatures which are to be used in proposed ASTM protocols or which are used in existing ASTM protocols are sensitive to small temperature fluctuations. The mineral matter present in ash residues from RDF or coal contains carbonates, sulfates, and firely divided metals. The decomposition of carbonates or sulfates can be responsible for marked fluctuations in the mass determined for an ash residue if the ashing temperature lies in the range in which such decomposition is significant. The oxidation of finely divided metals can produce an increase in the mass of an ash residue within a specified temperature range.

The ash content was determined for four selected refuse-derived-fuel (RDF) and four coal samples at $100^{\circ} \mathrm{C}$ intervals over the temperature range from 575 to $1225^{\circ} \mathrm{C}$. A $50 / 50$ mixture of RDF/coal is presently being studied over the same temperature range. X-ray diffraction analysis of these ash samples which were obtained at elevated temperatures reveals the presence of the more prominent crystalline phases present. These phases suggest which chemical reactiors may be taking place at the various ashing temperatures. The phase assemblage for the RDF ash samples are remarkably similar over the entire range of temperatures studied. This is also true for the coal ash samples, although to a lesser extent. Data on the higher heating value and ash content of 50/50 mixtures of RDF with coal show that these properties are additive.

\section{F. Enthalpy of Combustion of Microcrystalline Cellulose}

A test substances with characteristics and properties similar to those of cellulose-based solid waste products is needed to calibrate calorimeters and combustors which will be routinely burning refuse or RDF to determine their calorific values precisely for use in commerce. Microcrystlline celluose was found to be a good calibrant for this purpose. The enthalpy of combustion of microcrystalline cellulose, $\Delta H^{\circ}$, at $\left(25^{\circ} \mathrm{C}\right)$, was determined to be $-2812.40 \pm 0.56 \mathrm{KJ} / \mathrm{mol}(2 \mathrm{sdm}$ ) based upon the sample mass.

Plans for FY 1982

(A) Oxygen flow calorimetry of solids 
Construction of components of the 2.5 kilogram capacity flow calorimeter will be completed early in FY 1982. Assembly and testing will follow. Calibration will be carried out using microcrystalline cellulose. Calorimetric measurements are planned for both minimally processed and highly processed RDF.

(B) Oxygen bomb calorimetry of solids

Calorimetric measurements will be carried out to establish the comparison between bomb and flow experiments. Continued work on the synthetic RDF is planned in coordination with ASTM Subcommittee E-38.01 on Energy. Also, provide this Subcommittee with results of betweenlaboratory study on furnace ash and bomb ash procedures. Calculate results and prepare a manuscript on measurements performed in the $25 \mathrm{gram}$ capacity bomb calorimeter on Teledyne National (RDF-3 fluff) and (RDF-3 extrusions).

\section{(C) Metals in RDF}

A manuscript will be prepared describing the results of calorimetric studies on the doping of the synthetic RDF sample with finely-divided aluminum and iron.

\section{(D) Variability of municipal solid waste}

A manuscript will be prepared for publication on the variability of municipal solid waste and its impact upon the development of test procedures for the determination of higher heating value.

(E) RDF, coal, and RDF-COal mixtures

Ash content studies and combustion calorimetry of RDF-coal mixtures will be continued. If possible, the comparison of combustion of RDF-coal mixtures in pure oxygen and air will be carried out. 
Project Title: Research in Thermometry Applicable to Resource Recovery

Goal: (1) To provide technical assistance in the design and development of a large sample constant pressure flow calorimeter.

(2) To develop high temperature instrumentation for thermometry.

Technical Center for Absolute Physical Quantities

Areas at Temperature and Pressure Measurements and Standards Division NBS:

Personnel: M. L. Reilly, G. W. Burns, W. S. Hurst, G. T. Furukawa, J. P. Evans, and L. A. Guildner.

Accomplishments in FY 1981

A. Design and Development of a Large-Sample Flow Calorimeter

During FY 81, now ending, the following staff on the CAPQ have been directly involved in the development of a large-scale calorimeter for use in the NBS Resource Recovery Program: M. L. Reilly, G. W. Burns, W. S. Hurst, and G. T. Furukawa. Mr. Reilily, in collaboration with Dr. K. Churney and other colleagues in the Center for Chemical Physics, has participated in nearly every phase of the development work this year.

The first quarter of FY81 was devoted to the analysis of data obtained in 18 experiments using a prototype combustor in which samples of up to $2.2 \mathrm{~kg}$ of RDF or cellulose had been burned in Flowing oxygen. A detailed understanding of the performance of the combustor was a prerequisite for the design of the large-scale calorimeter.

The final design of the $2.5 \mathrm{~kg}$ capacity flow calorimeter was completed in the second quarter of FY31. The first draft of a manuscript describing the experiments with the prototype combustor and the analys is of the experimental data was finished. Because accurate flow measurements are essential to the success of the program, Reilly attended the Second International Symposium on Flow, Its Measurement and Control in Science and Industry which was held in St. Louis in March.

Much of the third quarter was spent in preparation of a manuscript for the Second International Symposium on Materials and Energy from Refuse (Antwerp, Belgiuili on 0ct. 20-22, 1981). Assembly of the final version of the 25 gram flow calorimeter was begun. Several trial burns were conducted to test the performance of the new cooling coils and water condenser/trap. Additional software was developed to support the instrumentation added particularly for flow measurements and infrared analysis of trace constituents of the exhaust gas steam.

During the last quarter of FY81 the heat of combustion of pure cellulose will be determined using the final version of the 25-gram capacity flow calorimeter. Cellulose is to be used as a chemical calibrant for the $2.5 \mathrm{~kg}$ capacity calorimeter. The purpose of these 
experiments is to establish a correspondence between the flow result and that obtained recently using the combustion bomb. A major feature of these experiments will be the electrical calibration of the flow calorimeter as well as calibration using a methane-oxygen combustion reaction.

As noted above, individual contributions to the success of the calorimetery project were made by other CAPQ personnel. Included in this group are the following:

George Burns provided advice about the selection and use of thermocouples for the final version of the 25 gram capacity flow calorimeter. A significant improvement was made in the measurement of the temperature of moist flowing gases. This technique will also be used in the large-scale flow calorimeter.

Wilbur Hurst, although not officially reprogrammed into the resource recovery area, has contributed signficantly to our data acquisition capability through his developmental work with the S-100 minicomputer systems. He provided new operating systems which interface our system with a real-time clock and the IEEE bus.

George Furukawa has prepared shop drawings for an assembly in which the quartz crystal thermometers to be used to measure temperatures in the flow calorimeter can be calibrated through comarison with standard platinum resistance thermometers.

One paper and one report on the calorimeter project resulted from work performed in part by personnel from this Center. These are:

Paper

Churney, K. L., Reilly, M. L., Ledford, A. E., Ryan, R. V., and Domalski, E. S., "An Oxygen Flow Calorimeter for Determining the Heating Value of Kilogram-Size Samples of Solid Muncipal Waste," (to be published in the proceedings of the Antwerp Conference).

\section{Report to Sponsor}

Kirklin, D. R., Colbert, J., Churney, K. L., Reilly, M. L., Ledford, A. E., Ryan, R. V., Kelly, R. V., and Domalski, E. S., "Test Procedures for the Determination of the Gross Calorific Value of Refuse and Refuse-Derived Fuel of Kilogram-Size Samples Using Constant Pressure Flow Calorimetry" (in press).

B. Development of High-Temperature Instrumentation for Thermometry

During FY81, the following staff of CAPQ have been involved in the development of thermometry appropriate for use at the temperatures commonly found in combustion processes: G. W. Burns, G. A. Evans, J. P. Evans, and L. A. Guildner. This work was separated into three component projects this year. 
The first project had as a major output the evaluation of thermometry feasibility in systems containing molten metal components. Its accomplishments include the following, produced by $G$. W. Burns and G. A. Evans:

1. Design of thermocouple test probe for first measurements of lifetime in molten metal. The design objectives include:

a) Probe life of 15-20 minutes;

b) Temperature range $1400{ }^{\circ} \mathrm{C}-1650{ }^{\circ} \mathrm{C}$;

c) Suitability as prototype for reference thermometer in evaluating disposable immersion thermocouple thermometers in an experimental 8-ton arc furnace at the Homer Research Laboratory of the Bethlehem Steel Company.

2. Acquisition of component parts and minerals sufficient to fabricate six probes.

3. Construction of two probes of the chosen design. These probes utilize Type B (Platinum-30\% Rhodium vs. Platinum-6\% Rhodium) thermocouples insulated with high-purity aluminum oxide and protected by a self-bonded Type KT silicon carbide sheath $13 \mathrm{~mm}$ o.d., $0.6 \mathrm{~m}$ long. The silicon carbide sheath, which is immersed directly into the molten metal, is joined mechanically to a $2.2 \mathrm{~m}$ long connecting extension wire of stainless steel. The stainless steel extension is protected by a multi-layer wrap of Fiberfrax 800 ceramic fiber paper and is of a concentric tube design to allow for forced air cooling.

4. Design and construction of a preliminary test crucible to be utilized in the NBS laboratory for preliminary probe evaluation. The test crucible was fabricated from A. P. Green Refractories Company castable AP-96.

5. Experimental test of thermocouple probe sheaths. The durability of two types of silicon carbide sheaths in molten iron was evaluated. Sheaths of the self-bonded type KT silicon carbide and of a chemically vapor-deposited silicon carbide were tested. In these tests, a batch of scrap iron was heated inductively in the laboratory crucible in air at $1350^{\circ} \mathrm{C}$ to $1450^{\circ} \mathrm{C}$ until a heavy slag layer formed. The sheaths were then immersed rapidly into the molten iron. After immersion for 3-6 minutes, the sheaths were withdrawn and inspected. Both types of sheath suffered gross chemical attack and erosion by the iron-rich oxide slag at the melt-air interface. The $3 \mathrm{~mm}$ thick wall of the sheaths was nearly eroded through after 5 minutes exposure to the slag.

The results of this test indicated a need for more durable sheath material to protect the test probe thermocouples. Another DoE contractor, T. Negas, recently completed investigation of several graded cermet-oxide ceramic coatings on molybdenum as protective covers in harsh chemical environments. Their results include a total time to failure 
in excess of 5 hours in molten gray iron for an arc plasma spray coating of $\mathrm{MgAl}_{2} \mathrm{O}_{4}$ on Mo tubes.

6. Redesign of the protective sheaths based on coated Mo tubing has been completed, Mo tubing ordered, and a local coating source has been contacted.

7. Progress reports presented at November 1980 and May 1981 meetings of American Society for Testing and Materials E-20.04, which has been organized for the purpose of facilitating development of test methods for molten ferrous thermometry.

The second project was initiated by Drs. Wing Tsang and Walter Shaub. It concerns the direct monitoring of reactions and temperatures in a combustion environment. The present activity involves the construction of a high-temperature furnace and the measurement of its temperature profile. The work accomplished so far this fiscal year includes the design of the furnace and the instrumentation. The CAPA portion of this project currently consists of a part-time effort on the part of $G$. W. Burns, who is providing design guidance to Dr. Shaub.

The third project is the continuing development and testing of special high-temperature resistance thermometers for optimum accuracy use at temperatures to $1100{ }^{\circ} \mathrm{C}$. This work is taking place in the hands of J. P. Evans and of L. A. Gui dner. During FY8I, nine thermometers have been built and evaluated. Six of these experienced diminished alphacoefficients after relatively short exposures of $1100^{\circ} \mathrm{C}$; analysis of the resistor elements indicated the presence of $\mathrm{Pd}$ and $\mathrm{Cu}$ contaminants at levels which could easily cause such effects. Of the other thermometers, one has showed excellent resistance to the effects of high-temperature exposure of several hundreds of hours. Its alpha-coefficient remained above 3925 after heating for more than 300 hours. Work on this project is continuing with the following directions:

1. Emphasis on methods of thermometer assembly to avoid contamination;

2. Study of mechanical modes of failure, including separation of leads from the resistor, shorting of turns of the resistor, and separation of the resistor from its support;

3. Evaluation of the feasibility of electrical guarding of nominal 2.5-ohm thermometers as opposed to utilizing heavier resistor wire for greater strength at the expense of reduced sensitivity and poorer thermal equilibrium properties.

\section{PTans for FY 1982}

Mr. Reilly will continue to work full time on the design and development of the large-sample flow calorimeter. Interaction by other members of the staff of the Temperature and Pressure Measurements and Standards Division will be based upon the specific need of the program as it develops. 
The work of Guildner, Burns, and Evans on the development of high temperature instrumentation for thermometry will be continued. 
Project Title: Applied Research on Combustion Characterization of Refuse-Derived-Fuel (RDF)

Goal: Phase I

(1) To perform tests on RDF using static measurements (bomb calorimetry, elemental analysis, ash content, moisture content, etc.) and dynamic measurements (TGA, DSC EGA(*), etc.).

(2) To study the entrained combustion of RDF particles in a specially designed Taboratory furnace.

Phase II

(3) To validate the results obtained in the test laboratory characterization of RDF developed in Phase I through a study of RDF combustion in a combined fixed-bed/entrained-flow industrial facility.

Answers to the following questions are expected from this study:

(a) What particle size range of the fuel is entrained under a given set of boiler parameters (excess air, temperature gas velocity)?

(b) Is the fraction of the fuel settling (under specified conditions) such that a grate is necessary?

(c) What are the devolatilization and combustion times of the entrained material (as function of excess air, etc.)? How do these compare with the analogous parameters for pulverized coal?

(d) What are the ignition times and temperatures for the entrained fraction?

(e) How do the ignition and heat release parameters in fixed-bed (grate) firing of RDF compare?

(f) Are the corrosion problems and boiler emissions ( $\mathrm{NO}_{\mathrm{X}}, \mathrm{SO}_{\mathrm{X}}$, chlorine, etc.) significantly different than in the case of coal?

(*) TGA, Thermal Gravimetric Analysis

DSC, Differential Scanning Calorimetry

EGA, Evolved. Gas Analysis 
Technical Center for Chemical Physics

Areas at Chemical Thermodynamics Division

NBS and E. S. Domalski, D. R. Kirklin, J. C Colbert,

Personnel: A. E. Ledford, R. V. Ryan, R. Kelly

Center for Chemical Physics

Chemical Kinetics Division

W. Tsanq, W. Schaub, 1. A. Walker, S. Stein

Center for Chemical Engineering

Thermal Processes Division

A. Macek, C. Bulik, S. R. Charagundla

Other

Agency

U. S. Department of Energy

Support

Office of Energy from Municipal Waste

Accomplishments in FY 1981

A. High Pressure Differential Scanning Calorimetry of

Refused-Derived-Fuel (RDF)

(to be presented at the Eleventh North American Thermal Analysis

Society Conference in October 1981)

The results of an investigation by $W$. Tsang and J. A. Walker are described on the properties of the organic portions of municipal solid waste as determined by high pressure differential scanning calorimetry under oxidative and pyrolytic conditions. It is part of the program of the Office of Recycled Materials at the National Bureau of Standards under the Resource Conservation and Recovery Act of 1976 (PL 94-580). More specifically, the present work is a response to the current interest in the use of municipal solid waste as an alternative fuel and addresses the need for defining the nature of the substance, determining methods for characterization and provide information with respect to end use contexts. The heterogenous nature of the substance, determining methods for characterization and provide information with respect to end use contexts. The hetergeneous nature of municipal solid waste in general and the organic fraction in particular makes thermo-analytical methods particularly useful since the thermograms may permit a degree of differentiation greater than that derivable from standard ASTM methods, but without the detail [which would be difficult to interpret] if molecular specific detection is employed. Furthermore, the heat released under controlled oxidative or pyrolytic conditions, represents an important combustion property. Nevertheless, the rates are much slower than the flaming combustion oi pertinence to alternative fuel applications. The physical phenomena that is being simulatd is probably more akin to smoldering combustion. However, there are marked similarities and a certain degree of correlation can be expected. Finally, we are particularly interested in comparing those results with the corresponding data for coal as well as the specific organic compounds presumed to be in municipal solid waste. 
Typical organic composition of municipal waste in the "as received" state contains paper, yard and food waste, as well as plastics, rubber, textile etc. (1). For fuel applications, Table I summarizes the present classification system (2).

Table I

Definitions for Refuse Derived Fuels

(RDF-1) municipal solid waste with white goods removed.

(RDF-2) municipal solid waste with or without ferrous metal

separation, and minimally processed to reduce particle size.

This material has a particle size such that 95 weight percent

passes through a 6 inch square mesh screen.

(RDF-3) shredded fuel derived from municipal solid waste processed for the removal of metal, glass, and other entrained inorganic materials. This material has a particle size such that 95 weight percent passes through a 2 inch square mesh screen.

(RDF-4) powdered fuel in which the combustible fraction of the refuse has been processed. This material has a particle size such that 95 weight percent passes through 10 mesh ( 0.035 inch square) screen.

(RDF-5) solid fuel in which the processed combustible fraction is densified (compressed) into the form of pellets, slugs, cubettes, or briquettes.

All of the samples that will be discussed in this work can be considered to be in the RDF-4 category. It should be realized however, that as received they are in the RDF-3 to 5 ranges, but the requirements of the experimental apparatus necessitates reduction to the powdered form. The higher heating value of refuse derived fuels of the type considered here are in the range of $8000-10,000 \mathrm{BTU} / \mathrm{lb}$ (3). This is in the range of values for lignite and is considerably lower than that for other types of coal. There have been several direct studies on the combustion properties of refuse derived fuels $(4,5)$. The complex interplay of physicochemical parameters makes such experiments difficult to interpret. It does appear however, that refuse derived fuel samples are more readily ignitable in comparison to coal.

\section{EXPERIMENTAL}

A11 of the experiments were carried out with the DuPont 1090 Thermal Analysis system associated with a High Pressure Differential Scanning Calorimeter (DSC) and a Thermal Gravimetric Analyzer (TGA). The majority of the samples used in these experiments have been prepared by members of the Chemical Thrmodynamics Division at the National Bureau of Standards. They have been engaged in an active program to determine the heating values of refuse derived fuels. In general, the prior preparation involved grinding and sizing the "as received" fuels into a form that can be used for the present investigation. The specific samples that have been tested are as follows: 
(a) RDF-5 from Teledyne; (b) RDF-3 from Teledyne; (c) RDF-4 from Combustion Equipment (Eco-Fuel II); (d) RDF-3 from Bureau of Mines (College Park, Maryland); (e) RDF-4 from National Center for Resource Recovery [low ash] and (f) RDF-3 from Americology (Milwaukee, Wisconsin).

Most of the work has been carried out with Teledyne samples since they were readily available. As a basis for comparison, studies have also been carried out with (a) bituminous coal Standard Reference Material, (b) newsprint and (c) polyethylene.

For the last two substances, except for shredding, no prior treatment was employed. All experiments were carried out in a dynamic mode with flow rates of the order of 50-100 cc/min (NTP), and at a pressure of 700K $\mathrm{Pa}(100 \mathrm{psi})$. The former assures the removal of volatile products and has been found to be an important factor in assuring reproducibility. All experiments have been carried out with open pans. The possibility of the samples igniting and thereby undergoing flaming combustion resulting in processes too fast to be followed, sets a limit on the oxidizing conditions that can be employed. This was apparently more serious for the RDF samples than coal.

\section{RESULTS}

Thermograms of the various samples under oxidative and pyrolytic conditions are summarized in the accompanying figures. They are divided into several broad categories. Figures II-IV represent data on the effect of process variables. They include the results of size changes, variation of heating rates and effect of pressure. We have also established that weight changes from 1-4 mgs have no effect on the thermograms. The second set of experiments as seen in Figure $V$ show the variation of four Teledyne samples that had been collected over a ten day period. Figure VI represent data which display the variation in the different types of refuse derived fuels listed earlier. The data in Figure VII represent experiments with "pure" samples as well as with the coal SRM. Finally in Figure VIII-X we display thermal gravimetric results for selected samples.

\section{DISCUSSION}

An examination of the thermograms given in the earlier section demonstrate that the fundamental signature from refuse-derived-fuel samples of the type studiej here involves four distinct peaks. The differences between this and thermograms of bituminous coal are clear cut [we have also carried out similar studies with other coal samples. They have similar thermograms] and is undoubtedly a reflection of the differences in chemical constitution. It should be noted that our problems with regard to the ready ignitability of refuse-derived-fuel samples in comparison with coal is in line with other evidence. In actual use contexts it should be recalled that this will be compensated by the higher heat of combustion of coal. The stimulus for coal ignition is in fact stronger.

The four peaks that are characteristic of refuse-derived-fuel combustion in a high pressure differential scanning calorimeter can be 


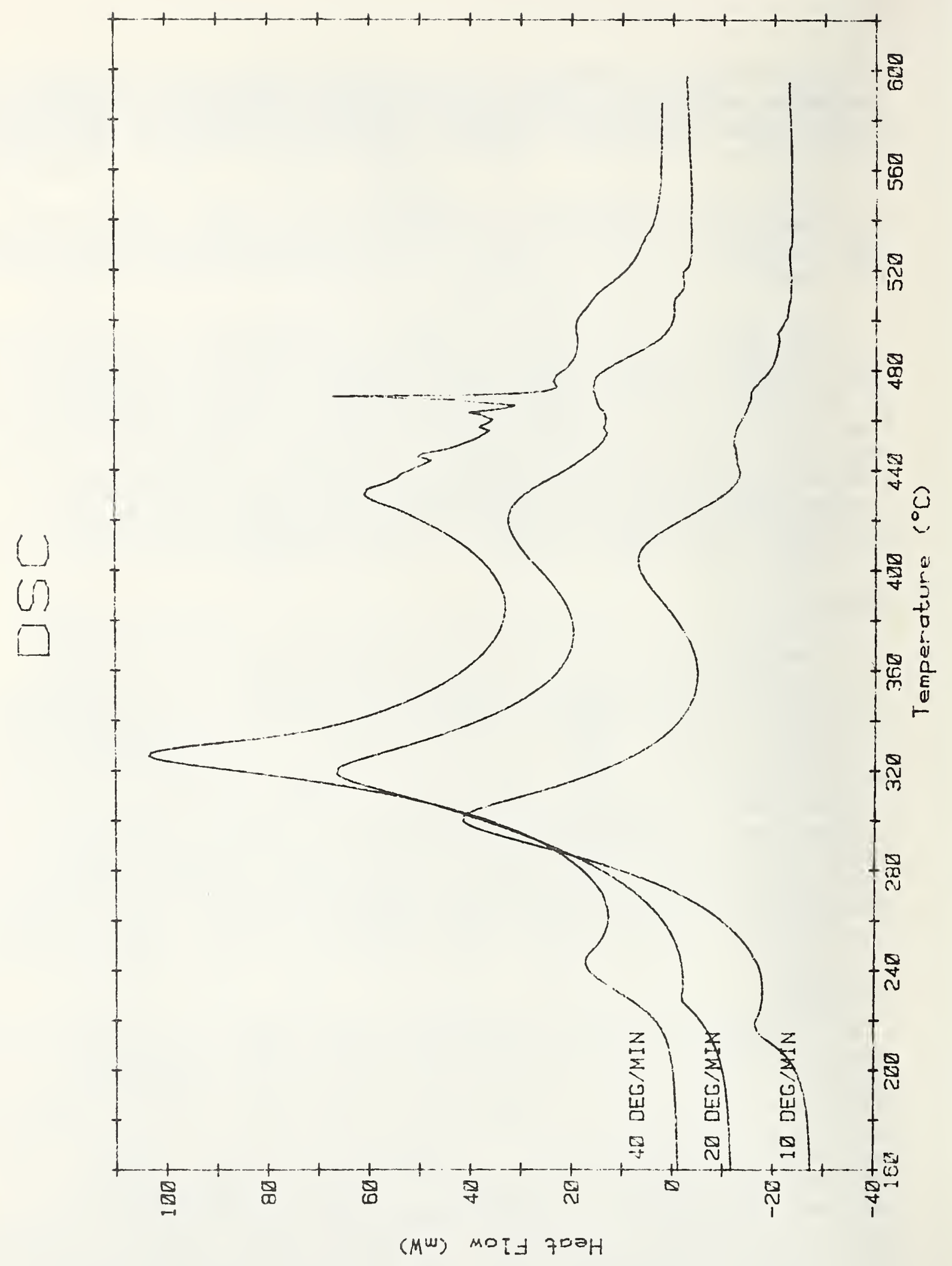

Figure II. Effect of Heating Rates 


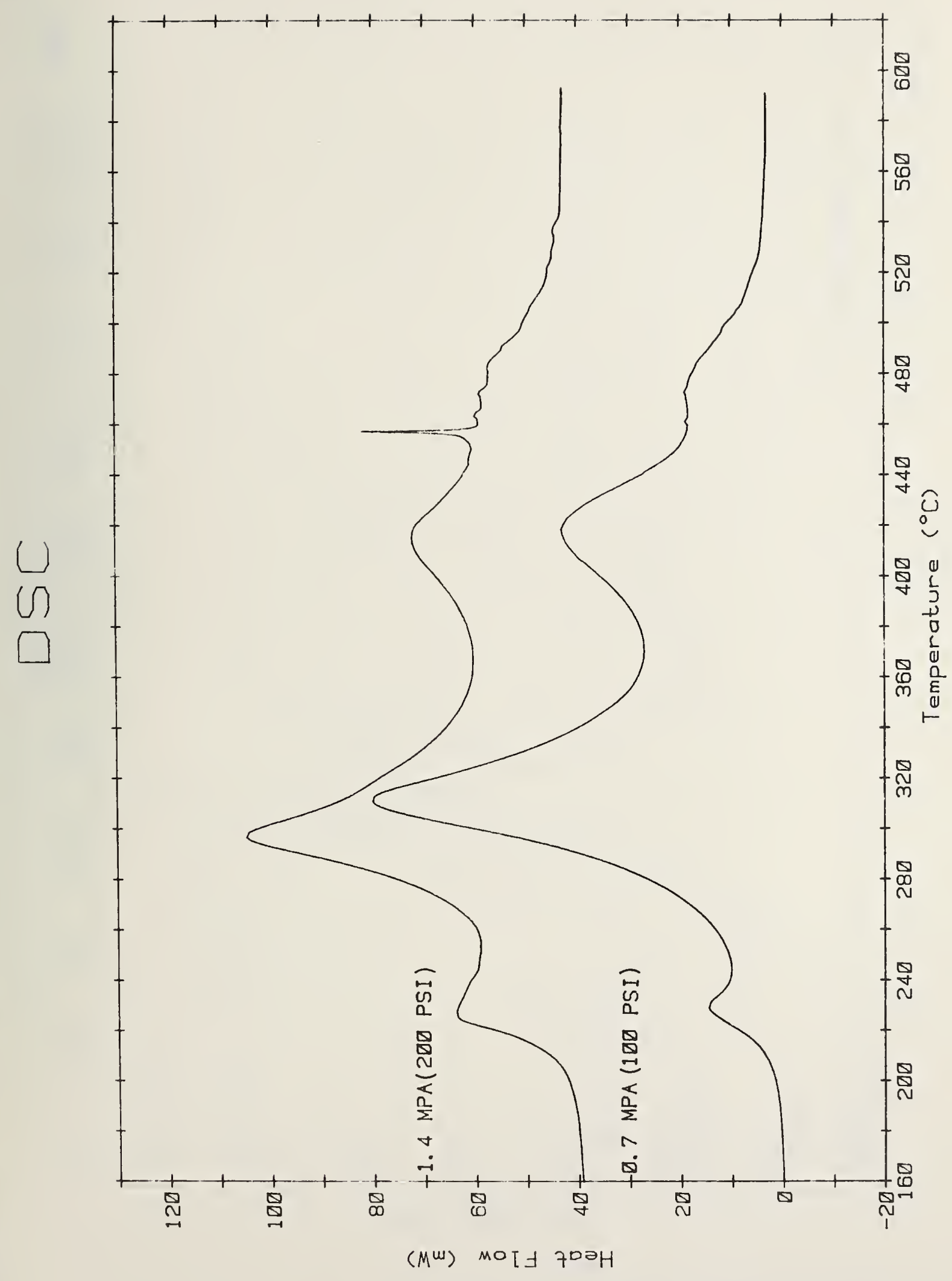

Figure III. Effect of Pressure 


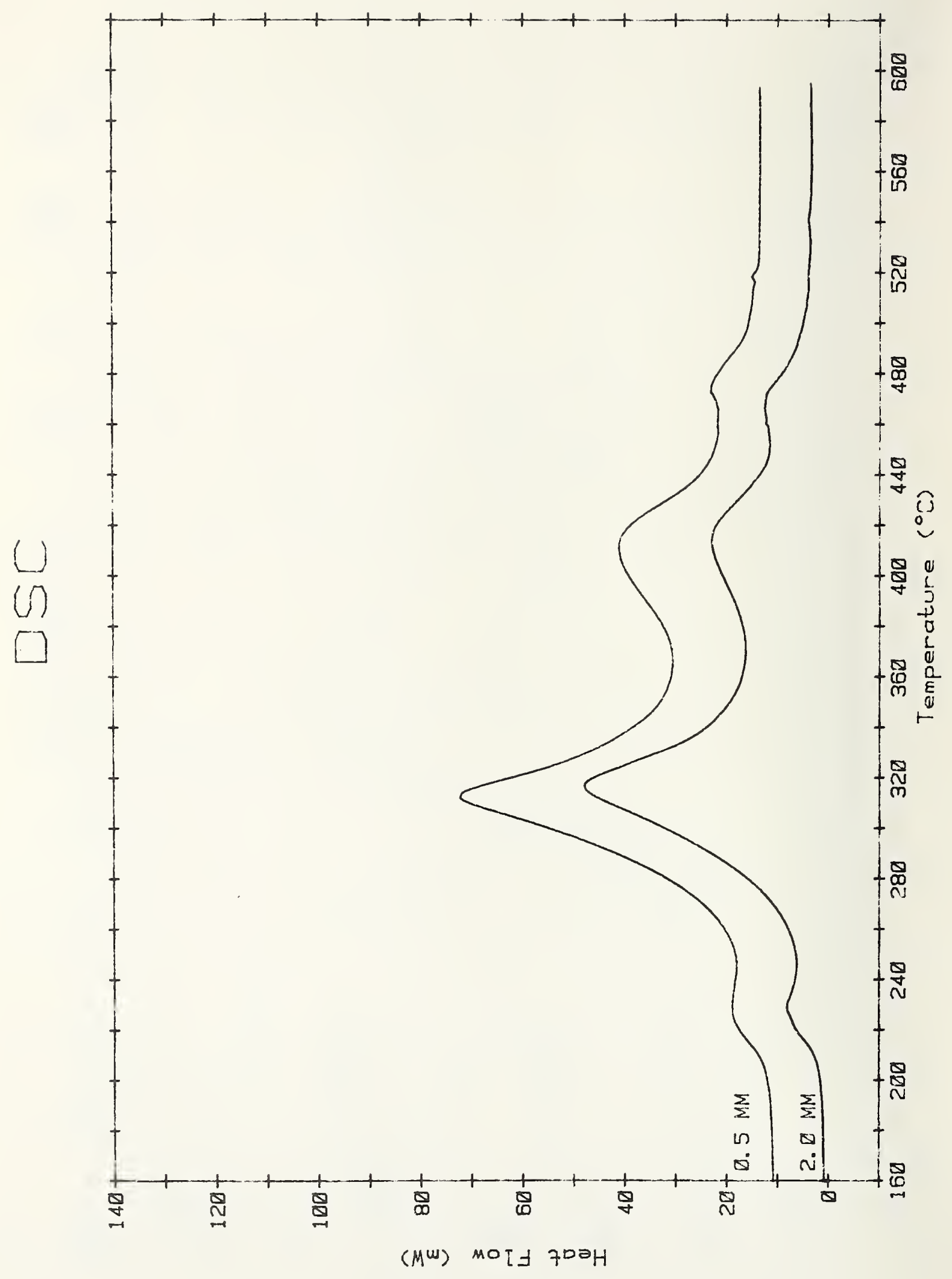

Figure IV. Effect of Particle Size 


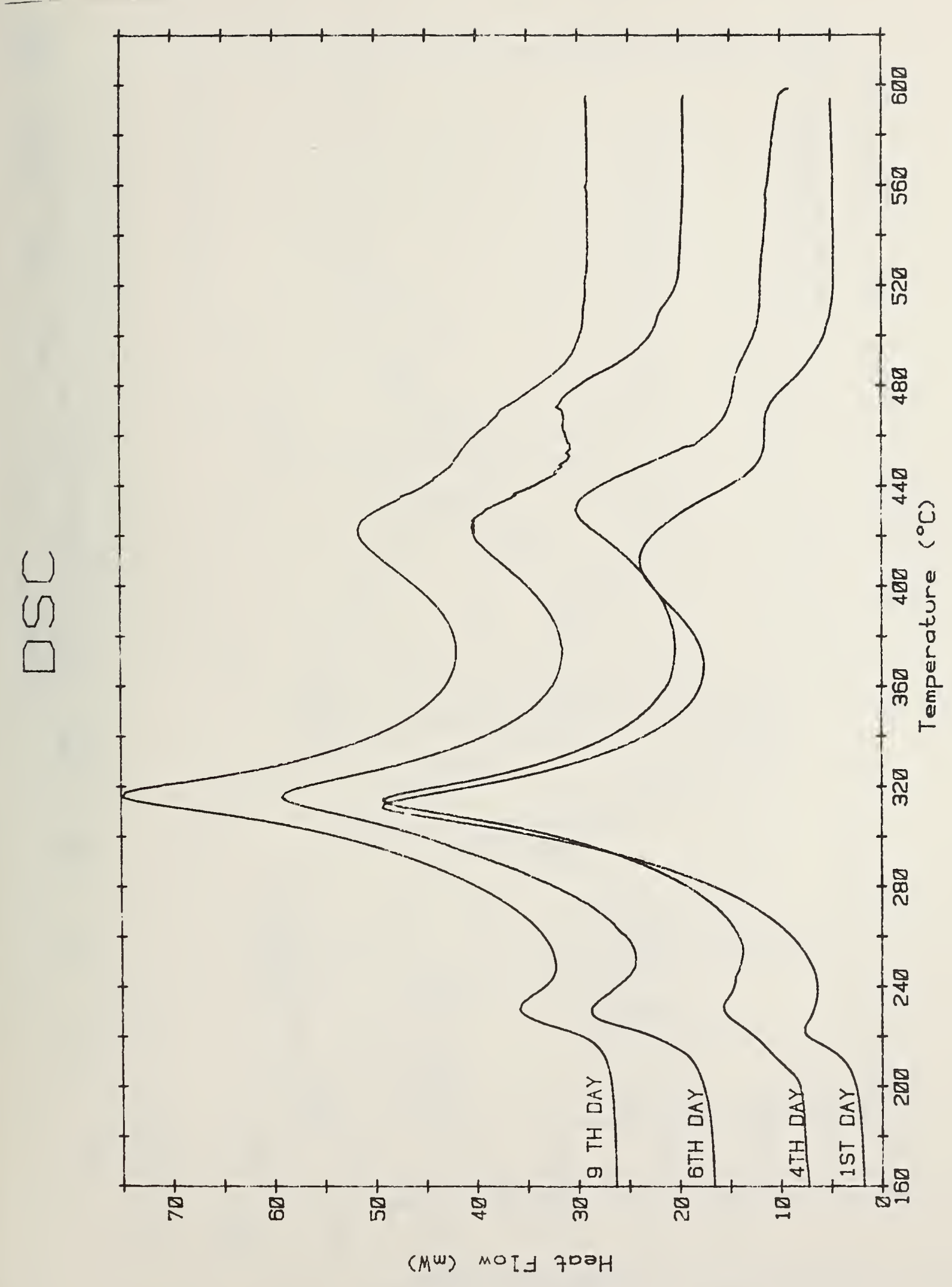

Figure V. Day to Day Variation of RDF from Same Site 


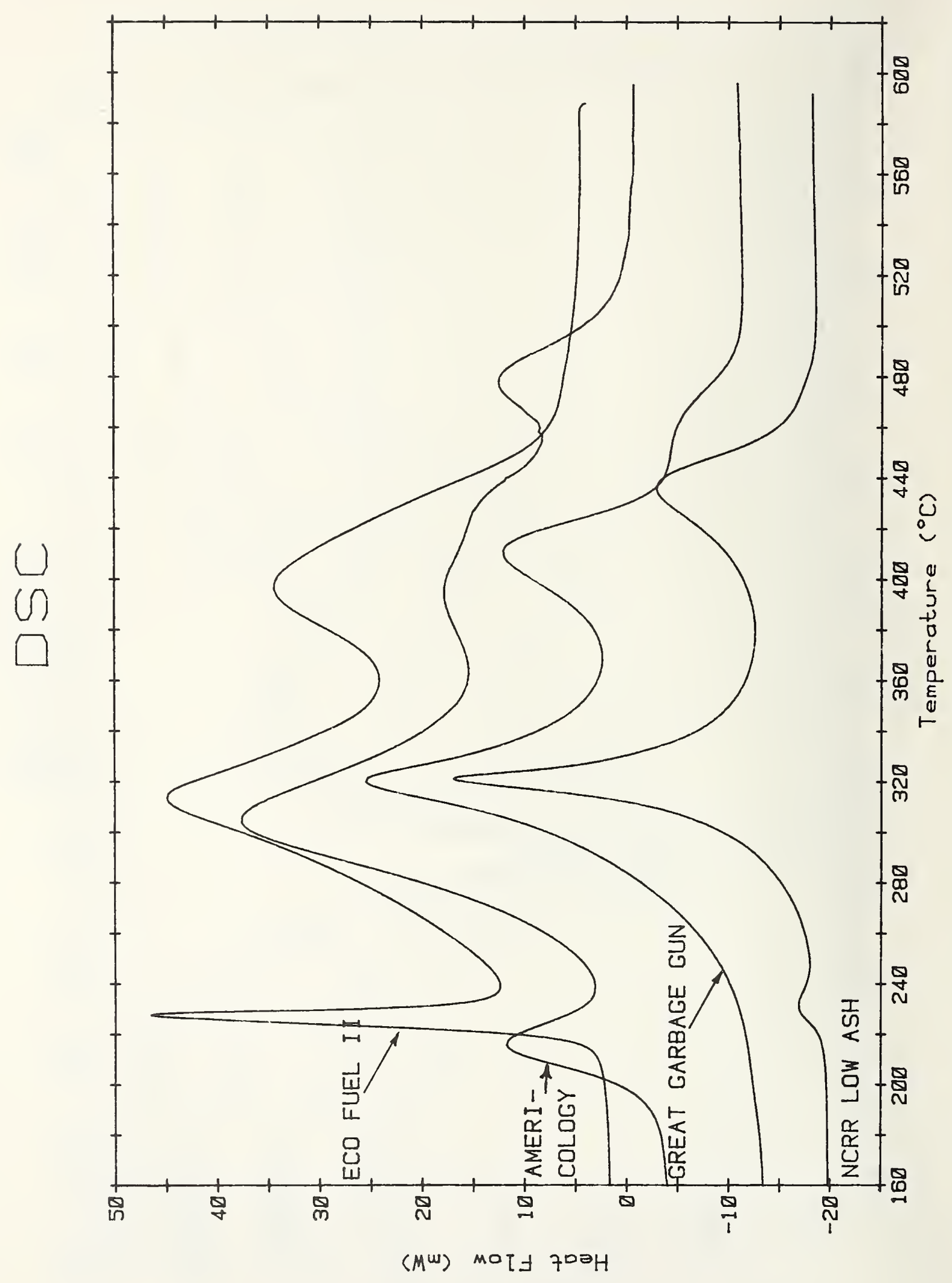

Figure VI. DSC Thermograms of RDF Samples from Various Sources 


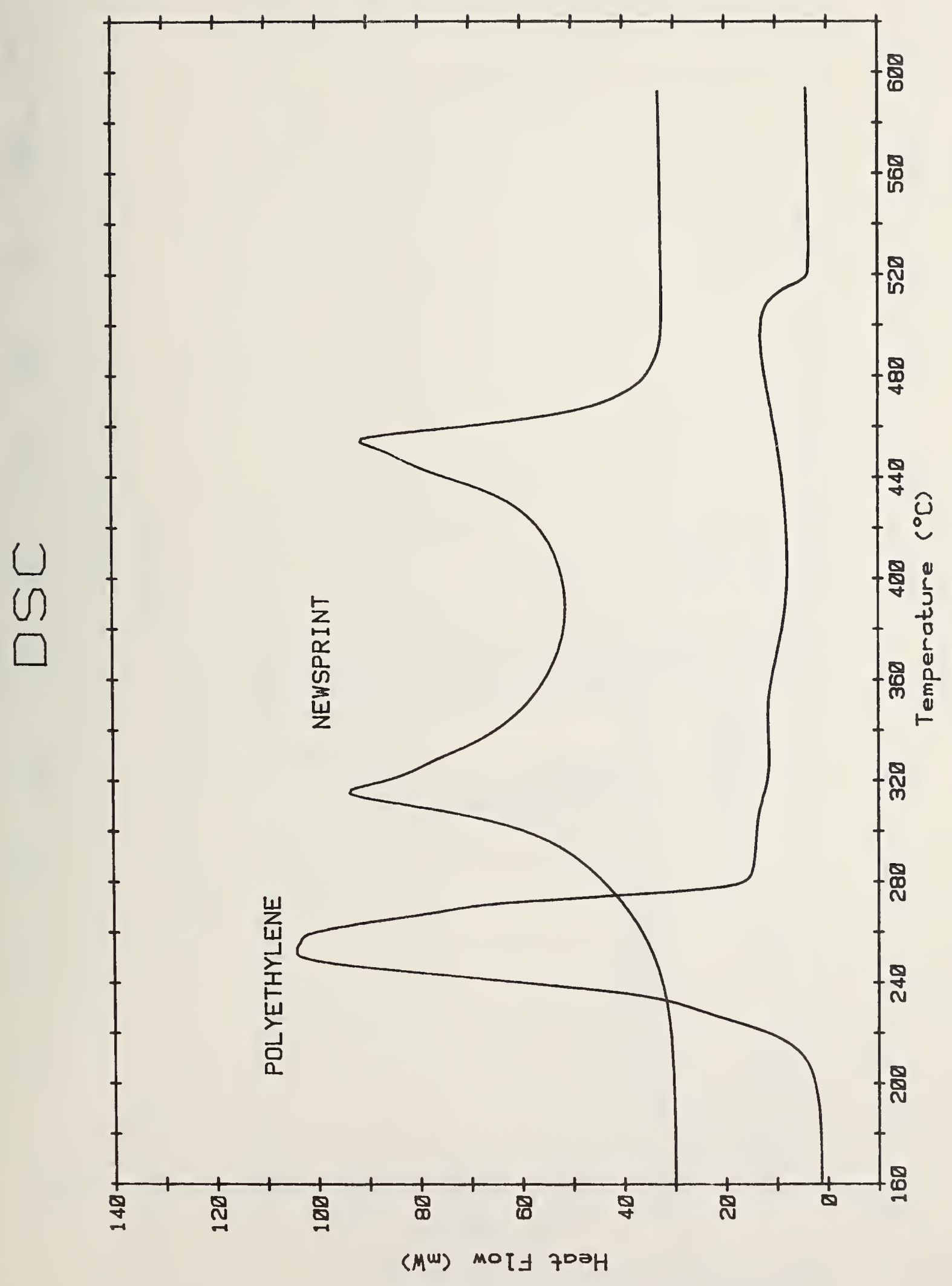

Figure VII. DSC Thermograms for Various "Pure" Compounds 


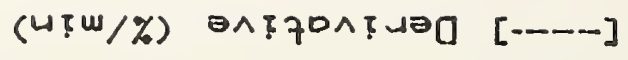

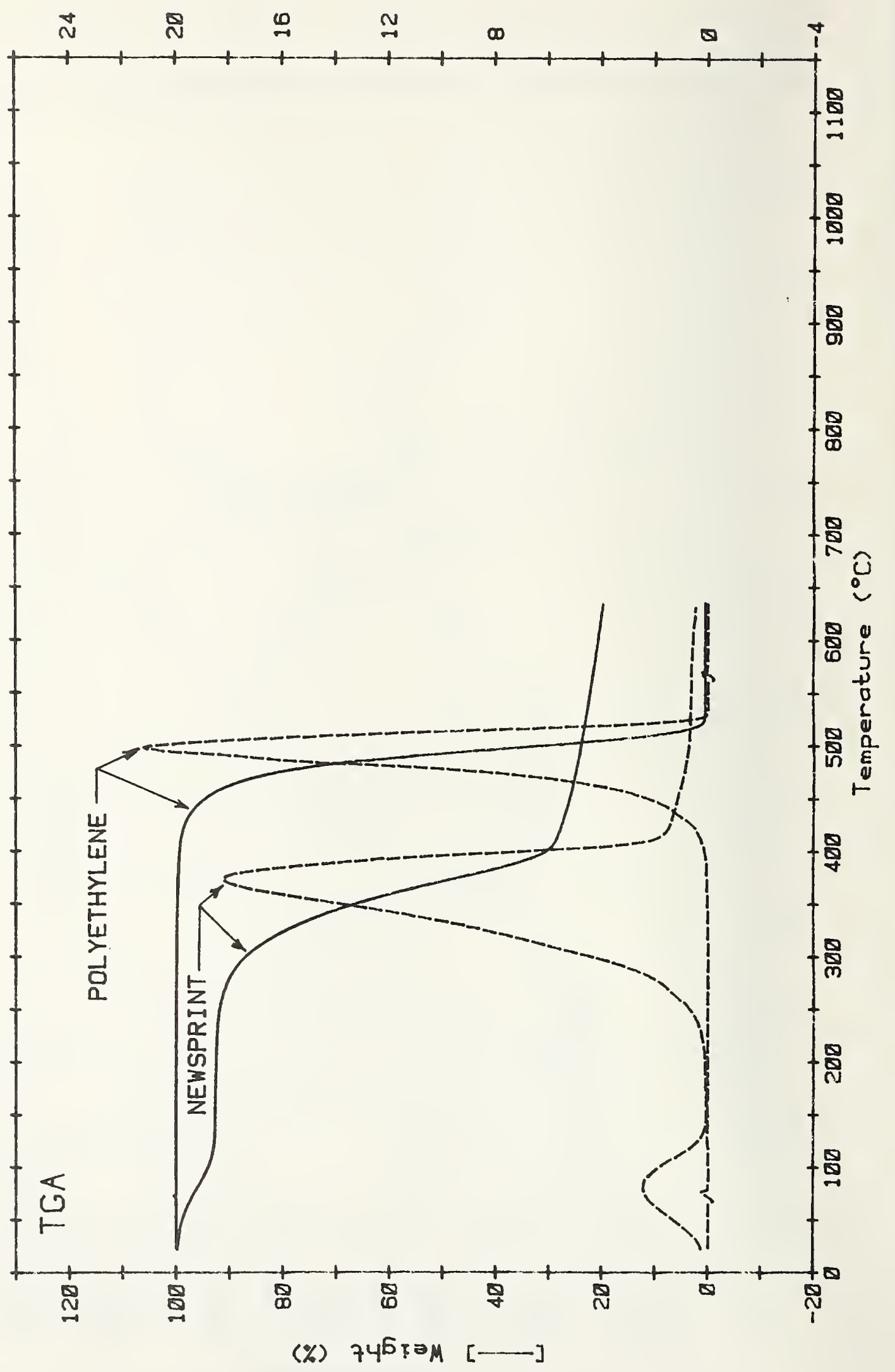

Figure VIII. TGA Thermograms for Polyethylene (dotted curver $=$ DGTA) 


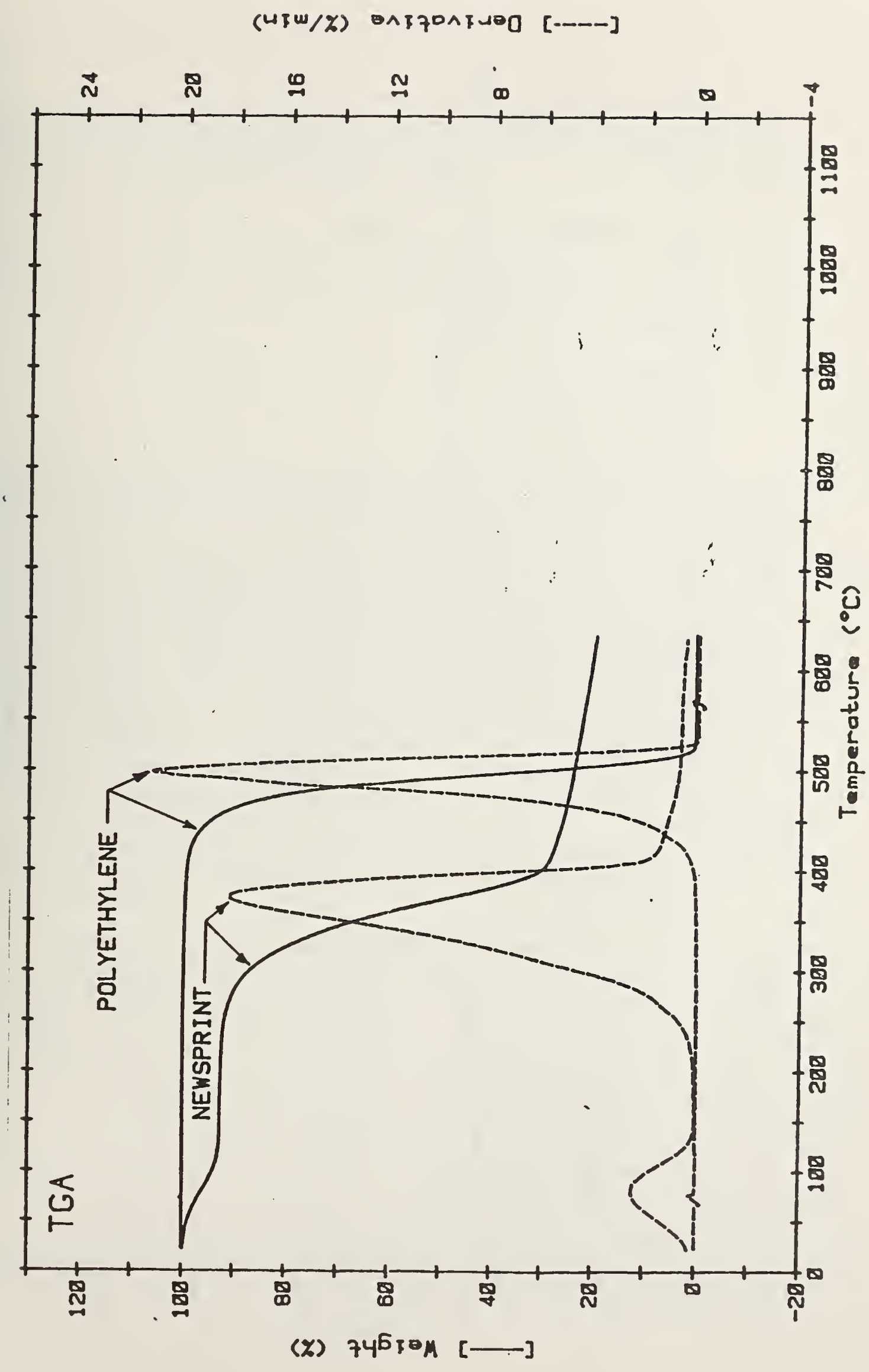

Figure IX. TGA Thermograms for Newsprint (dotted curve $=$ DTGA) (See previous page, Figures XIII and IX are combined) 


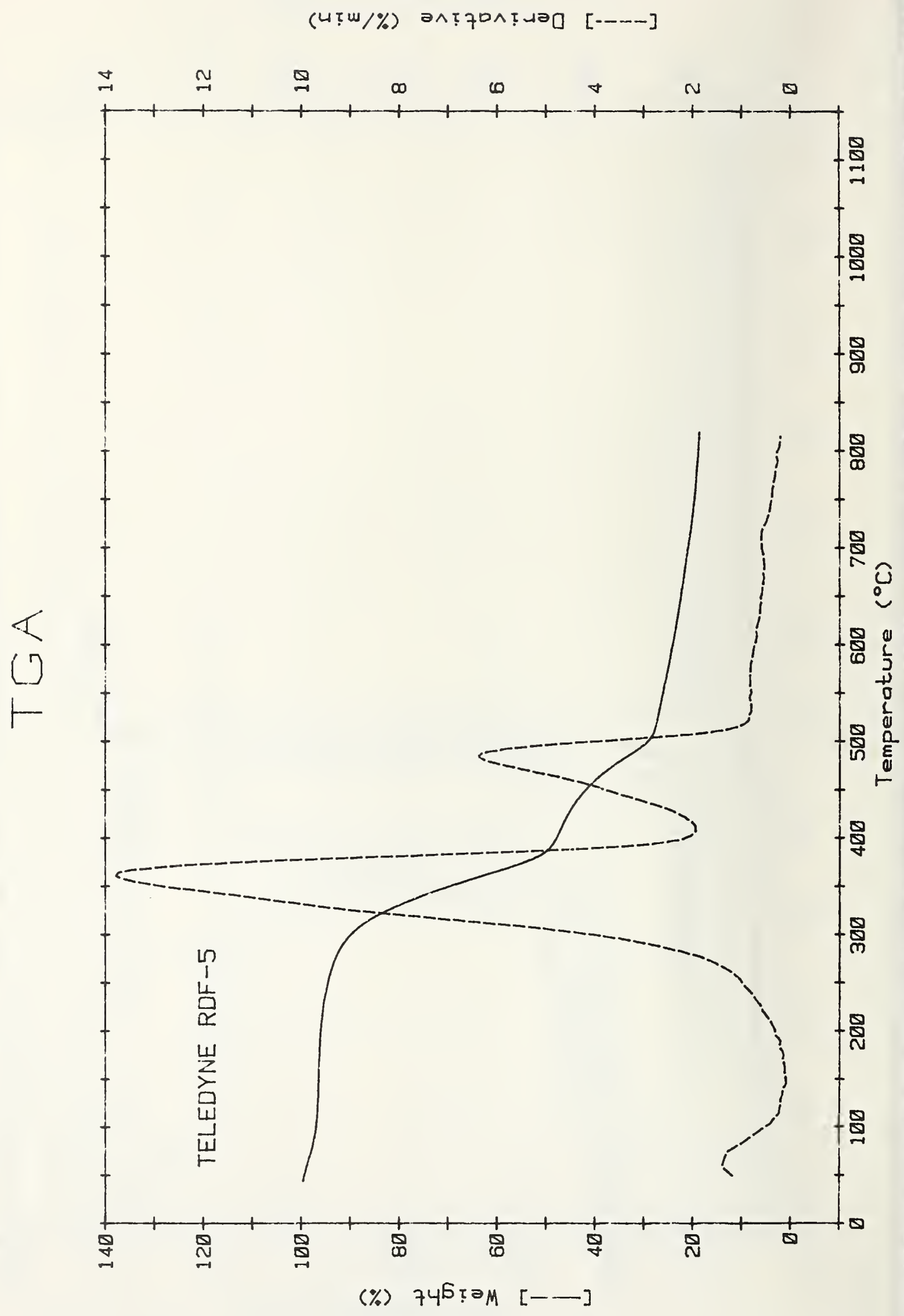

Figure X. TGA Thermogram for Teledyne RDF-5 (Dotted curve - DTGA) 
identified with the reactions of flastic [polyethylene], cellulosic products [mostly from newspaper] and apparently two different types of char. The phenomenological processes are:

$$
\begin{aligned}
& \text { plastics } \\
& \text { products }\left[\mathrm{CO}_{2}\right] \text {, oxidation } \\
& \text { char II, pyrolysis } \\
& \text { cellutosics } \\
& \text { products }\left[\mathrm{CO}_{2}\right] \text {, oxidation } \\
& \text { char I, II, pyrolysis } \\
& \text { char I, II } \\
& \text { products }\left[\mathrm{CO}_{2}\right] \text {, oxidation }
\end{aligned}
$$

Of considerable interest is a comparison of the thermogram for the "pure" substances and the refuse-derived-fuel mixtures. It would appear that under our conditions there is a considerable degree of orthogonality between the processes. With regard to polyethylene it is interesting to note that while smoldering under oxidation occurs in the $220^{\circ} \mathrm{C}$ region, the main weight lose under pyrolysis occurs at a much higher temperature. In contrast, the combustion and main weight loss peaks for cellulosic substances center about $325-350^{\circ} \mathrm{C}$. The interesting consequence is that when one compares the high pressure DSC tracings of refuse-derived-fuel oxidation and the TGA results under pyrolysis, there is a switch in the relative position of the peaks. Under actual boiler conditions

temperature stresses are much more severe and the time scales are vastly compressed. An important question will be the extent to which this general mechanism can be carried over. With the present equipment it is not possible to test for tnis possibility. However, a feasible approach is to extract from combustion devices partially combusted samples and subject them to thermal analysis. We are currently planning experiments in this direction.

An examination of the thermograms for refuse-derived-fuels carried out under similar cciditions demonstrate that there is considerable variation, especially with samples from different sources. Of some consequence are the data in Figure VI. It has been established (3) that for these samoles there are significant variations in heating value and in ash content. We are in the process of correlating these results. Also of interest is the rather characteristic thermogram derived from ECO-Fuel, see Figure VI. Densified refuse derived fuel sample from Teledyne has almost the same thermogram. An interesting question arises as to whether treatment to the RDF-4 and RDF-5 level may in fact change some of the combustion properties. Overall, the present results suggest that thermoanalytical techniques can play an important role in providing for quality control in the processing, handling and use of refuse derived fuels. At the same time, it is clear that important information on the nature of the combustion processes can be derived through careful experimental work. 


\section{REFERENCES}

1. H. Alter, Symposium on Materials from the Chemical Viewpoint, Joint Board-Council Committee on Chemistry and Public Affairs and Division of Industrial and Engineering Chemistry, 173rd National Meeting American Chemical Society, New Orleans, Louisiana, 1977.

2. ASTM E-38.01 - Editorial Draft Standard EDS-19 Standard Definition of Terms Relating to Resource Recovery (in progress).

3. D. R. Kirklin, J. Colbert, P. Decker, S. Abramowitz and E. S. Domalski, Test Procedures for the Determination of the Gross Calorific Value of Refuse and Refuse Derived Fuel by Conventional and Large Bomb Calorimetry, NBSIR 81-2278, National Bureau of Standards, Washington, DC 1981.

4. S. A. Hathaway ani 3. S. Lin, Thermogravimetric Analys is of Solid Refuse Derived Fuels and Coal, U. S. Army Corp. of Engineers Technical Report E-149, Construction Engineering Research Laboratory P. 0. Box 4005, Champaign, Illinois 61820, 1979 .

5. J.E.L. Rogers, A. F. Sarofim, J. B. Howard, G. C. Williams and D. H. Fine, 15th Symposium on Combustion, Combustion Institute, Pittsburg, Pennsylvania, 1974, pg. 1137.

B. Entrained Combustion of RDF Particles

(A. Macek, C. Bulik, S. R. Charagundla)

Phase I. The cold-flow elutriation apparatus (CFEA), designed at NBS, has been assembled and tested. The apparatus is designed to obtained data needed for determination of RDF particle size range which can be studied in suspension in the NBS 6-inch laboratory furnace. It has been found that CFEA is adequate for quantitative determination of settling velocities of particles having a wide range of shapes and densities in the size range of interest (up to about 0.5 inch). It has also been demonstrated that samples of finely ground RDF can be injected into the laboratory furnance by means of the fluidized feeder, developed and used earlier in this project for injecion of pulverized coal. RDF injected into the furnace in this fashion ignites readily at gas temperatures of $1200-1300^{\circ} \mathrm{F}$ without oxygen-enrichment. of the furnace gas.

A fluidized feeder for injection of RDF into the furnace has been constructed based on the experience obtained earlier in this project during the preliminary tests with pulverized coal. The major difference is that while the coal feeder was designed for and used with particles up to about $150 \mu \mathrm{m}$ only, the RDF feeder is designed for particles up to at least $3 \mathrm{~mm}$.

Terminal air-flow velocities for a variety of particles having different sizes and shapes have been determined by the Cold Flow Elutriation Apparatus, constructed recently in this project. Two 
exampies: $200 \mathrm{~cm} / \mathrm{sec}$ for $6 \mathrm{~mm}$ newsprint shreds and $800 \mathrm{~cm} / \mathrm{sec}$ for $1 \mathrm{~mm}$ glass spheres. The apparatus has also been found promising for aerodynamic discrimination of componerits of a given heterogeneous sample, such as shredded RDF.

Phase II. As a result of the survey of industrial test furnaces for a subscale study of RDF combustion, reported earlier, it has been decided that three test units may be applicable to this task: two at Combustion Engineering, Inc., Windsor, Connecticut, and one at Foster wheeler Development Corp., Livingston, New Jersey. Requests for Phase II test plans have been sent to these two industrial concerns. The requests were accompanied by a set of instructions for preparation of test plans (enclosed). The instructions incorporate the NBS conceptual outline of the subscale program.

\section{Plans for FY 1982}

In the Chemical Kinetics Division, we intend to continue thermal analytical studies on RDF and coal samples. The basic thrusts will involve (a) quantitation of the "fingerprint" data that we have obtained in fiscal 1981 (b) development and application of Evolved Gas Analytical techniques. The latter will in time permit studies at much higher heating rates and lead to investigations in a small research type furnace that is under construction. At the same time work on the combustion of large size samples of densified RDF will be carried out by $T$. Kashiwagi in the Center for Fire Research.

In the Thermal Processes Division, studies on RDF and coal samples will be carried out in the two aboratory units constructed during fiscal 1981: tre cold-flow elutricion apparatus and the 6-inch furnace. Two results are expected from the work with the elutriation apparatus: (a) physical separation of RDF samples according to their entrainment characteristics for subsequent laboratory combustion; (b) generation of data allowing estimates of settling velocities of RDF samples for applied (pilot and field) combustion. The furnace will be used to obtain burningtime data for a pulverized bituminous coal, lignites, and RDF samples consisting of sizes entrainable by furnace gases up to about $5 \mathrm{ft} / \mathrm{sec}$.

The plan for industrial (Phase II) studies of RDF combustion is nearly complete and a draft is expected to be submitted to DoE by November 13, 1981. 
Project Title: Chemistry of Hazardous Waste Incineration

Goa7: (1) To develop strategies and techniques for the destruction of hazardous waste by incineration using chemical thermodynamics and chemical kinetics.

(2) To examine the available physical and chemical properties on important hazardous waste components and utilize these data to develop useful predictive schemes for various properties.

Technical Center for Chemical Physics

Areas at Chemical Kinetics Division

NBS:

Personne 1: W. Tsang and W. Schaub

Other U. S. Air Force, Tyndall AFB Florida

Agency Air Force Engineering and Services Center

Support: S. A. Hathaway

Incineration has traditionally been a technological area dominated by physical considerations. Recent events mandating the destruction of hazardous organic wastes by incineration and increasing evidence that such substances may be formed during combustion process have made necessary a more "chemical" approach to these problems. Our work has been concentrated on building a conceptual frame work with regard to the role of chemical kinetics in these problems. Our analysis has identified unimolecular decomposition, as well as $\mathrm{OH}$ radical and $\mathrm{H}$-atom attack as the important processes in hazardous waste destruction. On that basis a scale of incinerability has been devised and chlorinated aromatics identified as among the most difficult compounds to destroy. Thermochemical properties of most of these compounds have been estimated and JANAF type tables prepared. Equilibrium calculations have demonstrated that there are no thermodynamic constraints on their destruction at temperatures in excess of 700K. Several papers have been prepared. We are in the process of developing an experimental program for the verification of our predictions and it would appear that the key questions involve chlorination of aromatics, the stability of such compounds to hydroxide radicals and the important processes involved in aromatization.

Accomplishments in FY 1981

Papers have been prepared on the following topics and are in the editorial review process:

(1) Chemical Processes in the Incineration of Hazardous Wastes by W. Tsang and W. Schaub, Chapter in text on: Detoxification of Hazardous Waste, Ann Arbor Press, Ann Arbor Michigan. (In press)

(2) Procedures for Estimating the Heats of Formation of Aromatic Compounds, Chlorinated Benzenes, Phenols and Dioxins, by W. Schaub; in review for Thermochimica Acta. 
(3) Estimated Thermodynamic Functions for Some Chlorinated Benzenes, Phenols, and Dioxins by W. Schaub; in review for Thermochimica Acta.

Plans for FY 1982

We plan to proceed with work to develop scales of incinerability for the list of 238 hazardous wastes tabulated by the U. S. Environmental Protection Agency. Construction will begin on a small scale laboratory furnace needed to simulate incinerator behavior. Rates of chemical reactions will be studied help implement and verify an incinerability scale for hazardous wastes.

Technical Center for Chemical Physics

Areas at Chemical Thermodynamics Division

NBS

Personnel: E. S. Domalski

Accomplishments in FY 1981

Eugene S. Domalski is a member of the Research Committee on Industrial and Municipal Wastes of the American Society of Mechanical Engineers (ASME) and was part of a special Ad Hoc Committee on Trace Organic Emissions. The Ad Hoc Committee was convened early in FY 1981 from the Research Committee membership for the purpose of bring together in one document the state-of-the-art regarding the chemistry, sampling, identification, quantification, and toxicology of chlorinated dioxins to assist in identifying and prioritizing research needs in this field. This study was contracted to A. D. Little, Inc. and is available from ASME (New York) under the title: Study on State-of-the-Art of Dioxin from Combustion sources.

Plans for FY 1982

Methods will be examined which can be used to predict the thermodynamic propertie: of hazardous materials. An overall predictive reliability of 1 to $2 \mathrm{kcal} \mathrm{mol}^{-1}$ for the enthalpy of combustion (related to the calorific value) and enthalpy of formation will be sought for the estimation methods. Similarly, an overall predictive reliability of 2 to 3 cal deg $^{-1} \mathrm{~mol}^{-1}$ would be sought for estimating heat capacities and entropies. 
Project Title: Research on the Corrosion of Materials Used in Muncipal Waste-to-Energy Incinerator Systems

Goa1: (1) To develop a data base of degradation characteristics of various metals as a function of combustion conditions, temperature, and gas composition leading to a better understanding of the degradation procedures occurring.

(2) To determine the possibility of developing a valid short term degradation test(s) for various metals over a variety of commonly used operating procedures, firing profiles, and fuel mixes.

Technical Center for Materials Science

Areas at Chemical Stability and Corrosion Division

NBS:

Personnel: E. Escalante and J. Fink

Other U. S. Department of Energy

Agency Office of Energy from Municipal Waste, and

Support: D. Walter, B. Greenglass, C. Kouts and L. Lehr

U. S. Air Force, Tyndall AFB, Florida

Air Force Engineering and Services Center

S. A. Hathaway

Accomplishments in FY 1981

The entire corrosion project was restructed. The project became effective on July 1, 1981 and will end on September 30, 1983. A visit to the NASA Langley Research Center Incinerator Facility in Hampton, VA on June 30,1981 established the cooperative relations needed to carry out the work. NBS will conduct the corrosion study on candidate alloys exposed to the fire stream of the NASA Langley Incinerator Facility. The investigation will be conducted according to the tasks listed below:

Tasks

Task 1: Probe Implementation. NBS shall develop a suitable test probe to support the analytical effort carried out in Task 6 below. NBS shall install a test probe in the combustion chamber of the RDF-fired boiler, and provide written instruction at the time of installation on the routine inspection and maintenance of the probes.

Task 2: Combustion Gas Analysis. The NASA Langley Research Center Facility, in cooperation with NBS, shall take samples of the combustion gases in the region of the probe and determine the chemical content of these samples.

Task 3: Thermal Profiles. NBS shall measure the temperature of the probe at several points along its length. 
Task 4: Deposit Analysis. NBS shall analyze deposits accumulated on the probe materials resulting from exposure to the furnace environment with emphasis on deposit-metal interfaces.

Task 5: Fuel Profile. NBS shall be provided with the fuel use profile of the RDF fired boiler. Fuel properties and consumption data presently being accumulated by the NASA Langley Incinerator Facility shall be made available to NBS.

Task 6: Material Characterization. NBS shall characterize test materials before and after long term exposure to the furnace environment and, based on this characterization, recommend appropriate materials for application in RDF-using heating and power plants. The characterization shall include but not be limited to: sample surface evaluation, metallographic examination, identification of the type of degradation involved, physical measurements (including weight loss, wall thickness reduction, pit depth), weld or other fabrication-related phenomena (including frotective coatings or other material protection systems), and other determinations required to evaluate the materials with respect to their tolerance to the furnace environment.

Task 7: Reporting. NBS shall provide a written interim letter report and a final technical report as stipulated below.

Plans for FY 1982 (also includes last quarter of FY 1981)

July 1 - Sept. 30: Complete examination and analys is of Probe I specimens. Remove Probe II from the incinerator envirionment and install Probe III. Obtain the combustion gas analysis data during exposure of Probe II from NASA Langley Research Facility personnel. Similarly, obtain the fuel profile data from the NASA Langley Incinerator Facility operators. Develop a preliminary evaluation of the durability of the various alloys exposed to the incinerator environment. Provide an arnotated bibliography on the degradation characteristics of various metals to obtain an understanding of previous efforts. The bibliography will include information on the known failures of incinerators due to corrosion. Submit an annual report to DoE. Oct. 1-Dec. 31: Perform a preliminary examination of Probe II specimens, and gather data on Probe II during exposure.

1983

Jan. 1 - March 31: Complete examination and analysis of Probe II specimens. Remove Probe III from the incinerator environment, and obtain the gas analysis data taken during exposure of Probe III from NASA Langley Researci Center personnel. Similarly, obtain the fuel profile data taken during exposure of Prove III from the NASA Langley Incinerator Facility operators.

April 1 - June 30: Perform a preliminary examination of Probe III, and begin a more complete evaluation of all data obtained related to the durability of the specimen alloys in the incinerator environment. 
July 1-Sept. 30: Complete analysis of all data including a characterization of the durability of the various alloys exposed to the incinerator environment. Submit a final report to DOE.

Plans for FY 1982

A visit will be made to Wright-Patterson Air Force Base, Ohio to initate a testing schedule for FY 1982 on their coal (RDF) - fired boilers which will to study corrosion on candidate alloy probes. 
Project Title: DoE/NBS Workshop on Environmental Speciation and

Monitoring Needs for Trace MetaT-Containing Substance

from Energy Related Processes

Goal: To convene a workshop on environmental speciation and monitoring and needs for trace metal-containing substances from energy-related processes

Technical Center for Materials Science

Areas at Chemical Stability and Corrosion

NBS:

Personnel: F. E. Brinckman

Other U. S. Department of Energy

Agency. Office of Health and Environmental Research

Support: G. Goldstein

Accomplishments in FY 1981

Increased national reliance on alternate sources for extracting fuels and oils either from fossil deposits or from recycled materials directs attention to the processing and environmental hazards shared by both technologies and their common measurement solutions. These joint concerns are raised because it is already clear that fossil sources, such as oil shale (kerogen) or coal, contain significant accumulations of many toxic elements, including arsenic, mercury, selenium, uranium, and cadmium. Dependence upon recycled mater $i$ ? s as prospective sources for organic feedstocks requires consideration of the anthropogenic incorporation of the same toxic elements during prior use. Underlying both technologies, is a major requirement for reliable trace measurement methods and standards.

Assessing or monitoring environmental hazards or impacts of such processes and their effluents, is inhibited by many unsolved problems: (1) What are the relationships between the source matrix (coal, shale, sludge, sediment) and the potential for release of toxic metal - or metalloid-containing substances during processing, disposal, or recycling? (2) What are the specific molecular forms of the toxic elements and their dosage effect(s) upon specific or diagnostic organisms? (3) What are (will be) the best means for detecting and quantitating these toxicants in the dynamic process environment as a real-time monitoring control?

At the request of the Office of Health and Environmental Research, Department of Energy, NBS organized a specialist workshop to address these timely questions and appraise the routes by which new relevant research could be most effectively performed. Twenty-four experts gave invited papers at the DoE/NBS Workshop o "Environmental Speciation and Monitoring Needs for Trace Metal-Containing Substances from Energy-Related Processes," at NBS, Gaithersburg, 18-20 May, 1981. Some 45 additional invited specialists from industry, Government, and academic participated in a full discussion of the issues cited above. The papers and edited 
discussion are currently in preparation as a Proceedings for publication in the NBS Special Publication series. The Workshop was sponsored by DoE and the NBS Office of Recycled Materials. 
Project Title: Determination of Trace Inorganic Components in Wastes and Recycled Materials

Goal: To develop test methods for the determination of trace metallic components in solid wastes and recycled materials.

Technical Center for Analytical Chemistry

Areas at Inorganic Analytical Research Division

NBS:

Personnel: E. Garner and R. W. Burke

Accomplishments in FY 1981

A. Inductively Coupled Plasma (ICP) Spectrometry

The ICP system being developed in CAC has demonstrated a great utility in the analysis of a wide variety of samples. The present instrument currently has a capability for determining up to 10 elements simultaneously with high sensitivity and wide linear dynamic range. This instrument has been specifically designed to offer complete freedom of spectral line selection while maintaining a high degree of resolution. Most instrument control functions, including background correction and signal integration time, are computer controlled. During the past year, much of the activity was focused on improving the accuracy of this multielement technique. One of the most significant sources of error is the observation that the accuracy of trace element measurements is affected by matrix constituents. The extent of this problem is a function of several instrumental parameters. In order to characterize and correct for matrix effects, the instrument computer has been connected to the NBS computer via the NES network. This data transfer capability represents a significant effort in hardware and software development and should provide the means necessary to improve the accuracy of ICP analyses.

\section{B. Metal Speciation}

Interest in metal speciation measurements is growing rapidly throughout the world. The key analytical question being asked, with increasing frequency, is not how much of a given element is present but rather in what form(s) it is present. Such speciation information is of critical importance to toxicological, nutritional, and biochemical research, to environmental science, and to industrial research. To develop a speciation measurement capability in CAC, the Group has initiated research for developing analytical systems for this purpose. During the past year, a high performance liquid chromatograph (HPLC) has been coupled to an atomic asorption spectrometer (AAS) and has been used for determining the various alkyl lead species in leaded petroleum products. A summary of this work has been submitted for publication in Analytical Chemistry.

A speciation problem of current interest is the determination of chromium (VI) in the presence of chromium (III). Because chromium (VI) is the toxic form, EPA has recently modified its hazardous waste regulations 
to acknowledge this fact. Using the same HPLC-AAS* system employed for lead, we have been able to determine chromium (VI) and total chromium in a variety of liquid samples, including the $\mathrm{pH} 5$ acetic acid extraction system employed in the EPA leach test.

\section{Laser Enhanced Flame Ionization}

Control of storage and dumping of chemical waste cannot be done without some means of monitoring the integrity of the storage site. For this purpose, the ultimate in low concentration analytical techniques is required. With such a capacity, very small leaks in the storage system can be discovered and remedied before a serious contamination occurs. If a clandestine storage area begins to leak into ground and/or estuarine water, it may be best located by using an ultra-trace technique. In fact, such methods prove most useful in general survey testing because rivers can be tested for the presence of chemical leakage hundreds of miles back into its tributaries. Conventional analyses would be hard pressed to overcome the high dilution factor. This need for ultra-trace quantitative analysis of water may benefit from some research on laser atomic spectroscopy that our group has been doing.

A new analytical method called laser enhanced flame ionization holds promise for direct analysis of water $w / 0$ preconcentration at the ten parts per trillion leve $1,1 / 10^{11}$, for a number of the important elements associated with toxic effects. In addition, the method which is explained in the enclosed publication has high selectivity from the presence of elements other than those being analyzed. This minimizes the number of false positives on a screening test. The selectivity is derived from the use of atomic excitation using two photons of different wavelength tuned between successive levels of excitation in the atom.

Plans for FY 1982

FY 1982 research efforts in the Inorganic Analytical Research Division will be directed toward activities in atomic spectrometry research. Studies with the inductively coupled plasma (ICP) will be pursued to identify and to develop schemes for correcting for matrix effects which can seriously affect the accuracy of this promising multielement technique. In the case of DC plasma/echelle spectrometry, research will be directed towards modifying the plasma system to process transient signals, using real-time background correction and synchronous detection. This modification will permit the interfacing of several adjunct preconcentration/separation methods (i.e., hydraulic generation for arsenic and selenium, cold vapor generating of mercury and high performance liquid chromatography for other priority pollutant elements) to enhance the applicability, selectivity, and sensitivity of the DC plasma technique. The transient signal processing will also permit the utilization of microsampling devices to increase the sample throughout this instrument. The third activity is in atomic absorption spectrometry and will support work in two specific areas. One is concerned with the

*HPLC-AAS High Performance Liquid Chromatography - Atomic Absorption Spectroscopy 
selection and systematic evaluation of various compounds which, when added as a matrix modifier, have been shown to greatly alleviate the effects of chemical interferences in the determination of a particular analyte element by graphite furnace - atomic absorption spectrometry. The other area of interest is concerned with the development of a high performance chromatographic separation - atomic absorption procedure for accurately determining chromium VI - chromium (III) speciation in aqueous system such as for example, solid waste leachates. 


\section{Project Title: Analysis of Trace Organic Constituents}

Goal: To develop test methods for the quantitative analysis of trace organic constituents in recycled materials. Although there has not been any direct application to recycled materials or waste streams, the basic research in these areas offers great potential for improved analytical methods in the future.

Technical Center for Analytical Chemistry

Areas at Organic Analytical Research Division

NBS:

Personnel: H. S. Hertz, D. J. Reeder, L. R. Hilpert, and R. G. Christensen

Accomplishments in FY 1981

A. Fluoroimmunoassay for the Detection of Toxic Organics in Water

Immunoassays have been used extensively in the clinical laboratory because they afford rapid, selective and precise methods of analysis for analytes in complex mixtures, such as human serum. These features of immunoassay procedures have attracted our attention and caused us to examine the potential of these assay procedures for utility as rapid screening procedures in the recycled material and environmental analytical areas. Since some prior research had been performed on the preparation of antibodies to 2,4-dinitrophenol, this was chosen as a model system.

Detection of trace amounts of the toxic pollutant 2,4-dinitrophenol (DNP) in water is an analytical problem tht presents many challenges to the analytical chemist. Laboratory investigations have shown that gas chromatography and high-performance liquid chromatography, while suited for analytical determinations of most of the toxic pollutants, are not as efficient in the separation and identification of the nitrophenols. The development of an immunochemical procedure for detection and quantitation of dinitrophenols in water has been the focus of efforts during the past year.

Previous work included optimization of the material (immunogen) to be injected into rabbits for production of suitable antiserum. If DNP is injected alone, no antibodies will be produced. Thus, a suitable "foreign" carrier protein (bovine serum albumin) was labeled with DNP (23 groups per mole of protein) and sent to a commercial supplier who immunized rabbits with this conjugate. When suitable antibody levels were attained, the rabbit antiserum was sent to NBS where we separated and purified the specific antibody-bearing immunoglobulin (IgG) fraction. This IgG was then covalently bound to solid-phase polymeric beads by coupling with a carbodiimide reagent.

The antibody, thus attached to the bead', was able to bind 2,4dinitrophenol. However, in order to use this capability in a quantitative assay, a compound that could act as a tracer needed to be synthesized. In 
order to be suitable in the assay, the tracer required dual functionality, i.e., dinitrophenol reactivity as well as having a physical property that can be measured, such as radioactivity or fluorescence.

The first quantitative competitive assay with which we had success utilized a tracer consisting of a double-labeled rabbit albumin molecule to which both dinitrophenol groups and fluorescein isothiocyanate chromophores were covalently bound. In the competitive assay, the tracer and free dinitrophenol compete for antibody sites on the specific antibody solid-phase beads. Maximuni sensitivity of the assay is determined by the amount of antibody-bound beads added, the quantity of the competing tracer in the mixture, and the time and temperature of assay incubation.

While the first assays were linear over two orders of magnitude at the microgram level, the sensitivity of the assay was not as great as desired. Achieving a sensitive assay capable of detecting part-permillion or part-per-billion level DNP in water required use of a different, more efficient tracer.

Considerable effort has gone into the organic synthesis of a tracer compound that has both a fluorescent moiety and a dinitrophenol structure. Pilot batches of such a tracer were prepared by reacting fluoresceinamine (Isomer I) and 2,4-dinitrobenzene sulfonylchloride in a 1:3 (mol/mol) ratio in dry pyridine at room temperature. The reaction is stopped after 30 minutes with $1 \mathrm{~mol} / \mathrm{L}$ HCl until a slight precipitate appears. Water ( 0.1 volume of reaction mixture) is added to precipitate more of the sulfonamide product. After centrifugation at $5000 \times \mathrm{g}$ for 10 minutes, the precipitate is collected and dissolved in acetone. Several crystalline crops of this compound were examined by thn-layer chromatography (TLC) (using methylene chloride: methanol, 85:15 as the developing solvent), as well as by ultraviolet, fluorescence, infrared, proton magnetic resonance spectrometry, NMR, and mass spectrometry. Although the compound is still not pure, there is good evidence that this synthetic procedure produces sufficient tracer to make it useful in an immunoassay. Work is continuing to improve yield and decrease impurities.

Work has also been focused on the selection and purification of specific antibodies from recently immunized rabbits by means of affinity column purification methods. We have also upgraded the capabilities of the flow-through fluorometer used in the assays and are currently developing more solid-phase reagents. During the remainder of the fiscal year, we will be directing our efforts toward increasing the reproducibility and sensitivity of the immunoassay system.

By combining the specificity of the assay with capabilities of concentrating dinitrophenols with an affinity "accumulator" column, detection of trace amounts of dinitrophenol in water should be achieved. This will be of importance in the monitoring of effluents from waste sites.

Plans for FY 1982

We plan to explore methods for optimizing the immunoassay procedures developed to extend sensitivities to the nanogram $/ \mathrm{mL}$ range. To do so will 
require further production of antiserum in rabbits using the recently produced conjugates (see progress report). Further work is required to synthesize, purify, and characterize the proper tracer molecule and use it in the solid phase assay system now opeating. Further studies with affinity-column purified antibodies will be performed to measure their acidity and cross-reactivity. Development of "accumulator" columns will require binding of the purified antibody (produced from rabbits) to solid phase supports and developing methods for binding, elution, and preservation of activity. Initial application of the improved system to some waste waters is anticipated.

\section{B. Negative Chemical Ionization Mass Spectrometry}

Negative chemical ionization (NCI) mass spectrometry is a sensitive state-of-the-art technique which involves the formation, mass separation, and detection of anions, in the gas phase. It is a technique which should allow greatly increased sensitivity of detection for certain types of environmentally significant molecules. Production of negative molecular ions by electron attachment in the gas phase requires (1) sample compounds which are electronegative or which have electronegative groups

attached, and (2) a large population of thermal electrons*. Compounds with high electron affinities such as halogenated pesticides, polychlorinated biphenyls, dioxins, etc., should yield high sensitivities in the negative ion mode.

A quadrupole mass spectrometer with a chemical ionization source and capability for detecting negative ions has been installed in the Organic Analytical Research Division. In preparation for conducting experiments in this field, a literature search of research papers dealing with negative ionization was conducted.

Initial experiments were performed to indicate which compounds or classes of compounds would yield intense molecular ions in the NCI mode. The first compounds studied were a series of phenols (phenol, o-cresol, pcresol; 2-chlorophenol) and $\mathrm{N}$-heterocycles (acridine and carbazole). Neither the phenols nor the $\bar{N}$-heterocycles gave enhanced sensitivity in the NCI mode over the positive chemical ionization (PCI) or electron impact. However, the phenols produced interesting spectra with methane as the reagent gas. Intense ions apear at $(\mathrm{M}-\mathrm{H})^{-}$and at a mass 12 amu higher than the molecular weight, possibly an $\left(\mathrm{M}+\mathrm{C}_{2} \mathrm{H}_{5}-\mathrm{OH}\right)^{-}$ion. Addition of one halogen atom, as in the 2-chlorophenol, did not significantly improve the sensitivity (the same interesting adduct ions were still observed though).

A mixture of Arochlors 1254 and 1260 was run in both the positive and negative chemical ionization modes using methane as the reagent gas. The Arochlors are mixtures of polychlorinated biphenyl isomers and should give

*Szulejko, J.E., Howe, I., Beynon, J. H., and Schlunegger, U. P. Negative Ion Mass Spectrometry: The Generation of High Concentrations of Low Energy Molecular Negative Ions at High Source Pressures, Org. Mass Spec. $15(5), 263$ (1980). 
greatly enhanced sensitivity in the NCI mode. The sensitivity was observed to be greater in the NCI mode than in the PCI mode. Also, different compounds in the mixture were detected with different relative sensitivities in each mode. In the positive ion mode, the $\mathrm{Cl}_{4}, \mathrm{Cl}_{5}$, and $\mathrm{Cl}_{6}$ polychlorinated biphenyl isumers are the preciominant species detected; in the negative ion mode, isomers with as many as seven chlorines are detected.

Plans for FY 1982

During the next year, work will continue on determining which types of compounds give enhanced sensitivity in the NCI mode. The fragmentation of negative ions is often straightforward, making spectrum interpretation easy. This negative ion information should be complementary to that obtained by conventional electron impact iniation, providing an additional tool for the identification of organic compounds in complex samples. Gas chromatography with selected negative ion detection will be explored for sensitivity and precision in quantitative trace analysis. The use of different reagent gases $\left(A r, N_{2}, N_{2} \mathrm{O}\right)$ to improve the production of molecular anions will also be studied.

\section{Combined Liquid Chromatography/Mass Spectrometry}

Liquid chromatography (LC) can be used for the separation of many nonvolatile and polar molecules that are not amenable to gas chromatography (GC), and can handle many samples in matrices not amenable to gas chromatography, such as water or heavy oil. Therefore, the coupling of a mass spectrometer (MS) to a liquid chromatograph has generated a great deal of interest. If this could be accomplished, many of the advantages of GC/MS could be realized in an LC separation. Numerous publications have appeared and two methods have been used in commercial instrumentation. However, neither of these instruments has been used for quantitative analysis.

We have constructd a unique LC/MS interface that operates by removing most of the excess solvent from the effluent stream as it flows down a heated wire. The residual concentrated solution is drawn into the vacuum of the mass spectrometer and volitilized into the ion source. This interface and some applications of normal-phase chromatography are described in Christersen et a1., Anal. Chem. 53, 171 (1981).

A large fraction of analytical LC is now performed using reversedphase chromatography. Therefore, it is desirable to have an LC/MS interface which will accomodate the aqueous solutions used in that mode. The only part of our system which did not operate well with water was the probe which introduced the concentrated stream into the ion source. The difficulties arose because of the high surface tension and heat of vaporization of water. Actempts to overcome these problems by heating the tip of the probe either by radiation of conduction were not successful. A sonic-powered spraying drvice was therefore developed, using a solenoid coil around the exterior part or the solvent introduction capillary. The capillary being made of nickel, is magnetostrictive, so that an alternating field causes it so vibrate. When tuned to resonance, the vibration is strong enough to atomize water droplets from the surface at 
the end of the probe. Concentrated buffer solutions can be sprayed without clogging the 8-10 um orifice; adenosine, a test compound of low volatility could be dispersed well enough to observe molecular ion peaks.

The first reversed-phase application using an actual analys is from a complex matrix was that of measuring the polar molecule, valproic acid (in serum), by a direct injection of serum onto the column. Preliminary trials suggest that quantitation better than 10 percent (relative standard deviation) can be obtained for 100 ppm valproic acid in serum. If somewhat better precision can be attained, it is an attractive method for certifying trace level constituents in complex Standard Reference Materials.

Although we propose to use labeled valproic acid as an isotope dilution internal standard in the above analysis, the good stability of the spray should allow quantitation by external standard for other compounds such as the aromatic and phenolic compounds mentioned in the paper referred to above, and present in waste waters.

Plans for FY 1982

In the next fiscal year, we plan to extend reversed-phase applications to quantitative analyses in complex waste samples, making use of the sonic-probe introduction method. Improvements and modifications of the instrument will be made only as they appear necessary to accomplish the applications.

The general features of a feedback circuit for controlling the evaporation rate of solvent from the concentrator wire have been decided. This device will be designed, constructed, and tried out if time is available. The envisioned principle of operation is droplet observation as droplets move down the lower, small-diameter, portion of the concentrator wire. The current flowing in the wire would decay at a settable rate, while each obsarved droplet would increment the current by a settable amount.

\section{Chemically Modified Electrode Detectors for Halogenated Hydrocarbons.}

Halogenated hydrocarbons are presently determined by gas chromatography following solvent extraction to separate and concentrate the analytes. An electroanalytical method has been proposed, which may be applied directly to the sample. Elimination of the preseparation/concentration steps is one advantage among several possible advantages offered by Chemically Modified Electrodes (CME).

We are interested in the development of chemically modified electrodes, which will electrocatalytically detect organohalide compounds. These chemically modified electrode sensors could allow the selective and sensitive detection of organohalide compounds in the presence of complex matric interferences.

We are conducting this study by pursuing two routes of investigation. Both of these involve attachment of electrocatalytic polymer films to metal electrode substrates (Au, Pt). 
During FY 1981, we accomplished the following: (1) synthes is of Schiff-base ligands, (2) formation of the nickel Schiff-base complexes, and (3) attachment of a nolyphenyl oxide polymer film to the electrode surface.

Plans for FY 1982

Further work for FY 1982 involves: (1) further film characterization via surface analysis, (2) electrochemical evaluation of these derivatized polymer films, (3) evaluation of the stability associated with these polymer films, and (4) the electrocatalytic efficiency as a function of film thickness and chemical composition.

An added consideration for the ferrocene polymer modified electrode is the construction of a specially designed cell which will allow light radiation to impinge on a modified electrode. 
Project Title: Characterization of Ash from Refuse-Derived-Fuels (RDF)

Goal: To develop test methods for the characterization of RDF and RDF ash using $x$-ray powder diffractometry.

Technical Center for Materials Science

Area at Ceramics, Glass, and Solid State Science Division

NBS:

Personnel: C. R. Robbins

Accomplishments in FY 1981

(1) Three refuse-derived-fuels, four coals and their inorganic residues after heating were characterized by X-ray powder diffractometry in order to identify the crystalline phases present at the various ashing temperatures. Observation of the sequential changes in phase assemblages with increasing temperatues show the dominant chemical reactions taking place in the inorganic fractions of the fuels. Specimens were heated in air at $100^{\circ} \mathrm{C}$ intervals over the temperature range $475^{\circ}-1225{ }^{\circ} \mathrm{C}$. On the order of sixty X-ray patterns were obtained and analyzed. This work is completed. It is part of a collaborative effort with the Chemical Thermodynamics Division (E.S. Domalski). A paper entitled "Ash Content and $X$-ray Analysis of Selected RDF and Coal Samples as a Function of Temperature" (D. R. Kirktin, E. S. Domalski, R. V. Kelly, C. R. Robbins) will be presented at the symposium on Resource Recovery and Environmental Issues of Industrial Solid Wastes in October 1981 in Gatlinburg, TN, and submitted to the journal: Resource Recovery and Conservation for publication.

(2) An abstract entitled "Characterization of Ash Residues from a Refuse Derived Fuel/0il Combustion Study" (with F. Hasselriis) has been accepted for presentation at the ASTM symposium "Alternative Fuels and Future Fuels Specifications, "to be held in Phoenix, Arizona (December, 1981).

(3) Work has been initiated on a suite of samples from a coal-RDF test burn. Fuel, fly ash and bottom ash will be included in the study. The samples are quite well documented with regard to conditions of burn and sample collection.

(4) Some of the work period during FY 81 has been spent on construction and testing of an NBS spray dryer for preparation of samples for quantitative $X$-ray powder analysis. One of the major sources of error in $X$-ray quantitative analysis is crystallite orientation. This is eliminated by converting the samples (which may be a mixture of fine powders) to spheres on the order of 10-30 um or less by grinding the powders in a special grinder, adding an appropriate vehicle, a binder and a dispersant to form a slurry. The slurry is then sprayed into the dryer in atomized or aerosol 
form, and the spherical particles are formed. This equipment has been completed, tested and is now operational.

(5) Some of the work period has also been spent in preparing spray dried pure reference compounds (or mixtures of compounds) for testing four computer programs recently completed for use with this project and another related one. Application of one program to a spray dried synthetic mixture of quartz $\left(\mathrm{SiO}_{2}\right)$, hematite $\left(\mathrm{Fe}_{2} \mathrm{O}_{3}\right)$ and mullite $\left(\mathrm{Al}_{6} \mathrm{Si}_{2} \mathrm{O}_{13}\right)$ was quite successful. Results of this preliminary test are given in the following table.

TEST OF NBS INTERNAL STANDARD METHOD FOR QUANTITATIVE X-RAY ANALYSIS

Compound

Weight Fraction

(Formu? ated)

Weight Fraction

(By $X-$ ray Analysis)

$\begin{array}{ll}\mathrm{Fe}_{2} \mathrm{O}_{3} & 10.00 \% \\ \mathrm{SiO}_{2} & 30.00 \% \\ \mathrm{Al}_{6} \mathrm{Si}_{2} \mathrm{O}_{13} & 40.00 \% \\ \mathrm{Al}_{2} \mathrm{O}_{3} \text { internal } & 20.00 \% \\ \quad \text { standard }) & \end{array}$

$10.07 \%$

$30.24 \%$

$42.38 \%$

The test data were taken with one scan, where normally, three scans would be taken and the results averaged.

\section{Plans for FY 1982}

(1) Ash residues from a laboratory study of the combustion of coal-RDF mixtures, ashed at various temperatures under controlled conditions, will be characterized by $x-r a y$ powder diffractometry, scanning electron microscopy (including energy dispersive analysis) and by light microscopy. Other analytical methods may be employed if desirable.

(2) Work will be completed on the characterization of fuel, fly ash and bottom ash from a coal-RDF plant test burn. Analytical results will be correlated with those from item 1 .

(3) A study of ash variability as a function of fuel type, particle size, and combustion conditions will be initiated during FY 1982.

(4) Additional studies of RDF-fuels, ashed under known laboratory conditions, will be performed as specimens are received. 
Project Title: Fly Ash Utilization in Cement and Concrete Products

Goal: (1) To review the nature of fly ashes and their levels of production and use in various countries.

(2) To estimate the potential achievable level of the use of fly ash in cement and concrete in the USA.

Technical Center for Building Technology

Area Structures and Materials Division

at NBS:

Personnel: J.R. Clifton

The stockpiling and disposal of fly ash is becoming increasingly more objectionable and subject to governmental regulations because of its effect on the environment. Over 60 million tons of fly ash are being generated in 1981. About 300 million tons of fly ash have already been stockpiled. Use of fly ash in cement, concrete and related products can potentially consume large amounts of fly ash. At present less than 7 million tons/year of fly ash are being used in cement and concrete products, whereas 18 million tons/years seems a realistic goal. The purpose of this project is to identify technical obstacles to the increased use of fly ash in cement and concrete products and to develop a research plan to overcome these obstacles.

Accomplishments in FY 1981

In fiscal year 1981, the opportunities for increased use of fly ash in cements and concretes were addressed. An estimate was made of the potentially achievable level of use of fly ash in cement and concrete in the United States. The estimate assumes that 20 percent of the mass of all the portland cement used in the United States could be replaced by the same mass of fly ash; it ignores possible competition from granulated blast-furnace slag as a finely-divided mineral admixture for concrete. It appears that about 16 million tonnes (18 million tons) per year of fly ash could be consumed in cement and concrete, provided there were fly ash sufficient ash of suitable quality and a general understanding of the technical requirements for satisfactory fly ash use. This information was given in the report "Fly Ashes in Cements and Concretes: Technical Needs and Opportunities," NBSIR 81-2239. Included in the report are requirements for fly ashes for use in cements and concretes, and barriers to increased use of fly ashes in cements and concretes. A research plan was developed for facilitating the use of fly ashes in cements and concretes. The main research needs, in order of priority, are a) development of methods for characterizing fly ashes, b) development of methods for determining or predicting the performances of fly ashes in concretes, c) development of standards for fly ashes; and d) development of methods for beneficiating fly ashes.

In another phase of the study, an assessment of the potential use of fly ashes in other building material has been undertaken. These uses 
include the manufacture of lightweight aggregates, lime-fly ash-aggregate highway bases and sub-bases, filler in asphalt, granules for roofing shingles, and brick manufacture.

We have been participating on ASTM Committees dealing with specifications for fly ashes in order to improve the fly ash standards. Dr. Frohnsdorff is the chairman of a task group which has the responsibility for improving the existing standards and developing new standards for fly ashes used in hydraulic cements.

\section{Plans for FY 1982}

In FY 81 the opportunities for increased use of fly ash in cements and concretes were evaluated and barriers to their increased use were identified. In addition, a plan was developed for research needed to facilitate the increased use of fly ash in cements and concrete. A similar approach will be taken in FY 82 in assessing the potential uses of fly ash in other building materials. The potential amounts of fly ash which it appears can be used in producing technically and economically viable building materials will be determined. These materials will include lightweight aggregates, 1 ime-fly ash-aggregate, roofing granules, and brick, as well as innovated materials. Technical obstacles to the increased use of fly ash in these materials will be identified and a research plan for overcoming the obstacles will be developed. The results of the study will be published either as an NBSIR, or in an appropriate non-NBS journal. 
Project Title: Durability of Polymeric Liner Materials Used in Waste Disposal

Goal: To characterize polymeric materials for applications as liners for solid and hazardous wastes

Technical Center for Materials Science

Areas at Polymer Science and Standards Division

NBS:

Personnel: J. C. Phillips and B. M. Fanconi

Accomplishments in FY 1981

A report was prepared on the Transport of Acetic Acid in Polyethylene (by J. C. Phillips). This report describes the mass loss and sorption/desorption of Acetic Acid (HAc) in polyethylene of different densities at various temperatures. Mass loss for a mixture of HAc and $\mathrm{H}_{2} \mathrm{O}$ three concentrations were also done at the highest temperature used.

Experimental data for mass loss were obtained at temperatures of approximately $40^{\circ} \mathrm{C}, 60^{\circ} \mathrm{C}$, and $78^{\circ} \mathrm{C}$ for a low density bottle (LDPE, p .92 $\mathrm{g} / \mathrm{cm}^{3}$ ) and a high density bottle (HDPE, $p \sim .94 \mathrm{~g} / \mathrm{cm}^{3}$ ). At $t=78{ }^{\circ} \mathrm{C}$ a mixture of $\mathrm{HAc} / \mathrm{H}_{2} \mathrm{O}$ consisting of $100 \% \mathrm{HAc}, 75 \% \mathrm{HAc}$, and $25 \% \mathrm{HAc}$ by volume was used as permeant in the LDPE and HDPE bottles. From the mass loss data, the loss rate and diffusivity were determined.

Data for sorption/desorption were obtained at temperatures of approximately $30^{\circ} \mathrm{C}, 50^{\circ} \mathrm{C}$, and $70^{\circ} \mathrm{C}$ at a vapor pressure of $\mathrm{p} 17 \mathrm{~mm} \mathrm{Hg}$. The polyethylene film had a density of $p \sim .906 \mathrm{~g} / \mathrm{cm}^{3}$ and a thickness of $4 \mathrm{mil}$ $\left(10.16 \times 10^{-3} \mathrm{~cm}\right)$. From the sorption and desorption measurements, diffusivity, solubility, and permeability were determined.

\section{Plans for FY 1982}

We plan to continue work in the area of stress crack resistance of common plastic liner materials for applications in hazardous waste containment. A successful polymeric liner must retain its mechanical and barrier properties in the presence of permanent contact with water containing diluted hydrophilic or suspended hydrophobic substances or solid particles. The first two kinds of material may diffuse into the polymer and eventually transform into a soft rubbery material or even disintegrate it by chemical attack. Solid particles may abrade the polymer surface and thus gradualiy degrade the useful properties of the polymer.

Hence, a special study is needed for the selection of the proper polymeric materials to be used as a liner for a given industrial or any other kind of effluent waste. Three types of action have to be considered: (1) diffusion with the ensuing lowering of the glass transition of the swollen polymer; (2) oxidative or any other type of chemical action which may lead to the disintegration or at least softening of the polymier; and (3) mechanical stress or abrasion. The effects are 
not independent. They may be strongly synergistic. As a polymer softens it becomes much less abrasion resistant. The softened or disintegrated naterial as a rule permits a much faster diffusion of penetrants than the unaffected material. 
Project Title: Glass Recovery from Municipal Solid Waste

Goal: To characterize glass (cullet) which is recovered from the municipal solid waste stream so that market development for cullet can be facilitated.

Technical Center for Materials Science

Areas at Ceramics, Glass, and Solid State Science Division

NBS:

Personnel: W. Haller and M. Cellarosi

Glass manufacturers use cullet (broken glass) as a percent of the charge to their furnaces. This long established practiced promotes the melting of raw materials and permits the reduction of furnace temperatures. Benefits of such practice translate into energy savings, extension of furnace linings life, and greater productivity. Most of the recycled cullet so far has been scrap glass from the manufacturing plant itself.

A potential new source of cullet is the glass contained in the municipal solid waste stream (about 12\%). Several large-scale reclamation facilities have been built and others are planned. These facilities will separate the glass fraction from the other components. The glass so reecovered must meet stringent standards for quality and consistency (e.g., color, contamination, etc.). Targets for reclaimed glass specifications and test methods have been set for reuse in container manufacture. Tentative standards applicable to the manufacture of glass wool insulation are currently under review.

NBS is cooperating with ASTM Committee E-38 on Resource Recovery, the glass industry, reclamation facilities, and various resource recovery facilities. These activities so far have generated two standards for recovered glass specifically, for reuse in container manufacturing.

Accomplishments in FY 1981

During FY 1981, our laboratory carried out testing of samples from initial recovery operations. Test methods cover determinations of moisture content, organic contamination, magnetic/non-magnetic contamination, color fraction, particle size, refractory content, and melt evaluations. Results of these tests indicate that the overall quality of recovered glass has improved, however, still falls short of meeting established acceptance standards. Current projections made by companies involved in recovery operations are that the glass will meet the specifications for quality, and also that it will be placed in the marketplace at prices competitive with the raw materials that it replaces.

Plans for FY 1982

A detailed report will be prepared which describes the tests carried out on cullet in FY 1981. 
Project Title: Research in Ferrous Recovery Through ASTM Committee E-38

Goal: (1) To cooperate with ASTM Committee E-38 through the review of technical proposals in resource recovery, provide support and assistance to NBS staff in areas such as standarads writing activities, and promulgate the development of test protocols in resource recovery.

Technical Center for Materials Science

Areas at Fracture and Deformation Division

NBS:

Personnel: J. Early

Accomplishments in FY 1981

Offices held and activity pursued:

(1) Secretary of E38 and Member of Executive Committee

Support was provided to the ORM and those NBS researchers associated with the technical program of ORM on an as-request basis in those aareas involving Committee E38, its various technical subcommittees, and their standards writing activities.

- (2) Secretary of E38 ASTM/EPA Contract Management Board

As a voting member(J. Early) of the ASTM/EPA Contract Management Board, the responsibility was shared for reviewing the technical proposals submitted by the E38 subcommittees and approving those consistent with the contract goals of developing draft standards and specifications for resource recovery, approving the project directors and the project budgets, and reviewing for acceptance the final report for each project. At total of 15 research projects have been approved and funded in the areas of energy recovery from wastes, glass, processing and unit operations, construction materials, ferrous metals, and a Thesaurus of resource recovery terms. During FY 81 , nine voluntary, national consensus standards were adopted by ASTM Based $n$ part on the results of these research efforts. Current funded projects include sampling of refusederived fuels (RDF), round robin testing of ferrous metals, and use of waste glass in brick manufacture.

(3) Vice-Chairman of Subcommittee E38.02, Ferrous Metals

During FY 81, a proposal for a round robin test program was submitted to the E38 ASTM/EPA Management Bcard for funding. The Chairman of E38.02 and Mr. Early, as director and assistant project directors, developed the test matrix for this effort. The raw materials for the standard samples to be distributed among the participating laboratories have been assembled at the Ontario, Canada, Ministry of the Environment Test Facility in Toronto, Canada. At the present, six laboratories will be involved and distribution of the round robin samples is expected in September 1981. 
Mr. Early will continue to serve as a voting member of the ASTM/EPA Contract Management Board. He will also serve as Assistant Project Director for the ferrous rcovery round robin testing effort which was initiated in FY 1981 but will not be completed until FY 1982. In addition, Mr. Early is writing a review of ferrous scrap recycling in the U.S. both municipal and industrial, with respect its history, current status, and future trends. The review will be issued as an NBSIR in FY 1982 . 
Project Title: Hazardous Waste Standard Reference Material Program

Goal: To develop standard reference materials which can used by test laboratories and related facilities to characterize hazardous materials

Location Coordinated through the Office of Recycled Materials at NBS

and

Personnel:

J. G. Berke and E. S. Domalski

by

for the

Center for Analytical Chemistry

Inorganic Analytical Research Division

Ernest L. Garner

and the

Center for Analytical Chemistry

Organic Analytical Research Division Harry L. Hertz

Other U. S. Environmental Protection Agency

Agency Environmental Monitoring Systems Laboratory

Support: Quality Assurance Division

Dr. Eugene P. Meier

Over the past few years a need for basic information on how to test for hazardous materials in the environment has emerged. Regulatory and enforcement agencies at all levels of government agree that technically sound measurement systems must be developed on a national scale to ensure that both the regulators and the regulated are measuring and testing in the same way. The EPA Environmental Monitoring Sysems Laboratory, Las Vegas, is responsible for providing standard reference materials to support their hazardous waste programs. These materials include:

standard solutions of pure chemicals; mixtures of chemicals in solutions; characterized reference materials such as wastes with known concentrations of chemicals; and synthetic mixtures of materials which represent a variety of wastes. Because of the nature of the problems inherent in preparation of these materials for use as references, the EPA joins in an agreement with the National Bureau of Standards for the NBS's experts to provide technical advice and prepare materials. Materials of interest are sludges and sludge-like composites.

Inorganic Analytical Research Division, TASKS for FY 1981

Continue studies on candidate sludges and sludge-like materials in order to ascertain their suitability for issuance as quality assurance standards. Significant outputs of this task are:

A. Complete evaluation of candidate sludges now under study.

B. Obtain profile leachate data for priority inorganics in any additional candidate sludges that can be identified and obtained in sufficient quantity before August 1, 1981. 
C. Investigate methods for improving the sampling reproducibility and stability of the candidate sludges.

D. Conduct concurrent studies on several simulated sludges as a back-up approach to developing a quality assurance sludge material possessing more desirble characteristics for multilaboratory testing than unstable real-world samples.

E. Select the best material and report on its suitability as a quality assurance standard.

F. Depending on the acceptability of the selected material as a qualty assurance standard, package, label, and deliver to EMSL-LV 500 units (100-105 grams/unit) of the standard sludge, characterized for the chemicals of interest by EPA procedures.

Accomplishments in FY 1981

Tasks A, B, D, E, and F was completed in FY 1981. Task $C$ was begun and will continue in FY 1982.

Plans for FY 1982

A. Prepare a final report giving details of the acquisition, packaging, blending, and characterization of the standard sludge.

B. Monitor stability of the standard sludge from at least 1 year following its release to EMSL-LV. This would go beyond FY 1982.

Organic Analytical Research Division Tasks for FY 1981

Inititate studies on a sludge or sludge-like material chosen by NBS and EPA for possible future (FY 1982) issuance as a complex type of quality assurance standard. The outputs of this task include:

A. Perform pilot leaching experiments using the EP procedure to see if sufficient concentrations of organic componds are leached to justify further examination of the material.

B. Collect, blend, sieve, and homogenize $50 \mathrm{~kg}$ of the chosen material.

C. Perform gross homogeneity tests on the blended material using solvent extraction/gas chromatography and total organic carbon analysis.

D. Further establish homogeneity of the material on the basis of an organic solvent extraction of representative aliquots of 
the material with quantitative analysis of 3-5 priority organic compounds.

E. Leach representative samples of the blended material using the EP procedure and perform quantitative analysis on 3-5 priority organic compounds in the leachate (additional compounds will be analyzed quantitatively as feasible).

F. Determine the extraction and analysis variability on the leachates derived from his blended material using the proposed EP procedure and the extractor built at NBS in FY 1979.

G. It Step $F$ is successful, carry out more detailed sample storage, stability, and homogeneity tests on the $50 \mathrm{~kg}$ of the selected sludge.

H. Obtain leachate data for EPA on an expanded series of priority organic pollutants using the proposed EP and the extractor built at NBS in FY 79 .

Completion of all the above tasks is dependent on continuing observation of material stability for organic compounds and upon repeated chromatographic characterization of the gross organic compound content. Result of the "total characterization" of the organic compound content of a chosen sample will be solvent dependent and therefore, quantitative analyses will be dependent upon the extraction procedure specified. 
Project Title: Fossil Fuel Technology Waste Sampling and Characterization Program

Goa 1: NBS proposes to assist the Department of Energy Laramie Energy Technology Center to develop a definitive and authoritative body of data on the physical and chemical proprties of fossil technology residues from the variety of combustion and conversion systems. The data protocols and test methods developed will assist DoE in the environmental management of waste streams from coal combustion and fossil energy conversion processes in a technically sound and economically acceptable manner.

Technical Office of Recycled Materials

Area $\quad$ Resource Recovery Program

NBS:

Personnel: J. G. Berke and E. S. Domalski

other

Agency

Support:

U. S. Department of Energy

Larmie Energy Technology Center

Dr. Larry P. Jackson

This effort has been sub-divided into the following tasks:

Task 1 Statistical Services

National Measurement Laboratory

J. Mandel and R. Paule

Task 2 Organic Analysis

Center for Analytical Chemistry

Organic Analytical Research Division

H. Hertz

Task 3 Physical and Chemical Characterization

Center for Materials Science

Ceramics, Glass, and Solid Science Division

C. R. Robbins

Task 4 Advanced Analytical Techniques

Center for Analytical Chemistry

Gas and Particulate Science Division

H. Rook

Task 5 Quality Assurance Ash Materials

Center for Analytical Chemistry

Inorganic AnaTytical Research Division

R. Burke and B. Diamondstone 
Task 6 Inorganic Analysis

Center for Analytical Chemistry

Inorganic Analytial Research Division

E. Garner, R. W. Burke, and B. Diamondstone

General Approach

1. Representative samples of fuel feedstock, fly ash, bottom ash and boiler slags will be collected. Feedstocks will include coal, blended coals, RDF-coal mixtures and RDF-oil mixtures.

2. Type of $\mathrm{plant}$ equipment and conditions of operation will be documented for each fuel feedstock and resulting ash and slag.

3. Feedstock will be characterized by quantitative elemental and phase analysis.

4. Fly ash specimens will be size fractionated for detailed study. Neutron activation analysis and atomic absorption methods will be used for quantitative elemental analyses for both major and minor elements.

5. Quantitative $x$-ray powder diffractometry methods will be used to identify and determine amounts of crystalline phases present, the ratio of crystals to glassy matrix and the average crystallite size.

6. The scanning electron microscope (SEM) and electron microprobe will be used to establish the locations or hosts of elements observed in (4) (whether in glass or crystalline phases present). Fine crystals on the surface of the particles will be of interest.

7. Coarse fractions w1l be studied by optical microscopy, SEM and $x$-ray microdiffractometry.

8. Bulk quantitative chemical analyses would be obtained for all samples. Surface areas of the various fly ash fractions would be determined.

Accomplishments in FY 1981

Delays encountred in the implementation of the sample collection effort have moved the schedule of work into late FY 1981 and throughout FY 1982.

Plans for FY 1982 -- Activities and Deliverables

9/81 Phase I site visits to five utilities

$11 / 81$ 1. General sampling guidelines 
$11 / 81$ 2. Five sample sets

11/81 Phase II site visits to 10 utilities

1/82 1. Six "Best" quality sample sets (4 ea.)

$1 / 82$ 2. Four sample sets

9/81 Commercial laboratory $Q A / Q C$ evaluation tests

11/81 National Bureau of Standards R \& D Projects

1. Inorganic particle analysis

2. Analysis of organics in leachates

3. Statistical support of FE waste characterization project

$5 / 82$ Detailed report of progress through $4 / 82$

11/81 Two commercial labs conducting routine waste analysis

6/82 Final results from analytical program

3/82 Ten commercial labs doing "precision" waste analysis

4/82 Test results from analytical program

4/82 Phase III site visits (\#TBD - MAX 17)

5/82 Remaining sample sets

5/82 NBS inorganic analysis of "Best" sample set

8/82 Report on "Absolute Value" on waste leachates

6/82 NBS statistical analysis of all analytical data

10/82 Report on precision and accuracy of various lab groups in analyzing LE wastes

8/82 Commercial laboratory QA/QC review

9/82 Report on performance of leach tests and analysis

8/82 Versar Project Summary

9/82 1. Finalized general sampling guidelines

2. Thirty two case study reports

3/82 Overall projects management

10/81 Report on QA/QC performance of Commercial Labs

8/82 Decision on out year level of effort 
3/82 LETC analysis of all sample leachates

7/82 Report on "Single Lab" analysis of leachates

2/82 Establish DoE archive of FE wastes

7/82 Archive inventory list

4/82 DoE (ETC's/NL's) inorganic sample analysis of "Best" sample

6/82 Report on results from "High Quality" laboratories

3/82 LETC management of ASTM D34.02.02

9/82 Decision on out year level of effort

11/81 Phase I DoE study with ETC's and NL's on GC/MS quantification of organics in leachate

$1 / 82$ Decision on overall project goals and level of effort

10/81 Analytical method development

12/81 Report comparing results of sequencial batch extraction vs. columr extraction on reference fly ash

10/81 Sample homogeneity study on waste samples

$1 / 82$ Report

10/81 Generate reference fossil energy leachate for organics

11/81 Standard reference sample

3/82 Impact on leachate quality by co-disposal of report water on spent same

8/82 Report

5/82 Phase II DoE study on GC/MS analysis of leachates applied to oil shale residues

7/82 Decision on integration with ASTM effort

4/82 Comparison of organic material on retorted shale vs. organics in leachates

6/82 Decision on value to LETC 
Project Title: Federal and State Level Procurement of Products Containing Recovered Materials

Goal: This program, in cooperation with seven states--Washington, Colorado, Minnesota, Florida, New York, New Jersey and Michigan will identify the technical barriers to the procurement of products containing recovered materials. The project will examine state statutes and policies regarding such procurements, identify successful or unsuccessful procurement experience, identify potential products and examine purchasing specifications for exclusionary citations, test methods or performance criteria on the use of recovered materials.

Technical Office of Recycled Materials

Area at

NBS:

Personnel: J. Berke and C. Hudson, State representatives in procurement or energy departments for the various states.

Accomplishments in FY 1981

The project was completed July 1981 when reports were submitted by the seven states. The executive summary report has been prepared and provides a summary, conclusions, and recommendations gleaned from a series of studies carried out in seven states on the procurement of products containing recovered or recycled materials. The participating states were Washington, Colorado, Minnesota, Michigan, New York, New Jersey and Florida. In addition to the seven states, the National Association of State Purchasing Officials (NASPO) participated as project observer and has provided a position paper reflecting the study and the future directions of public purchasing related to the procurement of products containing recycled or recovered materials.

The role of the National Bureau of Standards in this specific area of public purchasing originates with the mandates of Sections 5002, 5003 and 6002 of the Resource Conservation and Recovery Act (RCRA) (P. L. 94-580) as amended ( $P$. L. 96-462).

In selecting the participating states the NBS endeavored to select one state in each Federal region. However, several states that were approached could not participate at that time. It was then decided that in addition to the states that could participate in the study to select some states with contiguous boundaries so that the reader of the state reports might compare the experiences of these states with regard to products, manufacturers, and local distributors within the same geographical region. These state pairs were Minnesoa and Michigan, and New York and New Jersey.

The states were first approached through their respective Office of procurement. If the office of Procurement could not directly take a grant or could not carry out the tasks for any reason, they were asked to recommend a group who could undertake the project. These recommendations 
are reflected in the title pages of the individual state reports. The state procurement office in each state did offer full cooperation with the study teams and worked closely with them.

The task activities that NBS asked the states to perform are indicated in the following work statement:

1. Survey and report on state statutes pertaining to the procurement of products containing recovered materials.

2. Report on past, current or future programs and other state activities related to the procurement of products containing recovered materials.

3. Identify and report any legal, institutional, procedural, economic, or technical barriers to the state procurement of products with recovered materials.

4. Identify and report on any successsful or unsuccessiul attempts to procure products with recovered materials. This should include those initiated by state solicitation or offerings by suppliers and manufacturers.

5. Provide a listing of the State's top ten products purchased based on volume and/or dollar value. This should include any cooperative purchases for local governments, special districts or agencies.

6. Provide a listing, based on the best knowledge and experience in the State, of products that are most amenable to the inclusion of recovered materials. If not included in listing of ten products in item (5), then please provide volume and dollar value of such purchases.

7. For the list of products selected for item 6, provide all pertinent specifications, test methods, performance criteria and other information related to the procurement of each product.

The information was compiled from reading the individual state reports and summarizing the results. Highlights of specific state activities are presented following a general summary of each task. For further details regarding any of the participating states, interested parties are advised to read the specific state reports.

The states participating in this study indicate that purchases made by their procurement divisions do, in fact, include many products containing recycled materials. In some instances, the purchasing agent is unaware that the procured product contains recycled material because it is not labelled as to content, or the vendor chooses not to disclose such information for fear that the product may be viewed as inferior. There has been a long-standing bias against purchasing recycled goods and a preference for goods made from virgin materials, even when the quality of the two items is comparable. 
Many states indicate that the lack of standards and specifications for recycled products inhibits state procurement of products containing recycled materials. This information is needed by procurement offices in all states so that propr procurement decisions might be made. The importance of the link between products containing recycled materials and energy conservation is noted by several states. This point should be stressed in an educational program in order that more efficient allocation of resources might be effected.

Plans for FY 1982

1. We have asked the State of Florida to initiate work on a Public Purchasing Directory that will be national in scope. This project will identify on a national level, producers, manufacturers, or distributors of products containing recycled or recovered materials. Florida will prepare a directory based on the companies identified. The directory will include:

a) Table of contents.

b) Inroduction and statement that inclusion does not represent endorsement.

c) Sections for each group of materials used with companies listed by state in alphabetical order within each section. Listing will include company name, address, telephone number, key contact person, recovered or recycled material used, principal product(s) made from the recovered material.

d. Chart of products made from each group of recycled or recovered material.

e. List of agencies and organizations to contact for further information, including state solid waste offices.

f. List of directories on recyclers (these directories will include dealer/processors).

g. Bibliography.

This directory will be of assistance to all state, local, and national purchasing officials in their search for products containing recycled materials. The directory is scheduled for completion December $11,1981$.

2. The State of Colorado is developing a sample purchased product evaluation (bid modifier) for purchasing use, to compare similar functional items with differing values of recyclables material content. The state will:

a. Survey existing literature to determine what portions of the work statement can use existing data. Search the 
files of the Denver Conservation Library and other sources for related information.

b. List the various generic items and identify the specifications for the branded products. Prepare a list of component parts of each branded product showing the weight and kind of material for each component. Put this data in tabular form for use in later phases of the work statement.

c. Determine the average BTU required to manufacture and deliver each of the various products. Use Table 4 from the "Methodology for Estimating Energy Savings for State Conservation Plans."

d. Determine the alternative methods of disposal for each item and the relative BTU values for each method of disposal of each item. Review trash collection and disposal systems of representative Colorado cities seeking to include in the sample, disposal systems that bury trash, as well as those that burn trash. Compare these with reports on systems elsewhere in the U.S. that separate and collect recyclable materials from trash.

e. Determine the recyclable components of each item and the BTU potential for each item through recycling. From the data derived in a, above, and from tables developed by Colorado to evaluate bids for products containing recycled materials, estimate the BTU value of each component of each item if it were recycled.

f. Prepare a table which develops a sum of the BTU gains and losses attributable to each item and represent the result as a price adjustment factor, which will weight similar items in proportion to their recyclable value. Using the BTU values derived, develop a formula to represent the BTU adjustment as a factor against price. Test the factor and the formula on various Purchase Orders, making adjustments as necessary.

g. Prepare a report describing the methodology and

statistical approach used to develop the sample table, and make recommendations as to the potential value of a Complete Table for general use. Supplement the report with a workshop to present the findings and provide the NBS with clarification and insight during those discussions.

This project is scheduled for completion February 1, 1982. 
B. TECHNICAL ADVISORY CENTER 
Asso-iation of State and Territorial Solid

Waste Management officials

In September 1980, the Office of Recycled Materials issuad a grant to the Association of State and Territorial Solid Waste Management Officials (ASTSWMO). This Association is comprised of State officials responsible for the planning and implementation of State resource recovery and hazardous waste management programs unde: the Resource Conservation and Recovery Act of 1976 , as amended. Forty-three States are represented by the organization. This grant has and will assist the Department of Commerce fulfill its responsibilities under Subtitle E, specifically the charge to provide a forum for the exchange of technical and ecoinomic data relating to resource recovery facilities and to provide accurate specifications for recovered materials.

The Association has undertaken four major tasks under this grant:

- Preparation of a report identifying institutional and technical barriers to the recovery and reuse of industrial wastes; for example, waste solvents;

- A study id'ntifying State measurement needs under Subtitle $C$, hazardous waste management; Subtitle D, solid waste management; and, Subtit.e E, resource conservation and recovery;

- Evaluation of economic analysis methodologies to determine whether or not resource conservation and recovery is a feasible option; and,

- Preparation of a report identifying resource conservation and recovery information needs including description of State utilization of information exchange and dissemination programs.

Activities to Date

On Septemiber 30, 1981, the Resource Recovery Committee on behalf of the Association of State ard Territorial Solid Waste Management Officials submitted to the Office of Recycled Materials the report States' Measurement Needs. The report consists of the following sections:

- Part I: Final Report and Executive Summary: State summary charts depicting definitions of hazardous waste, measurement parameters, laboratory needs, and available training programs; Conclusions and Recommendations

Part II: State Profiles (Texas, Louisiana, Oklahoma, Pennsylvania, Mississippi, Virginia): Solid waste, hazardous waste and resource recovery program objectives; State agency organizational make-up; resources and manpower; selected regulations; data from field visits on laboratory capability; other appropriate documentation. 
- Part III: Analytical Operations Procedure Manual Model: A cohesive technical framework and outline of tools necessary to augment States' hazardous waste program based on experience and guidance of State of Louisiana.

In preparing this final report on Task II, the Association's Resource Recovery Committee considered the following questions:

(1) Does the State have adequate laboratory support staff, equipment, and resources or the services of a private contractor to perform RCRA-related measurement activities?

(2) What are State laboratory equipment holdings?

(3) Are the laboratories certified? Do they have a quality assurance program?

(4) Is there adequate laboratory and field protective equipment and clothing?

(5) What types of technical assistance do laboratory and field personnel need and from which entities?

(6) What are the overall priuritized needs in support of implementing the technical requirements under RCRA?

In the first phase, the Association Committee prepared profiles of six States' individual responses to the above cited inquiries. Those States were Oklahoma, Texas, Louisiana, Mississippi, Virginia, and Pennsylvania. In order to meet grant submission deadlines and present a representative cross section of States, the Committee and ASTSWMO staff selected these States. The Committee intends to continue to prepare selected State profiles throughout the remainder of the grant.

Findings, Task II

The Committee concluded that even though State programs vary in stringency of regulatory requirements, State measurement needs are similar in hazardous waste. However, Subtitle D resource recovery measurement needs, while identified, do noi exhibit the same level of priority associated with Subtitle C program. Nevertheless, standard analytical methods, protocols, and procedures specified in State regulations match those methods cited in Federal criteria. Development of standard lab and field methods for sampling and analyses as well as standard reference data is recuired. The lack of availability for such measurement tools is severely impeding national consistency on a State-to-State basis, timely program imilementation, and worker protection and safety. Consequently, a formal operating procedures manual is necessary to assure not only Stateto-State programmatic and enforcement consistency, but also in intra-State field and functional laboratory activities. A standard laboratory certification quality assurance program does not exist and will be helpful in attaining State-to-State consistency. Lastly, training programs and technical assistance for laboratory and field personnel is deficient at State level. 


\section{Information Exchange}

The Association's goal under Task IV is assisting the TAC by providing guidance in the establishment of a forum for the exchange of technical and economic data relating to resource conservation and recovery, particularly resource recovery and recycling facilities. The effort is designed to help TAC avoid duplication of past efforts by DoC and other Federa? agencies, and maximize limited resources available to assist governmental organization and targetted industrial sectors. Findings to date are that available information is redundant, out-dated, and inappropriate to current problems in the field.

According to the Association's preliminary report, data retrieval bases and compliterized information are existent but little used or limited in scope. Since many States are unaware of existing systems, the indications are that the user community needs guidance and assistance in problem clarification, system awareness, and facilitation of selecting the most feasible option for addressing individual State issues and problems. The ASTSWMO report for this task will strive to assess the following:

(1) What are State information/data needs and their availability?

(2) What data/information systems exist that are compatible or could be easily integrated with RCRA-related activities?

(3) Have the States litilized these and other information sources and systems in the past or present, for what type of problems, and the ease of use?

(4) What resources are necessary or available to establish and implement an information network?

(5) What type of information exchange or other options do the States need and how beneficial would such an effort be to RCRA-related activities?

Current1y, ASTSWMO has initiated data gathering aspects of this task and plans to conduct a seminar concerning the necessity and benefits of an information exchange form and the identification of training and education needs associa'ied with this activity.

Economic Analysis

By providing governmiental officials with economic analysis methodologies for considering the feasibility of resource recovery projects, the Office of Recycled Materials will fulfill a charge under Subtitle $E$ to identify geographical location of existing or potential markets for recovered materials, identify economic and technical barriers to use of recovered materials, and encourage the promotion of proven technology. To this end the Association will evaluate such models and methodologies as requested by TAC as well as those of the Association's interest and selection. To date, the Association has selected to study four States active in resource conservation and recovery: Connecticut, 
Florida, Minnesota, and Oregon. In addition, a survey of models appropriate to or utilized in the field has been conducted and preliminary evaluation commenced. 
Edward B. Berman Associates, Inc.

Resource Recovery Planning Model

The Technical Advisory Center explored the feasibility of developing a model design for economic evaluation of regional resource recovery systems on a statewide basis. A study sponsored by TAC concluded that a gross design of a mathematical model to serve the following purposes was possible:

(1) Generation of a preferred regional plan for resource recovery;

(2) Evaluation of a specified plan for resource recovery; and,

(3) Provision for the inclusion of source separation as an option.

The criteria selected for generating a preferred regional plan for resource recovery were:

- Minimize lifetime cost of selected plan; or

- Minimize lifetime discounted cost; or

- Maximize net energy balance; or,

- Optimize a composite of weighted cost and/or energy considerations.

Based on study resuit:, TAC concluded that the model encompassing three primary objectives ani preferred plan selection criteria was feasible. In addition, the model to be developed would include the capacity to report for each regional plan selected or generated:

(1) costs in total and category breakdown, annually and over lifetime of che plan; (2) discounted costs by total and category, annually and over lifetime of the plan; and, (3) energy balance by energy category and net system energy balance. For generared regional plans, the model selection would detail sites selected for processing; the recovery process selected for each site; capacity in tons per year for each site--process selected; as well as, the direction and flow of the materials in the system.

The structure of the model includes a front end, an optimizer with improved algorithm, and a back end. The front end receives all data and data categories and determines costs. In an optimizing mode, the model will utilize the matrix and optimizer. In an evaluation mode, the model bypasses the optimizer and the program proceeds to the back end.

The optimizer is the Walker Fixed-Charge Linear Prograrming Algorithm. This optimizer has the capability of treating costs in terms of slopes and intercepts which are the fixed charges. With this capability the consideration of economies of scale of centralized resource recovery processing facilities is possible and consideration of the tradeoff between economies of scale versus the transportation costs incurred in achieving such scales. 
The back end will receive either the specified regional plan from the front end, or the regional plan generated from the optimizer and report costs and energy implications. This portion will also detail the regional plan. The report will provide all cost categories in both constant and discounted costs and all energy categories.

Categories: Energy and Cost

The model manages a total of ten cost categories including two cost categories for each element in the model. Cost categories can be defined by the user. These cost categories permit the user to report separately those costs imposed on different constituencies involved in or affected by the regional plan.

The model encompasses ten energy categories including two separate energy categories for each element. For example, input--No. 2 oil per ton; output--steam per ton. In considering the maximum net energy balance function, the weights equal to BTU equivalents will automatically be assigned to energy categories. The user can define energy categories.

Options: Source Separation

The model will provide the user with the following source separation options:

- Mixed municipal solid waste (i.e., unconditionally no source separation);

- Unconditional source separation (i.e., capacity is provided for processing only the residue); and,

- Conditional source separation by price with a maximum of five price categories (i.e., capacity is provided for processing the residue plus the full paper tonnages).

In considering conditional source separation, paper only below the specified cut-off price will be diverted to the processing plant. The user must provide percentage splits for all price options offered to the model. Under conditional source separation, capacity is provided in the model for processing all paper since the processing plant must accept the paper whenever offered.

Commodity Categories

The model handles a total of fifteen commodity categories. Each source separation category offered on the model requires a commodity category. The user can also define commodity categories for intermediate recoverable products, final recoverable products, or residues.

The model incorporates twenty transportation categories to be defined by the user. Each category specifies a single commodity to be transported, a distance table for packer or van haul, cost factors, and energy balance. In the optimizing mode, each transportation activity determination will be made on whether packer or van haul is preferred 
based on the chosen objective function (e.g., least cost versus net energy balances).

To date, the model including improved algorithm is in the process of being entered onto the NBS computer facility and undergoing shakedown.

TAC and the firm of Edward B. Berman Associates, Inc., have entered into a cooperative agreement to develop and utilize the model in five case

studies. The Louisiana Resource Recovery and Development Authority and the City of New York have requested technical assistance in their respective resource recovery projects and have agreed to participate in preparation of case studies. The TAC staff has met and will continue to wiork with both governmental entities in development of case studies. TAC staff will cooperate with the Association of State and Territorial Solid Waste Management officials to assist that organization in its evaluation of the model, determination of its applicability to communities seeking a resource recovery option, and awaits the recommendations on facilitating end user manipulation of the model. 
Opportunities for Economic Development and Resource Recovery: Hazardous Waste Management in the Great Lakes Region

Throughout FY 81 the Great Lakes Basin Commission conducted a study to develop methodologies for projecting the economic development effects of hazardous waste management and to assess the potential for resource recovery of materials from selected waste streams. The three industrial and manufacturing activities were selected as case studies: steel manufacturing, electroplating, and paint manufacturing. This study commenced September 1980 and was scheduled for completion by May 1982 . However, the Great Lakes Basin Commission has expired as of September 1981. Since then the Michigan Department of Commerce sought and received from Office of Recycled Materials a new grant initiative to complete this study and to explore implementation options. The Michigan Department of Commerce has retained original project staff; consequently, the study will be completed by 1982. The Michigan Department of Natural Resources will assist as technical advisers to the project.

In the first phase of the study an assessment of the economic effects is being conducted if economically efficient hazardous waste management options are not available to generators. Analysis encompasses the cost of on and off site management options, volume reduction through process change, and resource recovery from hazardous waste streams as well as current recovery practices. A methodology for determining factors affecting the market-ability of recovered products is under development. Projections are being made on current market size, and impact of financial and institutional incentives on potential market size.

Selection of Case Studies

The project staff selected industries for case studies in two steps: 1) determination of criteria for selection; 2) development and uutilization of decision matrix. In general each candidate industry was scored for each criterion on a rank of one through three with one indicating most desirable, three least desirable. For example, a rank of one for the steel industry for the criterion "significance of industry to the region" would indicate a high level of employment or value added in the region. A total of twelve criteria were scored for twenty-five candidate industries.

Criteria can be divided into three general areas: 1) industry background; 2) waste stream characterization; and, 3) those related to impact of the Resource Conservation and Recovery Act of 1976, as amended, in the region. The first criteria group ensure that industries chosen are vital to the region; the second group designate industries with significant waste management problems, and, lastly, the third group address those industries seriously affected by implementation of RCRA in the region.

On basis of this two step approach three selections were made:

1) steel manufacturing; 2) electroplating; and, 3) paint manufacturing. Three other activities were considered but not selected since they are not as signficant to the region's economy: textiles, organic chemicals, and 
wood preserving. Other industries considered but scoring lower than selected industries: leather tanning, pulp and paper, electric utilities, petroleum refining, petroelum re-refining, pharmaceuticals, special machinery manufacturing, electronic components, rubber, plastic, pesticides, batteries, chemical wholesaling, drum reconditioning, agricultural services, gas and service stations, soaps and detergent, and glass.

In summary, steel manufacturing, electoplating, and paint manufacturing were chosen since all are a significant industry in the regional economy; have a strong potential for resource recovery, and have a high liklihood of incurring an adverse impact based on the implementation of RCRA.

\section{Data Acquisition}

Economic analysis of hazardous waste treatment and disposal options has progressed but encountered some difficulty in obtaining economic data from individual firms. Or in some cases, economic data has not been disaggregated. Nevertheless sufficient information has been obtained directly and indirectly to proceed with information gathering tasks.

The technical identification of treatment, disposal and recovery options have been completed.

\section{Methodology}

To date methodology for analyzing economic potential of recycling and resource recovery in the electroplating industry has been developed. A similar analysis for solvent recovery in paint manufacturing industry has been initiated. A preliminary report assessing the economic effect of federal and State policies on relative costs of different treatment, storage, and disposal options have been submitted.

Currently project staff are engaged in the development of a computer program to select an optimal treatment, disposal or recovery option given varying assumptions concerning 1 andfil1 costs, distance to disposal site and other parameters. When the logic for the program has been documented, programming wi 11 begin. 


\section{Discussion}

The RCRA-related program continues to be responsive to the needs of the parties concerned with resource recovery and solid waste management. In keeping with the wishes of the new Administration, the program has increased activities in calendar year 1981 with respect to non-hazardous industrial wastes, e.g., the steel sludge recycling project.

The work on the components of municipal solid waste can be expected to be completed within the next two years. Clearly, emphasis will be placed upon reporting these results; more research involving non-hazardous industrial waste will be undertaken as the municipal solid waste research is completed.

The Technical Advisory Center expects to complete three major projects in the coming fiscal year: The results obtained under the ASTSWMO grant will serve as the foundation for NBS research in cooperation with meeting State measurement needs in the field of resource recovery and recycling. The model being developed cooperatively by NBS and Edward B. Berman Associates, Inc., is expected to become the basis for selection of resource recovery options by State and local governmental entities. Thus, development of this model is responsive to Sections 5003 and 5004 of RCRA. The Great Lakes Basin Commission/State of Michigan survey of potential business responses to hazardous waste rules and regulations is expected to provide insights into incorporating resource recovery, recycling, reuse, and, consequently, waste reduction of discards deemed to be hazardous. Since each ton of hazardous waste which must be disposed costs approximately $\$ 200$, the potential for savings in both dollars and materials is very large.

The RCRA program has completed studies on the procurement of recyclables by State and local government. In addition, the burn-orrecycle issue with respect to fiber was the subject of an extensive study, the results of which are appended to this report. A survey of supply and demand situation for waste fiber within 4 states (Florida, Georgia, South Carolina and North Carolina) was completed. The report of these investigations which were carried out by the Bureau of Industrial Economics of the Department of Commerce is expected to be ready for public dissemination in early December 1981.

Interagency cooperation continues to be excellent despite program reductions in several other Federal agencies. This spirit of cooperation is, of course, expected to continue in the coming year. Furthermore, new cooperative ventures with the Department of Defense are likely to begin. DoD has apparently decided to implement resource recovery at many domestic military bases. Thus, NBS research can be expected to play an important foundation role in order that each base obtain the most appropriate resource recovery/recycling methodology consistent with minimum costs.

The cooperative program on resource recovery research initiated under the United States-Japan Scientific Treaty of May 2, 1980, has been selected by the Japanese as one of the two most important projects in the Non-Energy Group. The Japanese team will visit the United States in December 1981, and a U.S. team, chaired by NBS, will visit Japan in 1982. 
The clientele of the RCRA program includes persons at all levels of government and industry. Program personnel serve a variety of capacities in voluntary standards organizations such as ASTM and ASME, which contribute to the growth of resource recovery, recycling, and reuse of materials origirally destined for waste.

In light of recent cutbacks in other Federal agencies, ORM is the only major research center dealing with direct in-house research concerning resource recovery in the Federal establishment. Thus, the major responsibility for implementing resource recovery research in the United States has devolved upon ORM. ORM accepts this challenge and intends to meet it fully. 
APPENDICES

No.

I PROCUREMENT OF PRODUCTS CONTAINING RECOVERED MATERIAL: A SUMMARY OF ACTIVITIES IN SEVEN STATES

I I SUPPORT OF THE DEPARTMENT OF COMMERCE PROGRAMS UNDER THE RESOURCE CONSERVATION AND RECOVERY ACT

III RECENT FEDERAL ACTIONS WHICH WILL AFFECT PRICES AND DEMANDS FOR DISCARDED FIBERS

IV DETERMINATION OF THE CALORIFIC VALUE OF REFUSE-DERIVED-FUELS BY LARGE-BOMB CALORIMETRY SUMMARY OF THE 1978 FISCAL YEAR RESULTS

$\checkmark$ TEST PROCEDURES FOR THE DETERMINATION OF THE GROSS CALORIFIC VALUE OF REFUSE AND REFUSE-DERIVED-FUEL BY CONVENTIONAL BOMB AND LARGE BOMB CALORIMETRY

VI AN OXYGEN FLOW CALORIMETER FOR DETERMINING THE HEATING VALUE OF KILOGRAM-SIZE SAMPLES OF MUNICIPAL SOLID WASTE

VII A LABORATORY APPROACH TO OBTAIN SUSPENSION COMBUSTION DATA FOR REFUSE-DERIVED FUELS

VIII IPA PROGRESS REPORT NO. 1

IX IPA PROGRESS REPORT NO. 2 
NBSIR 81-2316

\section{Procurement of Products Containing Pecovered Material: A Summary of Activities in Seven States}

Office of Recycled Materials U.S. Department of Commerce National Bureau of Standards

Washington, DC 20234

July 1981

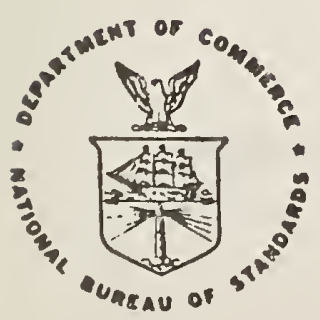

U.S. DEPARTMENT OF COMMERCE

NATIONAL BUAEAU OF STANDAROS 
NBSIR $81-2316$

PROCUREMENT OF PRODUCTS

CONTAINING RECOVERED MATERIAL:

A SUMMARY OF ACTIVITIES IN SEVEN

STATES

Joseph G. Berke and

Catherine $H$. Hudson

Office of Recycled Materials

U.S. Department of Commerce

National Bureau of Standards

Washington, DC 20234

July 1981

U.S. DEPARTMENT OF COMMERCE, Malcolm Baldrige, Secretary NATIONAL BUREAU OF STANDARDS, Ernest Ambler, Director 


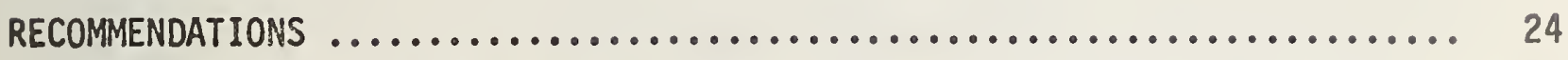

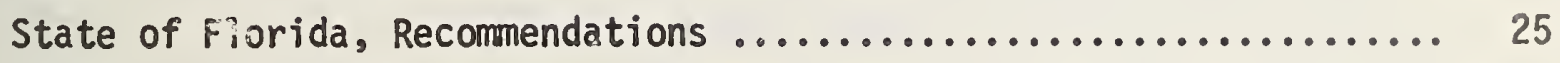

State of Colorado, Recommendations ...................... 30

State of Michigan, Recommendations ...................... 34

State of Minnesota, Summary of Recommendations .............. 36

State of New Jersey, Recommendations by Project Team ........... 38

State of New York, Conclusion and Recommendations .............. 41

State of Washingtion, Recommendations .................... 43

NASPO POSITION PAPER .................................. 46

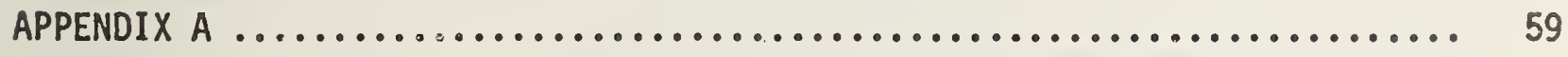

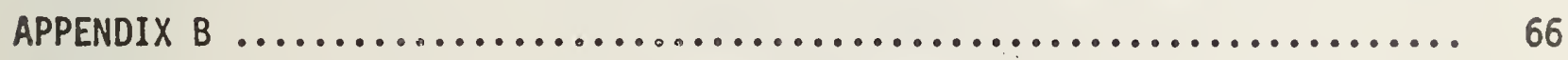

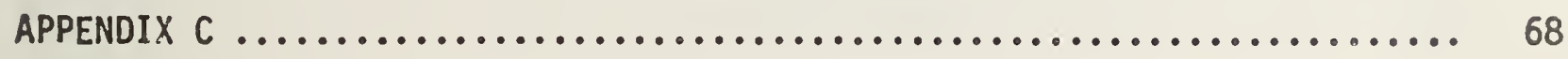

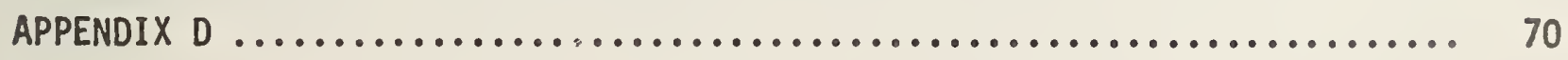


STATE MEASUREMENT NEEDS STUDY

FINAL REPORT

\section{Contributors}

Jacqueline M. Rams

Barbara Simcoe

Mary Gilroy

September 30,1981 
The Association of State and Territorial Solid Waste Management Officials has conducted a study for the Technical Advisory Center (TAC), Office of Recycled Materials, Department of Commerce to determine the State's technical capabilities and measurement needs resulting from implementation of RCRA, Subtitle C, Hazardous Waste Management regulations, Sustit?e D Solid Waste Management regulations, and Subtitle E, Guidelines for Resource Recovery and materials and energy recovery. Measurement needs associated with RCRA will demand standard reference materials, standard reference data, standard protocols and criteria for sampling and analysis and possibly new analytical techniques. This ability to sample and conduct reliable laboratory analyses becomes the enforcement tool of the act's mandate to protect the public health and the environment. It permits establishment of a baseline to which subsequent data can be legally and quantitatively compared and evaluated for potential compliance actions; provides extra time to develop innovative disposal, reuse, and reclamation technigues while acting as an early warning and quality control device for existing facilities and designs; provides the basis for setting acceptable emission levels and shaping design and performance standards for new activities; and it provides a means of acquiring a permit variance. It therefore behooves the States, in this case the regulator, to meet RCRA's measuremerit needs effectively, expeditiously, and consistently.

This report details six States' capabilities in meeting those objectives: Louisiana, Mississippi, Oklahoma, Pennsylvania, Texas and Virginia. With the exception of Virginia, which has entered into a cooperative agreement with the U.S. Environmental Protection Agency (EPA), the remaining five States have received authorization to run their own programs for Phase I program implementation. Laboratory capabilities in meeting the measurement requirements of RCRA vary from no laboratory support and the utilization of contractors (Louisiana) to full-service State laboratory support functions (Oklahoma, Pcnnsylvania, and Texas). The ability, then, for States to comply with RCRA's technical needs consistently on a State-to-State level has not yet been achieved ... ard their capabilities of doing so in the near future varies.

Measurement requirements associated with RCRA pertain to two general areas of waste management activities: identification of a waste to be hazardous or non-hazardous and monitoring expectations associated with permitting of facilities, existing or rew. Determination of the hazardous characteristics for a waste (and hence its definition of being hazardous or non-hazardous) requires analytica? testing for the following: ignitability, corrosivity, reactivity and EP toxicity. Monitoring requirements are associated with baseline analysis, operational analysis, and facility closure and post-closure to assure negligible environment insult and eliminate possible endangerment to the public health. Possible routes of entry into the environment: are via groundwater, surface water, air, soil, and leachate. Analys is of samples from these five dizcharge points will specify the substrate composition, concentration levels, the mobility of potentially threatening hazardous constituents, and hence the level of endangerment that exists for this activity. 


\section{RESULTS}

1) A comparison of State and Federal testing requirements under Subtitle $C$ is sumarized in Chart $A$, and for Subtitle D - Chart B. On the whole, measurement needs cited in Federal and State criteria appear ubiquitous. Even though some States differ in their degree of stringency (Louisiana, Pennsylvania, Oklahoma), States (with the exception of Virginia) have adopted the uniform and minimal requirements as specified in the Federal program. The trend, moreover, in the other states is similar for simplicity's sake in achieving Phase I program authorization. Subtitle D and Resource Recovery measurement requirements, however, do not exhibit the mandatory priorities associated with Subtitle $C$ wastes and are therefore incomplete in such specificities.

2) Standard analytical methods, protocols and procedures specified in State regulations match methods cited in Federal criteria. Subsequent development of standard $7 \mathrm{ab}$ and field methods for sampling and analyses, standard refer ence data by EPA-ORD has been detained and exascerbated by decreased funding levels. The lack of availability for such measurement tools is severely impeding State-to-State consistency, timely program implementation, and worker protection and safety.

3) Few laboratory personnel had an integrated understanding of their role in RCRA programs. Moreover, there is a serious need for a formal operating procedures manual to insure consistency from State-to-State and within State field and laboratory functional areas.

4) Training programs and/or technical assistance for laboratory and field personnel and appropriate safety equipment and clothing are critically deficient at the State level. Funding to meet these needs is either inadequate or not available.

5) A standard laboratory certification quality assurance program for RCRA does not exist. Development of such programs will assist in attaining Stateto-State consistency. 
Recent Federal Actions Which Will Affect Prices and Demands for Discarded Fibers

Sübstance of the Talk Presented October 23, 1980 by Harvey Yakowitz, Chief Office of Recycled Materials National Bureau of Standards 
Goed morning. As a result of recent legislation, national policies with respect to discarded fiber have been considerably altered. The purpose of this talk is to try to outline for you what these policies may mean in terms of both discarded fiber supply and possible influences on "bottom line" profits. Preliminary analysis indicates that the costs of waste news and boxboard may be driven upward by $\$ 10$ to $\$ 20$ per ton (1980 dollars) above current energy value for such fiber. For example, if the cost of energy is $\$ 4.50$ per million British thermal units (MBTU), then the energy value of a ton of "dry" ( $93 \%$ fiber - $7 \%$ moisture) newsprint is about $\$ 44$ per ton. New policies are likely to raise this cost to about $\$ 65$ per ton in many cases via provision of Federal funds. In addition, demand for the fiber is likely to increase strongly in the next several years. Lastly, there is a definite possibility that access to the fiber supply may be curtailed or even denied as waste-to-energy facilities compete for public and private sources of funding.

Key legislation which creates the impetus for these possible changes includes:

- Interior Appropriations for FY 1980 (P.L. 96-126) - Of the $\$ 19$ billion that was appropriated, $\$ 1.5$ billion is targeted for the purchase or production of alternative fuels by way of purchase commitments or price guarantees. Another $\$ 708$ million will support preliminary alternative fuels commercialization activities, including $\$ 100$ million for project development feasibility studies, $\$ 100$ million for cooperative agreements, and up to $\$ 500$ million for loan guarantees for the construction of alternative fuels production facilities. 
Crude 0 il Windfall Profit Tax (P.L. 96-223) - Industrial

Development Bonds are authorized for financing facilities primarily used to convert solid waste into alcohol and for equipment at facilities used primarily to convert fuel derived from solid waste into steam. Interest on obligations used to finance a facility may also be tax exempt under specific circumstances. P.L. 96-223 extended the biomass fuels tax credit from 1982 to 1985 as well.

In my opinion, the most important piece of legislation in this regard is the Energy Security Act (P.L. 96-294) which was signed into law on June 30, 1980.

The Energy Security Act requires the U. S. Department of Energy (DoE) to create an Office of Energy from Municipal Waste (EMW) within the Department. EMW was placed by the Secretary of Energy under the Assistant Secretary for Conservation and Solar. In addition, as required by P. L. 96-294, DoE produced a comprehensive plan dealing with:

(1) the anticipated research, development, ciemonstration, and commercialization objectives to be achieved;

(2) the management structure and approach to be adopted to carry out such plan;

(3) the program strategies, including detailed milestone goals to be achieved:

(4) the specific funding requirements for individual program elenents 
and activities, including the total estimated construction costs of proposed projects; and

(5) the estimated relative financial contributions of the Federal Government and non-Federal participants in the program.

This plan was transmitted to the Corgress and the President in late October 1980. This document will be referred to in this presentation as "the Plan".

The Plan sets forth goals for accelerating the commercialization of waste-to-energy facilities. In accordance with the provisions of the Energy Security Act, Federal financial incentives including construction loans, loan guarantees for construction, price support loans, price guarantees, demonstration projects and research and development are dealt with as the means to achieve the following general goals which are reproduced verbatiin from the Plan:

A. Achieve an estimated production or conservation of

- 100,000-200,000 barreis of oil equivalent per day (BOEPD) to 40 percent of the 1987 synfuel goal) by 1987. This goal can be met by encouraging viable existing systems to meet their planned capacity and by the construction and operation of 54,000 tons per day (TPD) to 130,000 TPD additional capacity plus by encouraging the recycling of an additional 40,000 TPD of materials. The additional capacity can be met by the construction of $40-95 \%$ of the projects now in planning. 
Additional production will be encouraged through DoE outreach activities.

○

250,000-280,000 BOEPD (12 to 14 percent of the 1992 synfuel goal) by 1992. This gcal can be met by having new system capacity expanded by 160,000-180,000 TPD and materials recovery expanded to another 70,000 TPD. It should be noted that municipal waste will provide an early impetus to achieving the nation's synfuel goals but larger resources of coal, oil shale and other nonrenewables which take longer to develop, will assume a larger portion of the goal in the future.

B. Integrate energy recovery systems and materials recovery systems. The removal of inorganics for recycling and energy conversion will enhance the operations and efficiency of most energy production facilities. The recycling of certain source separated organics such as used and overrun newsprint and cardboard boxes can displace significant quantities of energy.

C. Develop more energy efficient waste water treatment processes for integration into the EPA clean water program and for retrofit in existing facilities, where it is economically feasible.

In order to achieve these goals, DoE formally created EMW on September 11, 1980. The mission statement and organizational chart are shown as Figure (1), also taken from the Plan. 


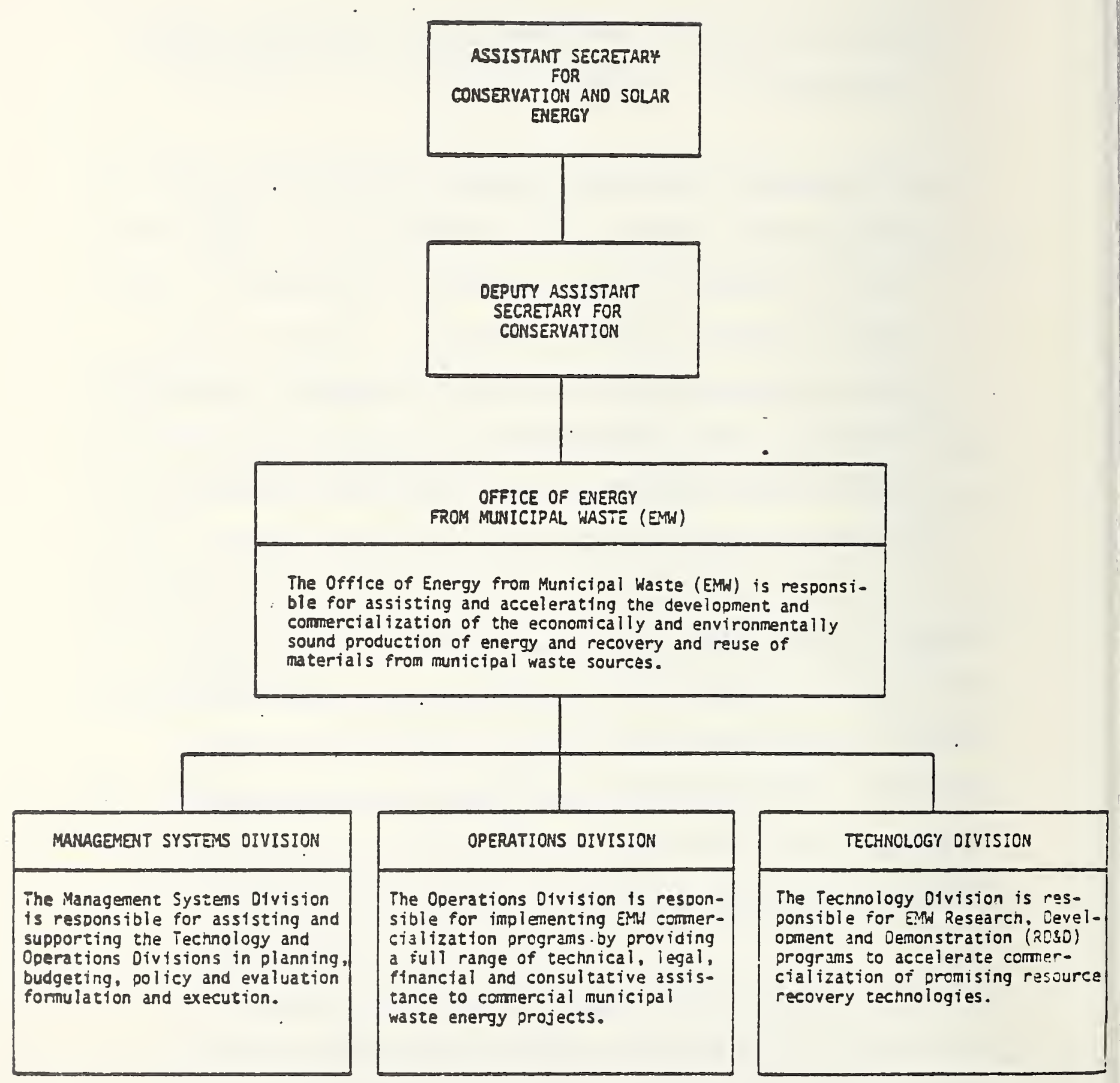


In order to achieve the goals set forth for 1987, i.e., 100,000 to 200,000 barrels of oil per day equivalent (BPDE), total investments of $\$ 5$ to $\$ 10$ billion (new capital) will be required. My best estimate is about $\$ 8$ billion plus an additional $\$ 1.5$ billion per year for operation and maintenance costs. To attain the 1992 goal would require additional capital investment of between $\$ 6$ and $\$ 11$ billion in the period 1987 - 1992. In other terms, the goal is to increase U.S. energy-from-waste capacity which currently utilizes about 9000 tons per day of municipal solid waste to about 160,000 tons per day by 1987 and to about 325,000 tons per day by 1992. Thus, a seventeen fold increase is sought by 1987 and 36 fold increase by 1992. Achievement of the 1992 goal would mean that over $75 \%$ of the available waste be converted to energy, and that about 200-250 new energy-from-waste facilities would be commissioned in the next 12 years.

The Office of Energy from Municipal Waste has chosen five methods to achieve these goals:

- Provide Financial Incentives for Accelerated Project Development;

- Maximize the Productivity of Existing Waste-to-Energy Plant Development;

- Reduce the Difficulties of Financing Pre-Construction Project Implementation Activities;

- Demonstrate Technologies with High Commercial Potential;

- Focus Research and Development Activities on Constraints to Improvement in Waste-to-Energy Technology and Project Success.

In order to begin the program, some $\$ 230.9$ million has been allocated to EMW For the 1981 fiscal year. Of these funds, EMW proposes to spend 
$\$ 10.9$ million on research and development for accelerating commercialization, $\$ 20$ million on demonstration of technologies deemed nearly ready for commercialization, $\$ 15$ million for cooperative agreements meant to accelerate commercialization, $\$ 25$ million for loan guarantees and $\$ 160$ million for price support loans.

The basic thinking of EMW is stated in the Plan:

"The primary strategy of EMW is to provide financial incentives sufficient to significantly accelerate the number of new project starts in the energyfrom-waste field. Delays in new starts are primarily caused by project costs which are not competitive with alternative methods of waste disposal. This obstacle can be overcome by providing additional revenue during the early years of project operation. This additional revenue would enable a project with attractive life-cycle economics to compete more favorably with disposal alternatives and appear more attractive to local decision makers and private investors.

The price support loan is best suited for solving the problem of early year cost disparities. Therefore, EMW proposes to rely primarily upon the price support loan authority for encouraging the more rapid commerialization of waste-to-energy projects. The Toan payback provision and other features of this mechanism accomplish a significant support mission with a minimum federal outlay and exposure. The program is expected to trigger substantial immediate investment of private capital for project financing.

The price support loan program available to both public and private bodies is expected to be a major factor in helping to remove political and economic impediments in early years of a project by utilizing the positive life-cycle 
economics to reduce early-year disposal fees. In doing so, it will improve the position of economically sound projects against competing waste disposal alternatives."

Note that price support loans prouide for a 5 year (existing facilities) or 7 year (new facilities) perisd in which the Federal government provides, in year one, about $\$ 2$ per million BTU delivered by a waste-to-energy facility; the amount of such a loan is desroased linearly for the period of the loan. No payback is required until year eight, and the Secretary of Energy may waive payback.

With respect to conditions for Federal financial assistance of any kind, the Energy Security Act contains what might be construed as conflicting recuirements. Section 235 of P.L. 96-294 states that no financial assistance can be provided unless the Secretary of Energy finds that necessary municipal waste feedstocks are available and it is reasonable to expect they will continue to be available for the economic life of the project. But Section 235 of P. L. 96-294 also states that the Secretary of Energy shall not provide financial assistance unless:

"... assurances are provided that the project will not use, in any substantial quantities, waste paper which would otherwise be recycled for a use other than as a fuel and will not substantially compete with facilities in existence on the date of the financial assistance which are engaged in the separation or recovery of reuseable materials from municipal waste."

And now the potential difficulties for the fiber recycling industry become apparent: 
- Major efforts will be made-utilizing Federal funds as a portion of the necessary funding - to rapidly accelerate commercialization of waste-to-energy facilities:

- The price of waste fiber will rapidly rise by factors of two to three above present market values;

- Demand for waste fiber will increase rapidly;

- Access to fiber markets may be curtailed or even denied;

- Markets currently served by the recycling of approximately 18 million tons of fiber annually will need to be served in large part by other sources of fiber.

The most important factor is market access. Many potential sponsors of energy-from-waste facilities may wish to obtain as much fiber as possible to convert to energy in order to increase income. Hence, local flow control ordnances may be enacted. Several such ordnances already are on the statute books; in general, such ordnances layclaim to the entire municipal waste stream for usage by the local governmental entity for whatever purposes it deems best in the interest of jocal health, safety etc. The net effect may be to divert fiber supplies to burning and to lock waste paper collectors out of the local market. Indeed, in at least one case, Akron, Ohis the right of a municipality to take control of the municipal waste stream has been upheld in Court. 
Therefore, concern exists that access to the waste fiber supply may be curtailed. Burning of such fiber may not be the most energy efficient use of the fiber in any case; conflicting claims exist with respect to this point. The Department of Energy in formulating policies regarding eligibility for Federal financial assistance for energy-from-waste facilities has not directly dealt with the issue of market access.

Apparently, eligibility for Federal financial assistance will depend only upon the technical and financial soundness of the proposed or existing wasteto-energy faciiity. Assuming that municipal solid waste can be burned to raise energy, the question of financial soundness remains, i.e., will the facility be able to survive economically with Federal assistance? Such a question invites one to place oneself into the role of "Head Official" of the waste-to-energy facility and examine the options available.

First, as any prudent business official will do, a "break even" chart will be prepared. This chart will list supplies of waste available, energy available from burning this material, probable operation and maintenance costs, insurance, working capital to construct the facility and interest on its financial obligations. Hence, there will annually be fixed costs, e.g., principal and interest, and variable costs, e.g., operation and maintenance. There will be anticipated income from energy sales, tipping fees for depositing waste at the facility, and perhaps sales of materials such as ferrous metals. The object is to determine where income matches or exceeds fixed plus variable costs as a function of the waste fed to the facility. Or, in simpler terms, what is the cost per ton needed to break even and how many tons of incinerables are required. 
The results of such an analysis are easily expressed in terms of a simple equation:

(1) $Q_{T}=\frac{C_{p}{ }^{I} F}{T_{y}}+M_{T}$

where:

$C_{p}$ is the capital cost of the project in current dollars

$I_{F}$ is the interest factor to repay the capital cost on an annual basis.

$T_{y}$ is the number of tons per year of waste burned.

$M_{t}$ is the cost of operations, maintenance and other annual items expressed

in dollars per input ton, and

$Q_{t}$ is the number of dollars required per input ton of waste in order to break even.

Consider now the potential average income from burning a ton of mixed municipal waste. If the trash contains 4500 BTU per pound or 9 MBTU per ton and if the conversion efficiency is $67 \%$, which is actually fairly high for burning of such waste, then 6 MBTU per ton are recoverable for use as energy. If the price of energy is $\$ 4.50$ per MBTU, then a sales income of $\$ 26$ is available per input ton of waste. In addition, tipping fees which are roughly competitive with local landfill costs can be added. In certain areas of the United States, notably the northeast, tip fees of $\$ 15$ to $\$ 20$ per ton are possible. In other areas, tip fees of $\$ 5$ to $\$ 10$ are possible.

For illustrative purposes, let the total income our hypothetical "Head Official" can reasonably expect be $\$ 36$ per input ton of mixed waste, i.e., $\$ 26$ in energy sales and a $\$ 10$ per ton tip fee. Presumably, the 
Head Official will know how much waste must be disposed. Roughly, If waste is being received from a population of 500,000 persons, 750 tons per day will be available. Hence, a capacity of 1000 tons per day is prudent to allow for peak loads and some expansion. Note that the municipal waste stream does not appear to have grown significantly in the past several years.

Most waste-to-energy conversion systems cost $\$ 50,000$ to $\$ 70,000$ per ton of waste to be treated daily. Assume our Head Official expects to spend $\$ 60,000$ per ton per day in capital or a total of $\$ 60$ million for the facility whose "shoehorn" capacity is 365,000 tons per year. If financing for 20 years at $10 \%$ can be arranged, an annual payback of principal and interest of $\$ 7.05$ million is required to deal with the current 750 tons per day (about 275,000 tons per year) of waste which can be expected to be treated at the facility.

A rough estimate for labor costs, operation and maintenance is $\$ 12$ to $\$ 18$ per input ton. Assume our Head Official expects costs of $\$ 15$ per ton. Solution of Equation (1) indicates that the breakeven value per input ton of waste to deal with 275,000 tons per year is about $\$ 41$ per ton. Thus, our Head Official is looking at a shortfall of $\$ 5$ per ton or nearly $\$ 1.4$ million per year.

In any case, only a few options are available to the Head Official:

(1) Get more waste.

(2) Increase conversion efficiency of the process.

(3) Utilize components having higher energy content to burn.

(4) Raise the tipping fee. 
(5) Raise the energy price.

(6) Obtain funds from outside sources, e.g., the Federal government.

Note that reduction of capital costs and/or variable costs is a difficult option to exercise. Reducing the capacity of the facility is perhaps not prudent when a total growth margin of $25 \%$ is allowed. Insurance and labor costs are also not likely to be easily controlled either.

Raising tipping fees or energy prices may cost the facility public support and/or customers for the energy to be produced. Obviously, without longterm customers for the energy produced, the facility is not feasible. Increasing conversion efficiency is not really an option for the customer; research is needed in this area. Hence, the Head official really is looking at increasing the output of saleable energy and/or obtaining outside sources of funds.

In our example, the Head Official needs to increase output by about 1.1 MBTU per input ton or approximately 18\%. Either that, or someone needs to provide $\$ 1.4$ million every year (1980 dollars) for twenty years to make the facility economically viable.

Our Head Official, as a result of the policies espoused in the Energy Security Act and their proposed implementation in the Plan, can solve his problems in ways which may allow him to reduce tipping fees and perhaps the energy price as well so as to attract customers. 
Recall that price support loans will be the major Federal incentive available to the Head Official. In the first year of operation--assuming the facility operates precisely as heped--a price support loan of up to $\$ 12$ per ton of waste burned is available, i.e., $\$ 2$ per MBTU by 6 MBTU per ton. But, Federal funds cannot allow the proprietor of a waste-to-energy facility to obtain a positive cash flow. If I were Head Official, I would want to capture the entire $\$ 12$ per ton. Hence, I need only obtain $\$ 29$ per ton in sales plus tipping fees. Furthermore, if the output of the facility can be increased, I can further control energy and tipping fees using still more Federal dollars to leverage the system.

Therefore, in fairly general terms, I conclude that any intelligent "Head Official" will move to arrange matters to obtain the highest possible output of energy per input ton of incinerable so as to maximize the possibility for increased Federal funds based upon delivered energy. For cases of existing facilities with underutilized capacity, the impulsive force to do so will probably be irresistible.

Accordingly, if I were "Head Official," I would take the following actions:

(1) Obtain as much source separated fiber--both boxboard and newsprint--as possible via municipal collection from citizens onto trash collection trucks with appropriate racks.

(2) Store this materiai under roof at the waste-to-energy plant for maximum economic leverage, i.e., sale to the paper industry at prices equivalent or higher than available from burning.

(3) Move to minimize my collection costs to obtain the fiber, e.g., flow control laws to reduce deriand competition. 
(4) Obtain waste tires, shred them at the facility, and store the chips to burn. Brokering of tires to the recapping industry might also occur.

(5) Obtain other possible high heating value combustibles such as wood chips or waste oil to charge to the incinerator.

(6) Apply for price support loans or other Federal aid based on total energy expected per year after implementing the five foregoing items insofar as possible.

Consider only the economics as applied to fiber. One ton of "dry" newsprint should yield about 10 MBTU as recoverable energy. The energy price in our example is $\$ 45$ per ton. The price support loan adds a potential $\$ 20$ per ton for a total of $\$ 65$ per ton value to the burn facility. Thus, the proprietor of the burn facility may be willing to sell newsprint at some price above $\$ 65$ per ton. Boxboard would be affected similarly except that the price would probably be in the neighborhood of $\$ 50$ per ton since the energy value is lower.

Such a scenario meets the requirement that the fiber be available for recycling. Existing fiber collectors would not be affected directly, but prices will rise.

As proprietor of the burn facility, I can expect to obtain about 50 tons per day of separated fiber. I would expect a daily increase in output of my plant of about 175 MBTU over that which would have been produced from 750 daily tons of mixed waste or an increase of about 12 percent. Rubber and other combustibles will increase this figure. 
Next, I will reduce tipping fees and/or energy prices so as to capture as much federal funding as possible. I will now have a viable facility and be in fairly strong control of the waste fiber in my area. In any event, waste fiber prices will probably treble and market access be curtailed. Furthermore, the proprietor may wel1 purchase a foreign-made incinerator system.

As a further spur toward implementing waste-to-energy systems, the Department of Housing and Urban Development (HUD) and the Department of Energy recently formed a technical assistance team headed by Oak Ridge National Laboratory, and assisted by the Conference of Mayors, to work with six cities in their attempt to link resource recovery systems with economic development objectives. Specifically, the team will offer whatever assistance desirable in the preparation of Urban Development Action Grant applications to HUD regarding urban waste-to-energy systems and the necessary additional information those applications require. In addition, the use of DOE's price loan guarantees for these projects will be explored.

The purpose in forming this team is to help cities demonstrate that with a relatively small amount of public funds, projects that previously experienced financing shortfalls will be able to proceed expeditiously. HUD and DOE's intent, however, is not to subsidize waste-to-energy projects, but to assist those projects that offer the opportunity to spur economic development in ways that are consistent with the purposes of the Action Grant program and urban revitalization in general. 
The Technical Assistance Team will meet with City representatives to determine what assistance would be most desirable and useful. The team may:

- Assist in identifying financing options;

- Assist in assembling project information as it relates to the requirements of UDAG;

- Help to define and measure the urban economic development impact of the project;

- Assess the impact of technical considerations of financing options by determining if all technical, legal, and marketing commitments are in order for the project to obtain the best financing possible; and

- Help to facilitate the transmission of project information to HUD/DOE officials.

- Technical assistance to a select group of cities could expedite their ability to use HUD funds for these projects and increase the quality of projects submitted for HUD's consideration.

In summary then, Federal policies are in place which are meant to increase waste-to-energy facility capacity by a factor of 36 in the next dozen years. Federal assistance is to be provided to accelerate commercialization of such facilities; financial incentives are directly available from DOE and perhaps from HUD as well. I believe that if the goals of these policies are met, the price of waste fiber will treble and that access to supplies may well be curtailed.

Implementation of these policies is currently underway and proposals for obtaining Federal assistance are currently being received by the Federal establishments. Awards are expected in early 1981. 


\section{Appendix}

Estimating Financial Requirements for a Waste-to-Energy Facility

As shown by Equation (1):

(1) $Q_{T}=\frac{C_{P} I_{F}}{T_{Y}}+M_{T} \quad$ where

$C_{p}$ is the capital cost of the project in current dollars

$I_{F}$ is the interest factor to repay the capital cost on an annual basis.

$T_{Y}$ is the number of tons per year of waste burned.

$M_{T}$ is the cost of operations, maintenance and other annual items expressed in dollars per input ton, and

$Q_{T}$ is the number of dollars required per input ton of waste in order to break even.

Rearranging to solve for the capital cost which can be borne for a given number of dollars income per input ton of waste.

(2) $c_{P}=\frac{\left(Q_{T}-M_{T}\right)}{I_{F}} T_{Y}$

Note that

(3) $Q_{T}=S_{T}+F_{T}+X_{T} \quad$ where

$\mathrm{S}_{\mathrm{T}}$ is sales income per input ton of waste to the facility. Note that customers are assumed to be under contract to assure these sales.

$\mathrm{F}_{\mathrm{T}}$ is the tipping fee per input ton of waste. Note that only "guaranteed" 
waste, i.e., under contract can be taken into account.

$X_{T}$ is any other source of income, e.g., Federal or other assistance, per input ton.

Now if we let $D_{\gamma}$ be the number of days per year the facility is operational, Equation (2) becomes

(4) $c_{P}=\frac{\left(n_{T}-M_{T}\right)}{I_{F}} \frac{T_{Y}}{D_{Y}}$

Note that $\left(T_{Y} / D_{Y}\right)$ is merely the number of tons per day of waste actually charged to the facility - not the rated capacity - taken over the number of days of actual operation. For example, if 1000 tons per day is charged six days per week, then $T_{Y}$ becomes

(4a) $T_{Y}=(6)(52)(1000)=312,000 \mathrm{TPY}$

while $T_{\gamma} / D_{y}$ is, of course, 1000 TPD

Rated capacity is nearly a meaningless term; the key to determining the probable costs of a waste-to-energy facility is the total number of tons of waste processed per day times the number of days per year the plant actually operates.

Interest factors depend upon the term of the loan and the rated interest. For a publically financed waste-to-energy plant, interest factors as a 
function of rated interest may be computed from

(6) $I_{F}=i \frac{(1+i)^{n}}{(1+i)^{n}-1} \quad$ where

$\boldsymbol{i}$ is the interest rate and $\mathrm{n}$ is number of years needed to pay back principal plus interest.

For $n$ of 15 and 20 years respectively, equation (6) may be approximated fäirly closely as

(6A) $I_{F}=0.80 i+0.052$

$n=15$ and $i$ ranging from 0.05 to 0.20 .

(6b) $I_{F}=0.85 i+0.034$

$n=20$ and $i$ ranging from 0.05 to 0.20 .

Analys is of Equation (6) indicates that if the interest rate increases by 0.0001 or, in the language of the banking community, by one basis point, then the break even cost per input ton of waste increases by about 1.6 cents.

Energy price values per ton of waste can be expressed simply as

(7) $\mathrm{S}_{\mathrm{T}, \mathrm{E}}={ }_{\mathrm{nHP}} \quad$ where

$S_{T, E}$ energy sales income per input ton of waste

$\eta$ is conversion efficiency of waste in to energy out.

$H$ is the heat content of the waste, and

$P_{0}$ is the delivered price of energy in \$/MBTU. 
Note that for mass burning, values of $n$ range from about 0.6 to 0.71 for mixed municipal solid waste. For dry newsprint and boxboard, $n$ values of 0.75 to 0.80 are expected; similar values for split tires burned on a spreader stoker can be expected.

With respect to heat content, $H$, mixed municipal waste averages between 7 and 10 MBTU per ton ( 3500 to 5000 BTU per pound). Dry newsprint has a heat content of about 14 MBTU while boxboard has about 11 MBTU. Tires contain about 16,000 BTU per pound of rubber or 32 MBTU per ton. Waste oi1 contains about 0.14 MBTU per gallon.

Thus, to increase sales income per input ton, a high conversion efficiency is extremely desirable. At a delivered price of $\$ 4.50$ per MBTU for energy, a reduction of 0.01 in conversion efficiency results in a loss of $\$ 0.405$ per input ton or more than $\$ 100,000$ per year to a facility treating 250,000 tons per year of waste.

Costs of operations, maintenance and other annual expenses need to be determined on a case-by-case basis in order to insert values for $\mathrm{M}_{\mathrm{T}}$.

Thus, with $Q_{T}, M_{T}, T_{Y}$ and $I_{F}$, one can estimate the total cost for a wasteto-energy facility which can be afforded. Or, if capital costs have been decided upon, one can obtain the required income to break even or earn a profit. By way of example, consider a situation in which the sponsor is assured of receiving 500 TPD of municipal waste, but the sponsor knows that an additional 500 TPD is in his "waste shed" now and wishes to capture it. 
Thus, the sponsor decides that 1000 TPD may be available now and wishes to construct a 1200 TPD plant to accommodate both the additional 500 TPD plus anticipated growth.

At current costs, a 1200 TPD rated capacity plant is likely to cost about $\$ 75$ million. If 20 year financing at $10 \%$ is available, then Equation (6) gives $I_{F}=0.118$. But only 500 TPD are assured; if the plant operates 300 days per year, then $T_{Y}=150,000$. Assume $M_{T}$ is $\$ 14$ per ton; such a value is consistent with costs in the east and midwest. Then from Equation (1);

$$
Q_{T}=\frac{\left(\$ 75 \times 10^{6}\right)(0.118)}{1.5 \times 10^{5}}+\$ 14=\$ 73.00 \text { per ton. }
$$

Thus, unless the additional 500 TPD are obtained prior to proceeding, and markets found for the energy produced, the proposed plant is probably not feasible. But with the additional 500 TPD, $Q_{T}$ becomes $\$ 43.50$. Sales income plus tipping fees plus any other source of funds must equal this figure for the plant to be financially feasible. With no sources of income save sales plus tipping fee, a tipping fee of $\$ 14$ to $\$ 18$ is likely. With a DoE sponsored price support loan of $\$ 12$ per input ton in the first year of operation, tipping fees of $\$ 1.00$ to $\$ 6.00$ per ton result. Note that the key points are securing feedstocks, i.e., sufficient waste, obtaining markets for the energy and reliable operation for 300 days per year at a conversion efficiency of about $67 \%$.

Suppose that obtaining the additional 500 TPD now appears to be impossible; 
and, therefore, the sponsor wishes to determine whether a 600 TPD facility is feasible. Assume that each ton of input waste results in 6 MBTU of saleable energy and that markets for such energy have been found. (Assumes 4500 BTU per pound of waste and a conversion efficiency of 0.67 ) The energy price is $\$ 4.50$ per MBTU or $\$ 26$ per ton. The sponsor finds that a tipping fee of $\$ 8.50$ per ton is accetable to the clientele to be served by the facility. Hence, with no other sources of funds, income per ton of input waste is $\$ 34.50$. The value of $T_{Y}$ is 150,000 and again, let $I_{F}$ be 0.118 , i.e., a $10 \%$ note for twenty years while $M_{T}$ is $\$ 14$ per ton. Then by Equation (2):

$c_{p}=\frac{(\$ 34.50-\$ 14.00)\left(1.5 \times 10^{5}\right)}{0.118}=\$ 26.1$ mi11ion.

Thus, the sponsor can afford to build a facility costing \$26.1 million having a rated capacity of 600 TPD or $\$ 43,500$ per ton per day to be treated. Such a price may be obtainable. If coupled with providing energy for new housing development, a hospital, school or Junior College, shopping area, etc., some degree of positive economic growth may be achieved using waste as a source of energy. 


\section{NBSIR 80-1968}

\section{Determinacion of the Calorific Value of Refuse-Derived-Fuels by Large-Bomb Calorimetry Summary of the 1978 Fiscal Year Results}

D. R. Kirklin, E. S. Domalski and D. J. Mitchell

Chemical Thermodynamics Division and the

Thermal Processes Division National Bureau of Standards

Washington, D.C. 20234

January 1980

Prepared for

U.S. Department of Energy

Office of the Assistant Secretary

Conservation and Solar Applications

Division of Building and Community Systems

Urban Waste and Municipal Systems Branch

Washington, D.C. 20585

and

U.S. Environmental Protection Agency

Municipal Envirormental Research Laboratory

Solid and Hazardous Waste Research Division

Cincinnati, OH 45268 
NBSIR 80-1968

DETERMINATION OF THE CALORIFIC VALUE OF REFUSE-DERIVED-FUELS BY LARGE-BOMB CALORIMETRY SUMMARY OF THE 1978 FISCAL YEAR RESULTS

D. R. Kirklin, E. S. Domalski and D. J. Mitchell

Chemical Thermodynamics Division and the

Thermal Processes Division

National Bureau of Standards

Washington, D.C. 20234

January 1980

Prepared for

U.S. Department of Energy

Office of the Assistant Secretary

Conservation and Solar Applications

Divison of Building and Community Systems

Urban Waste and Municipal Systems Branch

Washington, D.C. 20585

and

U.S. Environmental Protection Agency

Municipal Environmental Research Laboratory

Solid and Hazardous Waste Research Division

Cincinnati, $\mathrm{OH} 45268$

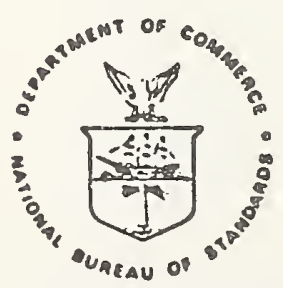

U.S. DEPARTMENT OF COMMERCE, Philip M. Klutznick, Secrotary

Luther H. Hodges. Jr., Doputy Secrotary

Jordan J. Baruch. Assistant Secrotory for Scionce and Technology

NATIONAL BUREAU OF STANDARDS. Ernest Ambler, Director 
Table of Contents

Abstract

Introduction

Experimental

Materials

Sample Preparation

Calorimetric Apparatus

Calorimetric Procedure

Discussion and Results

Calibration Experiments

RDF Combustion Experiment

Conclusion

References 


\section{List of Tables}

\section{Table I}

Calibration Experiments of the Bomb Calorimeters

Table II

MAF Calorific Values in $\mathrm{MJ} \cdot \mathrm{kg}^{-1}\left(\mathrm{Btu} \cdot \mathrm{Ib}^{-1}\right)$

of Teledyne National RDF

Table III

Moisture and Ash Contents of RDF Samples 
Determination of the Calorific Value of Refuse-Derived-Fuels by

Large-Bomb Calorimetry

Summary of the 1978 Fiscal Year Results

Duane R. Kirklin, Eugene S. Domalski and David J. Mitchell

National Bureau of Standards

Washington, DC 20234

\section{ABSTRACT}

An oxygen bomb calorimeter which can accommodate a 25 gram sample of refuse or a refuse-derived-fuel (RDF) has been designed and constructed at the National Bureau of Standards for the purpose of studying the effects of sample processing on the measured calorific value of such material. This large calorimeter is an enlarged and modified version of a conventional-size calorimeter also in use at NBS. The large calorimeter can handle samples ten times larger than the conventional-size calorimeter and therefore can be used to investigate RDF samples with either minimal or no processing. Calorimetric results are presented for calorific value measurements carried out on d(densified)-RDF in both calorimetric systems. Moisture- and ash-free (MAF) calorific values were obtained in the large calorimeter from six randomly chosen unprocessed RDF samples and had a mean value of $24.99 \mathrm{MJ} \cdot \mathrm{kg}^{-1}\left(10742 \mathrm{Btu} \cdot 1 \mathrm{~b}^{-1}\right)$. Another randomlychosen sample of unprocessed RDF was subjected to extensive processing to obtain a "homogeneous" analysis sample for use in the conventionalsize calorimeter. Individual measurements in the conventional size calorimeter on each of ten "homogeneous" sub-samples gave a mean calorific value of $24.99 \mathrm{MJ} \cdot \mathrm{kg}^{-1}\left(10743 \mathrm{Btu} \cdot 1 \mathrm{~b}^{-1}\right)$. The results of this investigation indicate that the calorific value of $d-R D F$ is unaffected by the sample processing technique used at NBS. 
List of Figures

Figure 1.

Pellets of benzolc acid (left), processed

RDF (middle), and unprocessed densified

RDF ( $r$ ight)

Figure 2 .

25-gram-capacity Bomb Calorimeter

Figure 3.

Inner arrangement of Large Combustion Bomb

Figure 4.

Small and large combustion bombs

Figure 5.

Large calorimeter system (a view from the top)

Figure 6.

Time-temperature curve for a bomb calorimetric experiment. 
NBSiR $81-2278$

\section{Test Procedures for the Determination of the Gross Calorific Value of Refuse and Refuse-Derived-Fuel By Conventional Bomb and Large Bomb Calorimetry}

SUMMARY OF THE 1979 FISCAL YEAR RESULTS

D. R. Kirklin, J. Colbert, P. Decker, S. Abramowitz, and E. S. Domalski

Chemical Thermodynamics Division

Center for Chemical Physics

U.S. Department of Commerce

National Bureau of Standards

Washington, DC 20234

June 1981

Prepared for:

U.S. Department of Energy

Assistant Secretary for

Conservation and Renewable Energy

Office of Energy from Municipal Waste

Washington, DC 20585

and

U.S. Environmental Protection Agency

Municipal Environmental Research Laboratory Solid and Hazardous Waste Research Division Cincinnati, OH 45268 
NBSIR 81.2278

TEST PROCEDURES FOR THE

DETERMINATION OF THE GROSS

CALORIFIC VALUE OF REFUSE AND

REFUSE-DERIVED-FUEL BY

CONVENTIONAL BOMB AND LARGE

BOMB CALORIMETRY

SUMMARY OF THE 1979 FISCAL YEAR RESULTS

D. R. Kirklin, J. Colbert, P. Decker, S. Abramowitz, and E. S. Domalski

Chemical Thermodynamics Division

Center for Chemical Physics

U.S. Department of Commerce

National Bureau of Standards

Washington, DC 20234

June 1981

Prepared for:

U.S. Department of Energy

Assistant Secretary for

Conservation and Renewable Energy

Office of Energy from Municipal Waste

Washington, DC 20585

5:

and

U.S. Environmental Protection Agency

Municipal Environmental Research Laboratory

Solid and Hazardous Waste Research Division

Cincinnati, $\mathrm{OH} 45268$

1

at

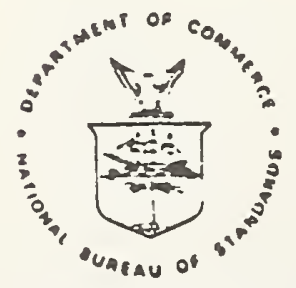

U.S. DEPARTMENT OF COMMERCE, Malcolm Baldrige, Secretary NATIONAL BUREAU OF STANDARDS. Ernesi Ambler, Direcior 


\section{Table of Contents}

Abstract

I. Introduction

1 II. Experimenta?

1

A. Materials

1. Benzoic Acid

2. Oxygen

3. ASTM Round Robin PDF-3 Samples

(a) First Round Robin Sample

(b) Second Round Robin Sample

(c) Third Round Robin Sample

(d) Bituminous Coal Round Robin Sample

4. Teledyne National RDF

(a) R.DF Pellets

(b) RDF-3 (Fluff) Sample

5. ECO FUEL-II RDF

5. Americology RDF-3 (Fluff)

7. New Castle County, Delaware MSW

8. Steam Size Reduction RDF

9. NCRR Storage Pi E RDF (Charred Storage Sample)

10. NCRR RDF (Low Ash Sample)

B. Oxygen Bomb Calorimeters

1. 2.5 gram capacity bomb calorimeter

2. 25 gram capacity bonb calorimeter 
C. Sample Preparation Apparatus

1. Steelman $450^{\circ} \mathrm{F}$ Electric Bake Oven

2. W. W. Grinder Corporation Hammer ilill

3. Wiley Hodel 4 Laboratory Mill

4. Patterson-Kelley Company

Twin Shell Dry Blenders

5. Carver Laboratory Press, Model M

D. Sample Preparation Frocedure

1. Sample Drying

2. Particle Size Reduction

3. Sample Homogenization

4. Preparation of Pelletized Analysis Samples

E. Calorimetric Procedure

III. Results and Discussion

A. Bomb Calorimetric Measurements

1. General Discussion

2. Test Procedures

3. Sample Preparation

4. Bomb Preparation

5. Calorimeter Preparation

6. Temperature Measurements

7. Calorimeter Corrections

3. Calculation of the Calorific Value

B. Calibration of the Calorimeters

1. NBS 2.5 gram Capacity Bomb Calorimeter

2. NBS 25 gram Capacity Bomb Calorimeter 
C. Calorimetric Measurements on RDF

1. ASTiM subcommittee E-33.01 Round Robin Testing on RDF-3

a. First Round Robin Sample

b. Second Round Robin Sample

c. Third Round Robin Sample

d. Bituminous Coal Sample

2. Americology RDF Sample

3. Large and Sinall Calorimeter Comparison Measurements

a. Teledyne National Sample

b. ECO FUEL-II RDF

c. Americology RDF

4. Bureau of Miries Processing of New Castle Ccunty, Delaware MSW

5. Representative or Unique RDF's

a. Teledyne National RDF.

b. Steam Size Reduction RDF

c. NCRR Storage Pile RDF

d: NCRR Low Ash RDF

IV. Sunmary and Conclusions

V. References

Appendix A

Evaluation of Data on Higher Heating Values Determined during ASTM Round Robin Testing of RDF-3

Appendix B

Large Isoperibol Bomb Calorimeter 


\section{Appendix C}

Emission Spectrochemical Analysis of Bomb Residues

1. Teledyne National RDF

2. ECO FUEL-II RDF

3. Americology RDF

Appendix D

Conversion Table for the Calculation of Data to Different Bases Appendix $E$

Calculation of Total Hoisture in an RDF Sample Acknowledgement 
To be presented at the Second International Symposium on Materials and Energy from Refuse; Antwerp, Belgium, October 20-22, 1981

\begin{abstract}
AN OKXGEN FLOW CALORIMETER FOR DETERMINING THE HEATING VALUE OF KILOGKAM-SIZE SAMPLES OF MUNICIPAL SOLID WASTE 1,2
\end{abstract}

\author{
K.L. Churney, M.L. Re1lly, A.E. Ledford, R.V. Ryan \\ and E.S. Domalsk1 \\ Chemical Thermodynamics Division, Center for Chemical Physics \\ Temperature Measurements and Standards Division, Center for \\ Absolute Physical Quantities
}

\title{
ABSTRACT
}

A new calorimeter is being developed at the Nat.. lonal Bureau of Standards to determine the enthalples of combustion of kllogram-size samples of municipal solid waste (MS'i) in flowine oxygen near atmospheric pressure. The organic fraction of 25 gram pellet.s of righly processed MSW has been burned in pure oxygen to $\mathrm{CO}_{2}$ and $\mathrm{H}_{2} \mathrm{O}$ in a small prototype Elow calorimeter. The carbon content of the ash and the uncertainty in the amount of $\mathrm{CO}$ in the combust10n products contriblite calorimetric errors of 0.1 percent or less to the enthalpy of combustion. Large peliets ô relatively unprocessed MSH have been successfully burned in a prototype kilogram-size combustor at a rate of 15 minutes per lilograll with $\mathrm{CO} / \mathrm{CO}_{2}$ ratios not greater than 0.1 percent. Design of the kilogramsize calorimeter has been completed and rabricailon has been started.

\section{INTRODUCTION}

The Nat1onal Bureau of Standards (NBS) has been mandated by the (I.S. Cozgress through Public Law 94-580, the Resolirse Conservation and Recovery ist of 1976, to develop guideiines for specificatiors or recoverable waste taterials. NES has made a commitment to develop a calorimeter to determine the caloriflc value of kiograx-size samples of unimally. processed minicipal solid waste (MSW). A large-scale calorimeter affords greater credibillty because kilogran-size samples of MSW should be more representative of the heterogcneous bulk materlal than the hishly processed gram-size sampies currently used in bomb calorituetric deterulnations.

Combustion of samples in flowing oxygen near atmospheric pressure rather than in the high pressure oxjien of a combustion bomb was adopted for

(1) Ofricial contribution of the National Bureau of Standards, not subject to ccpyright in the Unized States of America.

(2) Thls work is lolntly sponsored by the MBS Orflce of Recycled Materials ard the U. S. Department of Energy, Orfice of Energy from Piundcipal hiaste. safety considerations. However, the flow technique has not been used in any substantial way to determine the enthalpy of combustion of solids since the 1880's. Its development was disconinued because of the simpler techniques and wore quantitative results cbtained with the bomb caloriteter. Attaining complete comtustion was parilcilarly difficult with a flow system. As a consequence, the first goal of the NES project was to demonstrate that the oxygen flow technique could be used to obtain complete combustion of MSti.

To calculate the calorific value of the combustble fraction of MSW, the ash produced in each experiment must be determined quantitatively. Ash collection is simplified by burning peliets of the sample in such a way as to prevent ash dispersal. Therefcre the combustors were designed to burn pellers.

The rirst step in the program was to build a calorimeter for corbusition of 25 gram samples of highly processed MSW. The purpcse was to establish the equivalence of the flow resulis ith those obtained by boub caiorimetry (e.g. With the rew NES 25 gram capacity bomb calorimeter (1)). The preliminary results obtained with the 25 gram flow calorimetric system are described in Part II.

Experimerts with kilogram-size samples of miniwally processed MSW were undertaken as the second stef of tine iBS program. The primary $3 i m$ was to develop a methcd of burning a large heterozeneous sample completely with the rinicum scatterirg of ash. Calorimetric run-time conslderailons recuired the combustion time be $15 \mathrm{~min} / \mathrm{kg}$ or less. AcditIonal experiments were carried out to tast the suitability of ceilulose as a combustion calibrant for the kilogram-size calorimeter. These exper1ments are dessribed in Part III.

The design of the new kllogram-size calorimeter which is based on the resuits of the initial work is summarized in the discussion in Part IV.

(i) D. R. K.1rklin, E. S. Dowalsk1, and J. Mitchell, NBSIK b0-1909, January 1980. 


\section{25 GRAM FLOU EXPERIMENTS}

The combustor used in the 25 gram oxygen flow experlwents is shown in F18. 1. The sample pellet (D of Fig. 1) was placed on a quartz plate (F) ulch had elght radial slots and a small central hole which permitted circulation of oxygen beneath the sample. The plate sat in a quartz cruclble (E) which was supported by a nichrome stand (J). Primary oxygen $(H)$ was supplied locally to the sample through a three-port tubular quartz ring which was located imaediately above the crucible. The lower edge of the Pyrex thermal shleld (C) enclosed the ring and upper edge of the crucible. The outer boundary of the combustor consists of the stainless steel top $(N)$ and base (I) plus the Pyrex wall (L) which were sealed by rubber gaskets (B). A secondary flow of oxygen (C) swept down between the wall of the combustor and the thermal shield and confined the flow of the products of combustion to the interior of the thermal shield. Gases left the combustor through a stainless steel exit line (A) at the top. The temperatures of the product gases near the exit port of the thermal shield and of the midpoint of the interlor of the thermal shield were monitored usling Type $\mathbb{K}$ thermocouples. The thermocouples were supported in helical Pyrex tubing (K) which stood within the thermal shield.

The combustor was placed in a provisional calor $1-$ aetric assembly similar to the rinal design shown in Fig. 2. The provisional assembly consisted of an Insulated bell jar filled with water which was circulated by a stirrer (J of Fig. 2) mounted from the bell jar cover. The flow shield (E) caused the water to circulate up past the combustor (L) and down along the inner wall of the jar (analogous to $B)$. The temperature of the water was measured with a long stem platinum resistance thermometer (C). The product gases flowed through the helical exit gas coll (D) into the water trap (F) and then through a second coil before leaving the calorimeter. The coils and trap were made from Pyrex.

Arter leaving the calorimeter the product gases were scrubbed by bubbling then through water and then the entire gas streati was passed successively through a variable orifice floweter and nondispersive infrared detectors for measuring the concentrations of $\mathrm{CO}$ and $\mathrm{CO}_{2}$. Prelidinary analysis of the product gases by both mass spectrometry and conventional infrared spectroscopy showed $C O$ to be the only species present due to incomplete combustion

Sample pellets for the 25 gram experlments were prepared from a blended powder of minus $0.50 \mathrm{~m}$ parilcle size. The powder was made by willing larse batches of minus $15 \mathrm{~cm}$ MSh from which most of the metals, glass and entrained inorganles had been first removed. This powder is referred to as RDF-4. The cylindrical pellets, which were 3.5 ca in diameter and $2.5 \mathrm{~cm}$ high, were prefared by pressing the powder. In a die using a force ranging from 45 to $160 \mathrm{kN}$. The residual molsture content of the powder was deterained to be about 58 using

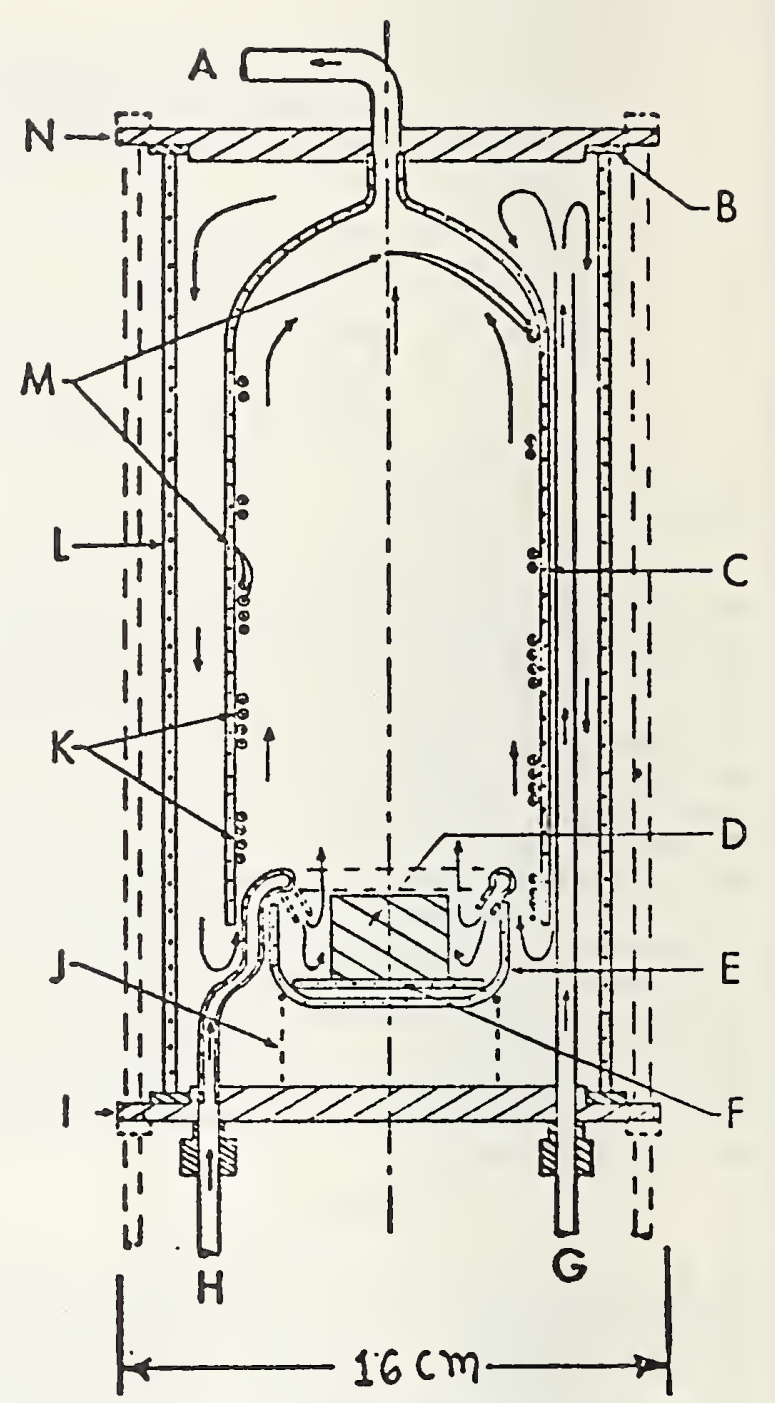

Fig. 1. The 25 Gram Combustor.

Notations: A denotes the product gas exit line, $B$ the gasket, $C$ the thermal shield, D the RDF-4 sample, $E$ the crucible, $F$ the plate, $G$ the secondary oxygen, $H$ the primary oxygen, I the combustor base, $J$ the crucible support, $K$ the thermocouple coils, L the combustor walls, $M$ the thermocouple junctions and $\mathrm{N}$ the combustor 11d.

the ASTM Standard Test Method D 3173-73 (Mo1sture in the Analysis Sample of Coal and Coke).

In a typical experiment, the calorimeter was assembled and the combustor was flushed with pure oxysen. The temperature of the calorimeter water was recorded as a runction of time for approximately twenty olnutes arter a steady inltial drift rate was attained. Just before ignition, the primary and secondary oxygen flow rates were set at approximately 8 and 5 / win, resfectively. The sample was isnited by passing electrical current through an iron fuse wire (net shown in F18. 1) whlch was in contact with the top of the 


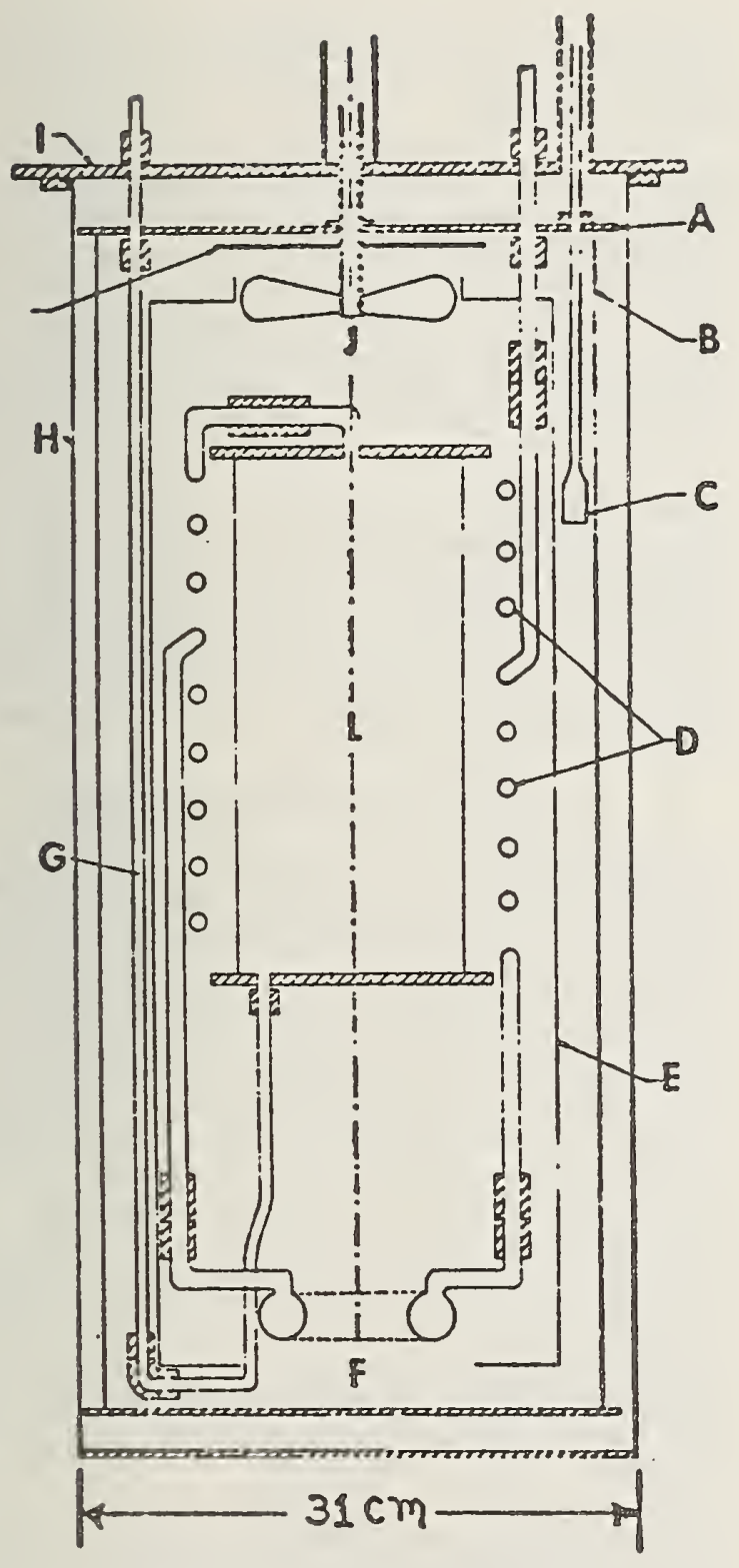

F18. 2. The 25 Gram Flow Calorimeter.

Notations: A denotes the vessel 11d, B the vessel can, $C$ the thermometer, $D$ the exit gas coils, E the 510 shield, F the water trap, G the oxygen supply lines, $H$ the submarine can, I the submarine $11 d, J$ the stirrer and $L$ the combustor.

pellet. A 25 gram pellet typically burned within fourteen minutes. Upon ignition the pellet burned with a diffusion rlame which spread over its entire surface within the rirst 30 seconds. The rlame temperature was cetermined to be greater than $1500^{\circ} \mathrm{C}$. A small but detectable peak in the co concentration occurred at abouc 3 minutes. The surface rlame disapreared at about the eighth ainute. The glowing saple continued to burn internally leaving a porous ash structure that had almost the same shape as the origlnal pellet. The product gases contalned increasing amounts of $\mathrm{CO}$, which reached a peak near the eleventh winute. However, the ratio of $\mathrm{CO}$ to $\mathrm{CO}_{2}$ remalned low. A typical $\mathrm{CO}-\mathrm{CO}_{2}$ composition proflie of the product gases is shown in Fig. 3 .

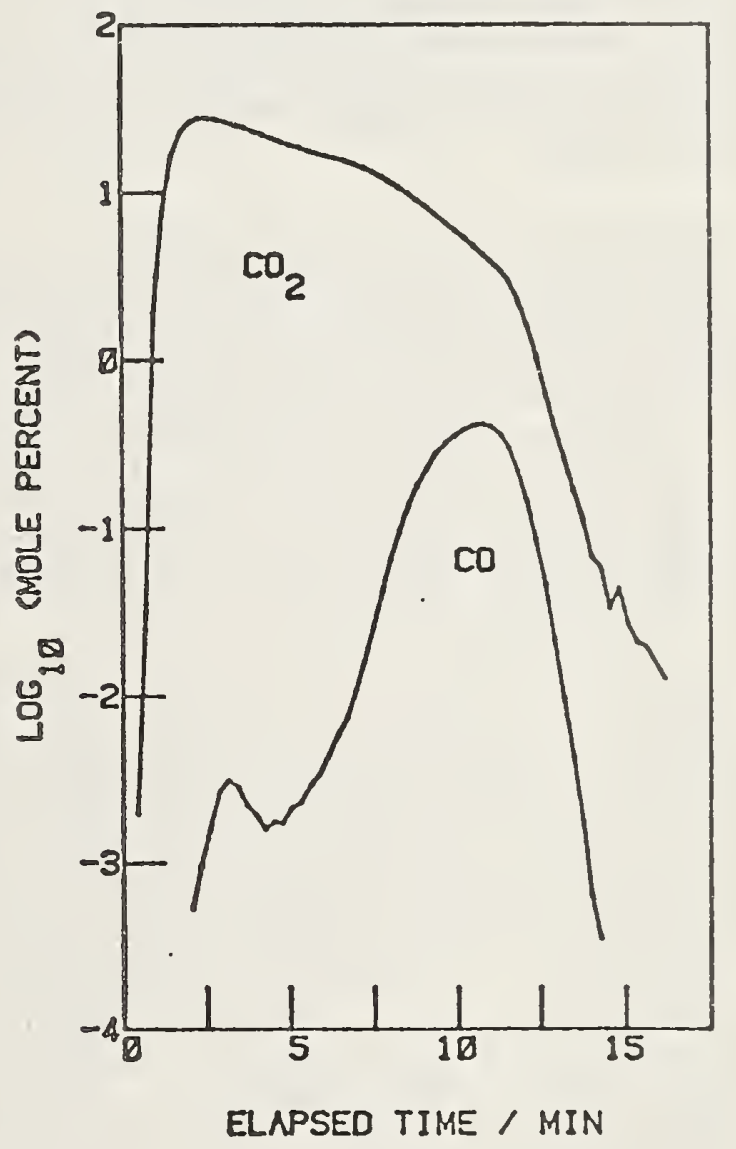

F18. 3. The $\mathrm{CO}-\mathrm{CO}_{2}$ composition of the product gases vs the elapsed time frou ignition for a typical experiment.

The temperature of the product gas stream at the top of the combustor rose quickly to a peak near $600^{\circ} \mathrm{C}$ sowe 30 seconds after ignitior. and then decayed exponentially as the combustion proceded. The product gases were cooled in the exit gas colls and approximately $85 \%$ of the water formed was collected in the trap. The gas has further cooled in the second exit coil. Throughout the combustion, the temperature of the prodict gases leaving the calorimeter was less than $0.1^{\circ} \mathrm{C}$ above the temperature of the calorimeter water.

During the flrst seven wlnutes the temperature of the calorimeter water rose linearly at a rate near $0.25^{\circ} \mathrm{C} / \mathrm{m}$ in. Subsequently, the temperature of the calorimeter water continued to rise a: 3 prosressively diminishing rate until a riar: siczdy-state drift rate was attained about forty-ive minutes after ignition. To establish the final drift 
rate, temperatures were recorded for at least thirty additional minutes. The temperature rise (from the end of the initial drift period to the beginning of the rinal drift period) was typlcally $2.3^{\circ} \mathrm{C}$.

After disassembly of the calorimeter, the ash and the quartz crucible were weighed. The carbon content of the ash was determined from the sum of the wass decrease produced by heating the ash and crucible with an oxygen-gas flame plus subsequent analysis for total occluded carbon. The carbon in the ash ranged from 0.015 to $0.1 \%$ of the initlal sample mass.

A small amount $(<1 \mathrm{mg}$ ) of white residue was depositeo on the thermal shleld during each run. In about one-half of the experiments, the water condensed in the trap (see Fig. 2) was greenish blue rather than clear. The trap also contained some black residue. Apparently this was trapped fly ash whlch had partially dissolved. Analysis showed that no carbon was present in the residue and that the colored solution contained Fe, $\mathrm{Cr}$, $\mathrm{N} 1, \mathrm{Na}$ and $\mathrm{K}$ (i.e. In the range of $100 \mu \mathrm{g} / \mathrm{ml}$ ) in addltion to the usual acidity $(0.1$ to 0.2 milliequivalents per milliliter).

The provisional calorimeter setup was callorated by burning five pellets of RDF-4 (Lot 1) whose energy of combustion had been determined previously with a gram-size bomb calorimeter at NBS. The enthalpy of combustion of a different RDF-4 (Lot 2) was measured in six experiments. The 1mpreciston of the flow measurements on Lots 1 and 2 were 0.9 and $1.2 \%$, respectively, at the $95 \%$ confidence level. (The corresponding imprecision obtalned with the bomb calorimeter for four samples of Lot 1 was $0.8 \%$ and for four samples of Lot 2 was $0.5 \%$ ). The ratio of the two enthalples meastred by the' flow technique was 1.009 with an Imprecision of $1.5 \%$ and an uncertainty (which includes estisated systematic errors) of $2.7 \%$. The corresponding ratio for the bomb calorimeter data was 1.027 wth an 1mprecision and uncertainty of 1.08. The ratios agree within their combined uncertalnties. The uncertainty of the flow ratio Is greater than its imprecision because of the errors associated with the residual moisture determination for each lot.

He belleve the major error in the flow measurements is in the correction for heat leak applied to the observed teaperature rise; corrections ranged from -0.7 to $4 \%$ of the observed rise. The corrections assume that the temperature of the calorimeter environment is held constant and that steady-state heat transfer between the calorimeter water and the environment is achieved rapidly. These conditions were not wet by the proyisional setup.

Other significant correction: and their approxiate magnitudes are: for co formation ( $0.6 \%)$, for heat transport by gas flow ( 0.4\%), for vaporlzation of water ( 1.68 for Lot 1 and $\sim 1.38$ for Lot 2 when inlet oxygen was saturated and $\sim 4.38$ for dry inlet oxyeen). No corrections for carbon content of the ash or residue on the thermal shield were made. The error incurred is probably less than 0.18 .

Benzolc acid was found to be unsatisfactory as a solld callbrant waterial for flow work. Pellets melted and burned with a fuel rich flame that produced large amounts of soot. Ultra-pure carbon powder also proved to be unsatisfactory; it was very difficult to ienite. Flame calorimetry cal1brants (gaseous $\mathrm{H}_{2}$ or $\mathrm{CH}_{4}$ ) were not tested because apparatus necessary for quantitative determination $(0.018)$ of calibrants combusted was not available.

After the RDF-4 experiments, one gram pellets of pure cellulose were test burned in a similar corbustor. The pellets ignited easily and burned completely. Subsequently, bomb calorimetric measurements here initiated to establish the enthalpy of combustion of this waterial so that it can be used as a standard solid calibrant for the flow calorimetry measurements.

\section{TRIAL KILOGRAM COMBUSTIONS}

A large combustor was designed to burn kilogramsize pellets of dried RDF-2. RDF-2 is municipal solld waste which has been processed to reduce the particle size so that 95 mass-percent passes through a $15 \mathrm{~cm}$ square mesh screen. The burning characteristics of the kilogram-slze pellets in oxygen were unknown and were expected to differ from those of the 25 gram pellets. The kilogramsize pellet composition was more variable and the physical heterogeneity measured against the sample size was greater than the 25 gram pellet.

The goal of the trial experiments was to develop a method for completely burning $2.5 \mathrm{~kg}$ samples in approximately 40 minutes or less. This time limlt was estimated to be the maximum time which would guarantee that the imprecision contributed by the calorimetric measurements would be less than one percent.

Trial combustions of samples up to $2.2 \mathrm{~kg}$ of RDF-2 were carried out in a burner cooled by convective and radiant heat losses to ambient temperature. The burner was mounted in a large exhaust hood. The burner design was similar to that used in the 25 gram experiments in that thermal shields were employed to keep the hot, reacting, combustion product sases from being cooled by contact with the outer burner walls. The combustor differed from that used in the 25 gram experiments in that all of the oxygen was supplied locally to the sample; no oxygen flowed between the thermal shield and the cool combustor walls. Oxygen was supplled in the form of high velocity jets which were directed elther at the top of or the slde of the sample or both depending on the experiment. A diffuse, slower, flow of oxygen was directed upward at the bottom of the sample.

The combustor, as it appeared in the rirst of the trial burns, is shown in cross section in F1g. 4. The unit consists of two chambers. The lower chamber, which was the cylindrical region enclosed by 


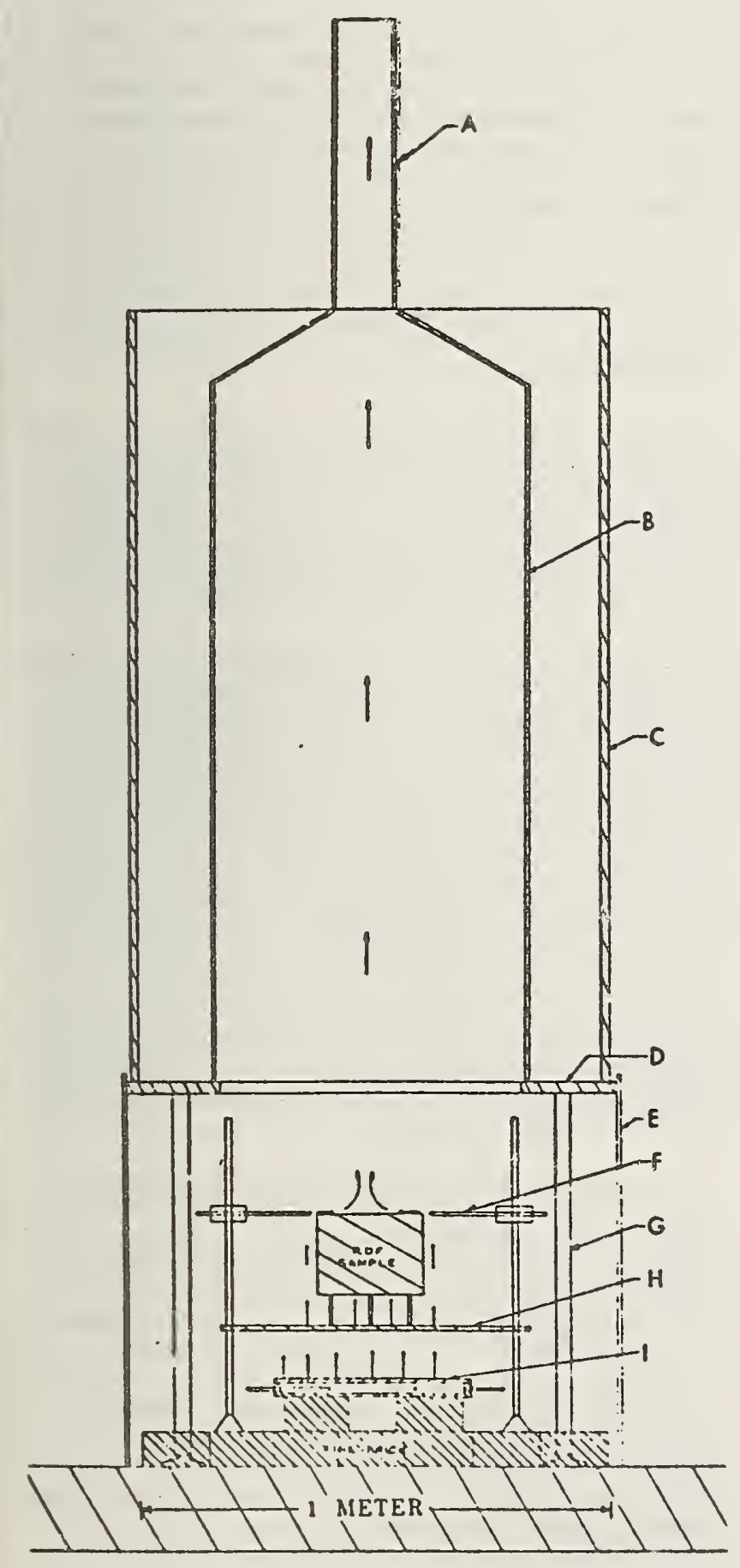

Fig. 4. The 2.5 Kilogram Corbustor.

Notations: A denotes the stack, B the upper thermal shield, $C$ the upper burner jacket, D the annular plate, E the lower burner jacket, $F$ the secondary oxygen inlets, $G$ the support rod, $H$ the sample support and I the primary oxygen inlet. the lower burner Jacket (E of Fig. 4), contalned the sample and two oxygen supply inlets. The sample was. supported on vertical stalnless steel Dins which Iit into the hoies of a porous stainless steel plate (H). This support 3ystem was analogous to the quartz plate of the $25 \mathrm{gram}$ combustor. Primary oxyeen was supplied to the botion of the sample from the inlet I. Secondary oxygen was directed at the top of the sample by three jets aimed radially and horizontally by the inlet $F$. The intent of the sample-oxyzen supply arrangement was to mimic as rar as possible the 25 gram flow experiments while maintaining an unobstructed view of the combustion. Hence, no crucible was used.

The thermal shield (B) of the upper chamber and upper burner jacket (C) sat on a annular stee? plate (D) which was supported by three rods (G) that projected through the lower chamber to the concrete floor. The annular plate also supported the lower burner jacket which was bolted to the plate around two-thirds of its circumference.

For access to the lower chamber, one-third of the circumference of the lower burner jacket was a sem1-cylindrical door. Two Pyrex glass viewing ports (not shown in Fig. 4) were installed in the door so that the course of a combustion could be observed.

Oxygen was supplied to the primary and secondary inlets in the lower burner jacket by independent sources, each consisting of three standard 6,200 liter (STP) oxygen tanks equipped with reducing valves and connected in parallel. Flow rates were measured with variable orifice flowmeters. A product gas analysis train similar to that used in the 25 gram experiments was used to monitor the $C O$ and $\mathrm{CO}_{2}$ production.

Temperatures were monitored at as many as twelve different locations using 18 gauge Iype $K$ thermocouples.

The RDF-2 frow which the sample pellets were tade was obtained from the Teledyne National Resource Recovery Facility in Cockeysuille, Maryland where municlpal solid waste of Baltimore County :s processed. Lots were uithdrawn at random from the conveyer beli leavine the primary shredder. At NBS, the large noncoubustibles were removed and the remainder was dried in air at $105^{\circ} \mathrm{C}$ for 12 to 16 hours. Sample pellets were made by compressing the dried RDF-2 in a cylindrical die piece with a sorce ranging from 265 to $625 \mathrm{kN}$. A single compression yieioed a pellet with reasonably good adhesion of the various heterogeneous hor:zontal layers. This adhesion was not icproved by wetting the waterial with water prior to pressing. The finished pellet had a diameter of $22 \mathrm{~cm}$ and a height of about $0 \mathrm{cro} / \mathrm{kE}_{\mathrm{g}}$ sample mass. To test the efrect of increased surface area, three or seven vertical holes were orilled in some of the pellets using a wetal drill and $j i g$ to hold the sample. One cellulose pellet was wade by presilng pure cellulose rlurf using the same technique. 
In all, elghteen expcriments Here carried out to test the efrectlveness of: (1) varlous arrangements of primary and secondary oxygen inlets, (2) preheating the oxygen, and (3) reducing heat los3es from the sample by the use of a crucible and a radiation shield. Thirteen experiments were run with RDF-2 pellets. Five experiments were run with pure cellulose or its substitute (a stack of unglazed paper plates).

Changes in the apparatus made as a result of these tests are 11lustrated by Fig. 5 which shows the configuration of the lower chamber of the combustor used in the final two experiments. An RDF-2 sample with seven vertical $2.5 \mathrm{~cm}$ diameter holes sat on a horizontal lattice of alumina rods which rested on a stainless steel support (see D or Fig. 5). Two tiers of secondary oxygen inlets $(B$ and $C$ ) were aimed radially inward and horizontally at the side of the pellet. The lower tier of

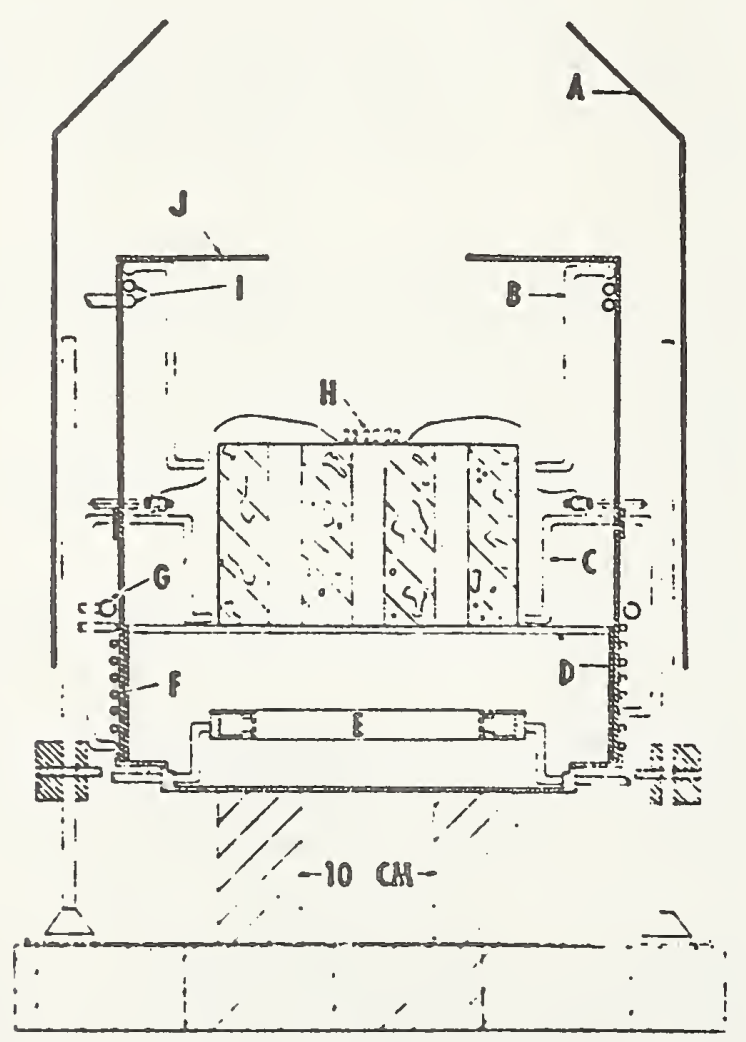

F1g. 5. The configuration of the lower chamber of the corbustor for experiments 17 and 18 . Notations: A denotes the lower thermal shield, B the upper tier of secondary oxysen inlets, $C$ the lower tier of secondary oxygen inlets, D the sample support, E the pritury oxygen inlet, F the lower tier preheat coil, C the multiport ring oxygen inlet, it the Iron fuse, I the upper tier preheat coll and $J$ the crucibie $11 d$. six inlets was supplied with oxyeen that was preheated by passing it through colled tubing (F) which was wound on the outside of thc cruclole. The upper tier of three inlets was supplied with oxygen that was preheated by passing it through the coll (I) which was inside of the crucible. oxygen was supplied to the bottoa of the sample from the primary oxyeen inlet (E). Most of the ash ralls through thc center of the inlet to the bottom of the crucible. A radiation shiteld which just fits the inside diameter of the annular steel plate ( $D$ of F1g. 4) has been placed around the crucible to reduce heat losses.

Back flow of the product gases between the crucible side and the lower thermal shield was prevented by a low uphard flow of diffuse oxygen from the multiport ring inlet (G of Fig. 5). Rectangular openings were cut in the crucible and thermal shield in urder to obscrve the combustion. A Pyrex window covered the opening in the thermal shield.

In a typical experiment, the combustor was rlushed with oxygen for ten minutes. The sample was then Ignited by passing electrical current through an iron fuse wire (H of Fig. 5) touching the top of the sample. The flow rates were adjusted to preselected initial values $\mathrm{fcr}$ the experiment. Primary and secondary oxygen flows were varied to study the effectiveness of different rates and inlet arrangements. The ratio of diffuse to directed flow was of the order of $3: 1$ or greater and the total flow rate ranged between 3.5 and 11 moles per minute. At the end of the ourn, the combustor was flushed with oxygen and allowed to cool. The ash was collected and weighed. The ash contents of RDF-2 pellets ranged from 15 to $32 \%$ of the initial mass and no unburned organic material was identified in the ash.

In general the most rapid burning of the sample occurrcd on the areas where the secondary jets of oxygen struck the sample. As the secondary flow velocity was increascd, these areas became white hot and the rlame became ever more turbulent. Above a critical flow rate, the sample began to rragment vigorously with significant scattering of burning matter and ash. As the temperature of the preheated secondary oxyen was increased, the Ilow rate at which these changes occurred was lowered. Intense burning occurred in the vertical holes, when present. Bright columns of flame were observed above the holes.

No distinct glow period, analogous to that of the 25 gram samples, was observed. However, Co production tended to be larger during the corbustion of the last quarter of the sample. The fraction combustcd at any time was assumed to bc the ratio of $\mathrm{CO}_{2}$ produced up to that time divided by the total $\mathrm{CO}_{2}$ producilon. The ratio of total $\mathrm{CO}$ to $\mathrm{CO}_{2}$ ranged from 2 to less than 0.1 mols. The time required to burn the 13st quarter of all RDF-2 samples was always longer than that required to burn the first three quarters of the sample. Th1s was due to the prosence of noncombustibles which tended to inhiolt the combustion of the last quarter of the unburned material. Peak temperatures 
of the exhaust gases at the exit stack ranged from 365 to $500^{\circ} \mathrm{C}$, depending upon the experiment, and occurred before half of sample had been corbusted. The slame temperature above the sample was determined to be in excess of $1400^{\circ} \mathrm{C}$. The peak temperature of the combustor components nearest the sample ranged from 500 to $1200^{\circ} \mathrm{C}$ for the top of the primary oxygen supply and 440 to $500^{\circ} \mathrm{C}$ for various parts of the cructble and lower thermal shield. Only surface corrosion of the these components occurred and this appeared to be ainicul after one or two experiments. Actual Ignition of the combustor components only took place when the burning sample fell from its support and came into contact with the oxygen inlets.

The total burn time of $R D F-2$ pellets was reduced from 77 minutes per kilogram initial mass in the early runs $w i t h$ the experimental arrangement llustrated in Fig. 4 to an acceptable $15 \mathrm{~min} / \mathrm{kg}$ using the arrangement of Fig. 5. As more than one change in sample and/or combustor configuration was wade in each trial experiment, interpretation or the efrects due to the individual changes tends to be somewhat ambiguous. However, we draw the following conclusions: (1) The introduction of a crucible (having a side wall one half the height of that shown in Fig. 5) caused a reduction in burn times for RDF-2 pellets of $33 \%$. (2) The introduction of vertical holes reduced burn times between 10 and $50 \%$. (3) Burn times for a single tier of lower secondary oxygen inlets (equivelent to C of Fig. 5) were about $50 \%$ less than those obtained using a single tier of upper secondary inlets (which were directed downward at a $45^{\circ}$ angle toward the top edge of the pellet).

We found that cellulose pellets were easily igaited and burned smoothly leaving negligible ash. Burn times for cellulose samples were up to $50 \%$ shorter than those for RDF-2. Cellulose appears to be a satisfactory potential calibrant.

\section{2.5 KILOGRAM CAPACITY FLOW CALORIMETER}

The In inal design adopted for the large scale calorimeter is illustrated in Fig. 6 with dimensions or 1rterest presented in Table 1. Stainless steel (type 304). will be used in the rabrication of all components except as noted.

The combustor (A of Fig. 6) will incorporate all of the reatures which were evolved during the tria? burns plus additional ideas which we were unable to test completely due to the various constraints. The sample pellet is to be supported by a parallel horizontal lattice of alumina rods held by notches in the upper edge of the pan in which the ash is to be collected. The bottom of the ash pan will be covered by a layer of sand to prevent its ignition if large pieces of burning sampie rall on it. Three indepenoent tiers of up to six secondary inlets each (not shown in drawing) will penetrate the wall of the combustor in the region surrounding the sample. A similar tier of six inlets will also penetrate the ash pan to provide oxygen $\$ 10$ beneath the sample.

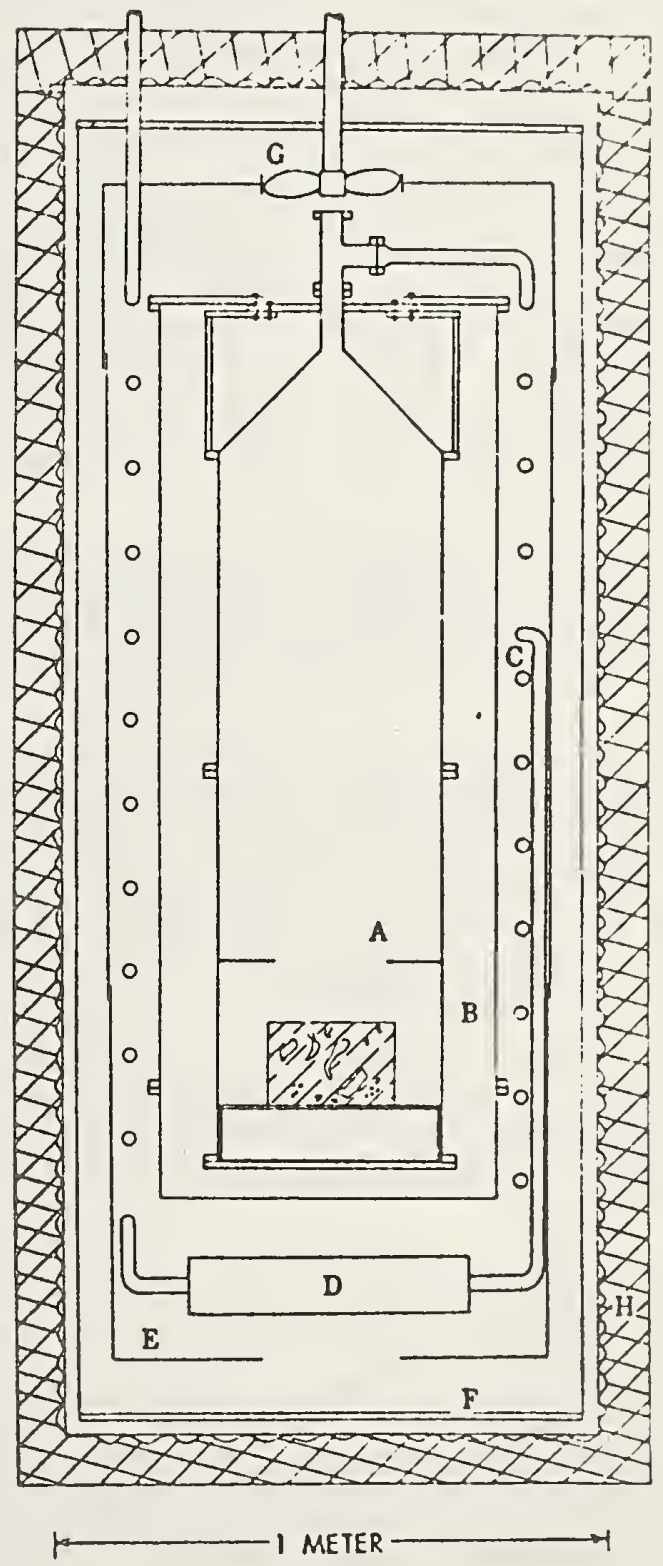

Fig. 6. The 2.5 Kilogram Capacity Flow Calorimeter.

Notations: A denotes the combustor, $B$ the combustor enclosure, $C$ the exhaust cooling colls, D the exhaust concenser, E the rlow shield, F the caloriweter vessel, $G$ the stirrer and $H$ the water-wall jacket. 
Thls arrangement replaces the priary inlet of the ir dal combustor and overcomes the awkward ash recovery procedure used during the trial burns. in annular disk divides the combustor into two zones. The dianeter of the combustor ( $41 \mathrm{~cm}$ ) and space betweecn the sample pellet and the annular disk $(15 \mathrm{~cm})$ are comparable to the dimensions of the crucible and lid arrangement shown in Fig. 5 . An additional tier of six oxyzen inlets is to be placed in the upper zone. All oxygen can be preheated in coils welded to the outer wall of the combustor. Provision is a ade to introduce one or more interior preheat coils in the lower zone of the combustor if cesired. Initially the entire corbustor is to be made from 316 stainless steel with welded construction and as -tight seals at the rlanges. The various oxyen inlets will be sealed at the combustor wall.

The combustor enclosure (B) is to be filled with argon which will provide a clean, inert environment in which all tubing and conrections as well as electrical and thermocouple wiring will be protected.

The combustor enclosure and exhaust cooling coils (C) will be innersed in the calorimeter water held by the calorimeter vessel (F). There will be three complete turns of the cooling coils preceding the exhaust condenser (D) and seven turns before the exit from the calorimeter vessel. The exhaust cooling coils and the exhaust condenser will be made from Incoloy 825 .

The rlow shield $(E)$ and stirrer (G) are deslgned to circulate the caloriater water completely throught the vessel about once in five minutes. For a $2.5 \mathrm{~kg}$ pellet of pure cellulose, we expect a temperature rise of about $10^{\circ} \mathrm{C}$.

To reduce the total mass and volume of the assembly, we plan to enclose the calorimeter vessel with a water-wall jacket (H). Water from a thermostatted reservoir will be circulated through its walls to provide the necessary constant temperature environment for the calorimeter. The jacket replaces the subwarine vessel and lid (cr. $H$ and I of Fig. 2) and the thermostatted, stirred-water bath into wich the conventional isoperibol calorimeter is immersed. The water bath and submarine for a calorimeter of this size woulc weigh about $2800 \mathrm{~kg}$.

Asserbly and testing of the $2.5 \mathrm{~kg}$ Capacity flow Calorimeter is scheduled to begin in the rall of 1981.
TABLE 1.

\section{$2.5 \mathrm{~kg}$ CAPACITY FLCW CALORIMETER}

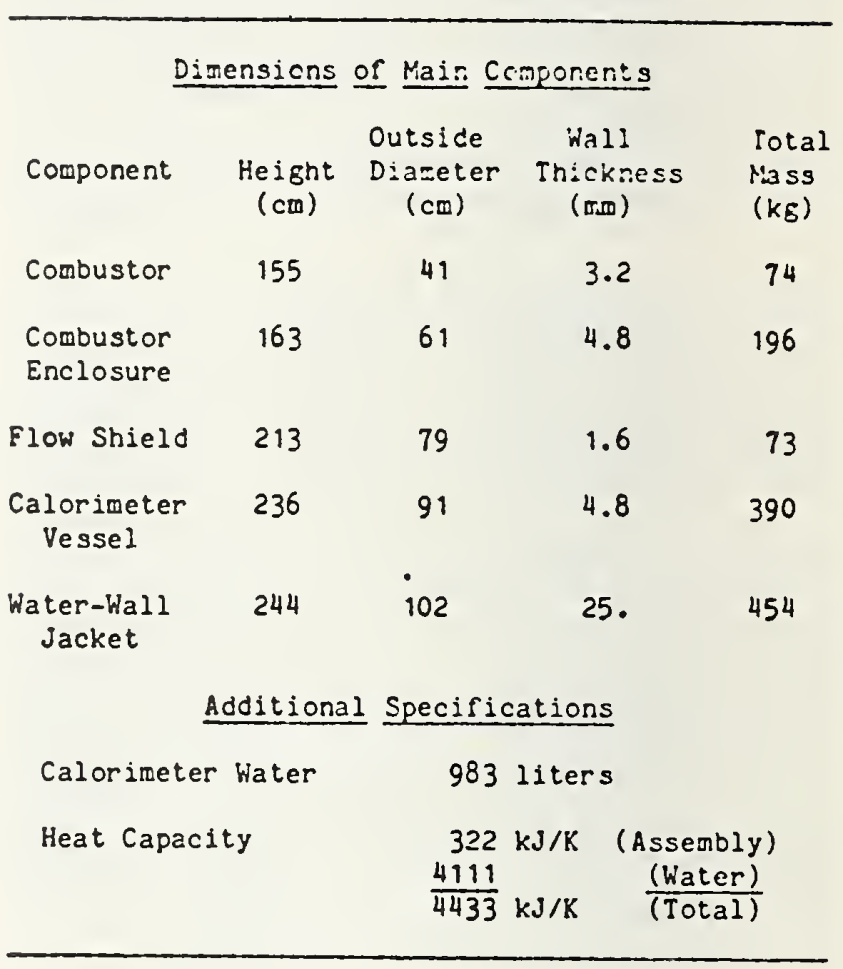


A LABORATORY APPROACH TO OBTAIN SUSPENSION COMEUSTION DATA FOR REFUSE-DERIVED FUELS

\author{
A. Maček anḋ S.R. Charagundla \\ Thermal Processes Division \\ U.S. National Bureau of Standards \\ Washington, D.C. 20234, U.S.A.
}

\begin{abstract}
The objective of this research project is laboratoryscale measurement of burning rates of entrained RDF samples. The resulting data are expected to be relevant for estimating the characteristics of (a) pulverized-fuel combustion and (b) the suspension fraction of spreader-stoker combustion. A furnace is described allowing direct measurement of fuel-particle burning times as functions of the parameters of the entraining gas flow. Preliminary results on combustion of a pulverizedcoal sample in that furnace are presented. Inasmuch as $\mathrm{RDF}$ samples consist of particles having a wide variety of sizes, shapes, and densities, an ancillary study of entrainment characteristics of these samples has been made in a cold-flow elutriation apparatus constructed for that purpose. Settling velocity data are presented (a) for particles of controlled sizes, shapes and densities representative of RDF and (b) for two screened fractions of an RDF sampie. These results will be used in subsequent RDF combustion studies.
\end{abstract}

\title{
I. INTRODUCTION
}

Over the years a large amount of information has become available on various aspects of coal combustion in small-scale laboratory furnaces ${ }^{1-4}$. This information forms a body of basic data which a combustion engineer can draw upon as a rough but very useful guide for prediction of coal combustion characteristics in industrial boilers and furnaces. Among the most important data available from laboratory experiments are fuel burning rates as functions of both fuel properties and parameters of gas streams surrounding the fuel particles. This information is required for estimation of key boiler parameters: rate of heat release, furnace retention time, and furnace outlet temperature.

The equivalent laboratory information does not exist for refusederived fuels (RDF). The objective of the present project is to fill some 
of the gaps in the data base in this area, specifically for combustion of $\mathrm{RDF}$ particles in suspension. The data are thus expected to be relevant to (a) pulverized-fuel combustion and (b) the suspension fraction of spreaderstoker combustion.

This is the first progress report on the project. It includes (a) a statement of the need for and the rationale of laboratory experiments, (b) description of the laboratory equipment, and (c) the results to date.

\section{EXPERIMENTAL APPROACH}

An important problem attending the combustion of $\mathrm{RDF}$ in boilers is that of particie burnout in suspension. A recent estimate based on modelling ${ }^{5}$ indicates that the RDF char may not be completely burned in 2 seconds of fuel residence time in the furnace even for very small fuel particle sizes (about $1.5 \mathrm{~mm}$ diameter). Indeed, practical boiler and incinerator operations frequently indicate particulate carryover from furnaces; it must be mentioned however, that most of these observations refer to larger initial particle sizes. The problem is not confined to $\mathrm{RDF}$. Combustion of wood waste fuels can also lead to extensive particulate carryover, as shown by both practical and analytical studies 9 . The common problem with these waste fuels is that they consist of irregularly shaped particles, even the initial density of which is low compared to that of coal. The density of the solid particles (char, ash) remaining after devolatilization is exceedingly. low, so they tend to elutriate rapidly with incomplete combustion. Thus, the entrainment of fuel particles also requires characterization.

The experimental approach to the problems of fuel particle entrainment and combustion in our laboratory is being carried out in two units, a furnace and an elutriation apparatus. This equipment is described in Section III. Here, we outline only the basic concepts of their use.

Combustion is being studied in a furnace, the basic function of which is to supply a uniform ducted gas stream simulating the temperature and the chemical composition of spreader-stoker or pulverized-fuel boiler gases: Pulverized fuel is injected into the furnace in a stream so dilute that its combustion does not alter significantly the parameters of the hightemperature gas stream. Thus, the range of burning times of a fuel sample is determined in each experiment as a function of a given set of gas composition and temperature, constant throughout the experiment. The direct objective is to obtain particle burning times as function of (a) the fuel parameters (particle size, heating value, ash content, etc.) and (b) the gas-stream parameters (primarily temperature, concentration of oxygen, and particle Reynolds number). The ultimate objective is to provide a sufficient body of burning-rate data for modeiling of particle combustion in large-scale (pilot or field) furnaces where compositions and temperatures of gases surrounding the fuel particles generally vary continuously from ignition to burnout.

The fact that $\mathrm{RDF}$ consists of particles having a variety of shapes and sizes introduces a serious problem of entrainment characterization. The problem can be stated by comparison of RDF with coal. In view of the reasonably uniform shapes of pulverized coal particles (all three 
dimensions being of the same order of magnitude), the double-screening of the material produces a sample of reasonably well defined average diameter and with suitably narrow size distribution. This simple sample preparation technique allows two a priori estimates: (a) the entrainment characteristics (e.g., the limiting settling velocity in the surrounding gas) and (b) the burning time. In a diffusion-limited regime the latter quantity can then be calculated from the particle diameter well within an order of magnitude. No such correlations can be made for RDF, because the sieving of the material produces a sample with a very wide range of entrainment characteristics. Thus even prior to any attempt at estimacing particle combustion rates one is faced with the problem of the entrainment characteristics of RDF samples.

To address the entrainment problem, we designed and constructed a coldflow elutriation apparatus. The function of the apparatus is to separate particles of any given sample into several fractions, each characterized by its limiting settling velocity which, in turn, is determined by a combination of three properties of particles: size, shape, and density. This approach is usefuI for two reasons: (a) it defines an operational procedure for defining RDF samples, equivalent to the customary "size cuts" which suffice for definition of samples of regularly shaped particles (ideally only spheres of constant density, but practically also materials such as pulverized coal); (b) it allows, by means of engineering correlations, an estimate of the fraction of $\mathrm{RDF}$ settling in applied combustion tests which use larger particle sizes.

\section{LABORATORY EQUIPMENT}

\section{A. Combustion Apparatus}

\section{Furnace}

A schematic representation of the laboratory furnace with its auxiliaries is given in Fig. 1. The outer structural support is mostly made of stainless steel. The shaded areas represent refractory lining. The assembly consists of (a) a turbulent propane/air burner which supplies a hot (essentially adiabatic) primary stream of combustion products, (b) the mixing/diffuser sections where the burner products are mixed with a cold secondary diluent and expanded into a cavity having an area of about $130 \mathrm{~cm}^{2}$, and (c) the furnace itself, which also has about the same area. Windows made of high-temperature glass extend over almost the entire front and rear sides of the furnace. The furnace is separated from the upstream sections either by a porous refractory plate or, interchangeably, by a perforated stainless-steel distributor.

The temperature and the composition of the gas flowing through the furnace are varied by use of different diluents (usually oxygen or air) and by variation of the primary/secondary gas stream ratio. The most useful ranges of the two key furnace-gas parameters so far have been: temperature from 850 to $1100 \mathrm{~K}$ and the oxygen content from 10 to $40 \%$. Temperatures are measured as described in Section III A 2. Furnace-gas compositions are assumed to be the result of complete combustion of propane, i.e., to consist entirely of $\mathrm{N}_{2}, \mathrm{O}_{2}, \mathrm{H}_{2} \mathrm{O}$, and $\mathrm{CO}_{2}$. Gas velocities in the furnace, typically, are 50 to $35 \mathrm{~cm} / \mathrm{sec}$. These flow velocities have been adequate for 
the work done so far. Minor modifications of the furnace are planned allowing the flow velocities to be increased to about $150 \mathrm{~cm} / \mathrm{sec}$. Under all these conditions the gas flow will remain laminar.

Fuel particles are injected into the furnace horizontally through side ports. In the preliminary runs with coal particles (see Section IV A) we found it convenient to locate the injection port at least half way (18 $\mathrm{cm}$ or more) above the bottom of the furnace, because larger particles in the sample tend to fall initially, due to gravity, and then rise when ignited.

The requirements for injection of reasonably uniform, controllable streams of particles without agglomeration are always demanding and had to be addressed with care. No suitable commercial injectors appear to be available. The feeder constructed in our laboratory out of a transparent plastic, shown in Fig. $Z^{2}$, is a modification of designs reported in the research literature, 10. The two functions of this instrument are (a) gengeneration of a suspended cloud of separated particles by fluidization and (b) transportation of particles by a carrier gas, usually nitrogen. These functions are accomplished by separate regulation of two gas streams: the fluidizing stream and the carrier gas. It was found that agglomeration, largely due to electrostatic charges, is minimized by vibration of the horizontal transport tube.

The feeder has been found to operate adequately with pulverized bituminous coal, lignite, and RDF over a range of particle sizes having diameters around $100 \mu \mathrm{m}$. Variations of the two feeder gas streams allows a wide variation of mass injection rates of the fuel. The particle size range of this instrument is satisfactory for completion of the work with bituminous coal and lignites. The design for a further modification for larger RDF particles has been completed and the feeder is under construction.

\section{Temperature Instrumentation}

The furnace assembly has been instrumented for temperature measurement at a number of stations by means of Chromel-Alumel thermocouples with digital readout.

The highest upstream section where the temperature is measured is the plenum just upstream of the distributor plate. The main purpose of this measurement is to ascertain that the temperature distribution is uniform over the cross-section. Continuous temperature monitoring at two stations in that section, at the center and near the side-wall respectively, shows that the requirement of uniformity is satisicied when the walls are hot. Normal heat-up period for operation of the furnace is about 20 minutes. Temperatures in that area are typically maintained between 1250 and 1400K; the readings of the two thermocouples are normally within $10 \mathrm{~K}$ or less of each other. The farthest downstream thermocouple (not shown in Fig. 1) is located in the stack, mainly for safety. None of these three thermocouples, although rather large (28 gauge wires, corresponding to about $0.8 \mathrm{~mm}$ bead diameters), present problems of radiation correction. This is so for two reasons. First, accurate values of temperatures at these three stations, while useful for characterization of the furnace performance, are not needed for measurement of combustion parameters. Second, the assumption 
that the gas temperature equals the bead temperature in these sections is good, because the two upstream stations are inside a radiating cavity and the downstream station is in a gas stream at high velocity (> $1000 \mathrm{~cm} / \mathrm{sec}$.) and low temperature (600K or less).

On the other hand, thermocouple measurements inside the furnace require a significant correction because of high temperatures, low gas velocities, and relatively low radiant surroundings at most measurement stations. Direct estimates of radiant losses are difficult, because the effective temperature of surroundings is unknown and, furthermore, it varies with the location in the furnace: it is relatively high near the bottom of the furnace because of the proximity of the highly radiant distributor plate, but It decreases toward the top of the furnace. However, since the temperature loss due to radiation is proportional to the diameter of the radiating body, a good semi-empiral correction can be made by recording the temperature at each measuring station with two adjacent thermocouples with spherical beads of two different diameters, $\mathrm{d}_{1}$ and $\mathrm{d}_{2}$. The procedure for obtaining the gas temperature from such measurements will now be described briefly.

The relationship between the gas temperature $\mathrm{T}$ and the (measured) thermocouple bead temperature $\mathrm{T}_{b}$ in a given convect $\mathrm{g}_{\mathrm{v}}$ and radiative regime can be written

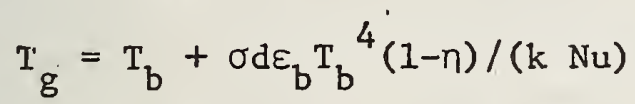

where the emipirical parameter $n$ can be thought of as a "view factor", i.e. the fraction of the solid angle around the measuring station having a high radiant temperature. Other symbols are defined in the Glossary. As $\eta$ approaches unity, the correction in Equ. 1 vanishes; as explained earlier this is the assumption made for the cavity upstream of the distributor plate $\left(r_{g}=T_{b}\right)$. The othef extreme assumption, $n=0$, is usually made in open noh-luminous flames ${ }^{\text {. }}$.

Inasmuch as both $\mathrm{Nu}$ and $\eta$ are only weak functions of the bead diameter, we found it convenient to rewrite Equ. 1:

$$
T_{g}=T_{b}+K d T_{b}^{4}
$$

where $\mathrm{K}=\varepsilon_{\mathrm{b}} \sigma(1-n) / \mathrm{k} \mathrm{Nu}$ is assumed to be the same for any thermocouple at a given location in a given gas stream (varying, of course, from location to location and for different gas-stream parameters). Simultaneous recording of two temperatures $\mathrm{T}_{\mathrm{bl}}$ and $\mathrm{T}_{\mathrm{b} 2}$ by thermocouples with bead diameters $\mathrm{d}_{1}$ and $d_{2}$ respectively allows elimination of $\mathrm{K}$ from the set of two resulting equations $\left(l^{\prime}\right)$. The expression for gas temperatures becomes:

$$
T_{g}=T_{b 1}+\frac{T_{b 1}-T_{b 2}}{\left(d_{2} / d_{1}\right)\left(T_{b 2} / T_{b 1}\right)^{4}-1}
$$

The term $\mathrm{T}_{\mathrm{b} 1}-\mathrm{T}_{\mathrm{b} 2}$ is usually a small difference of two large numbers, leading to low accuracy from Equ. (2). For example, it has been found that for gas temperatures around $1000 \mathrm{~K}$ near the bottom of the furnace (large $\eta$ ), 
and the two bead diameters of 0.32 and $0.81 \mathrm{tm}, \mathrm{T}_{\mathrm{b} 1}-\mathrm{T}_{\mathrm{b} 2}$ is only about 25K. A refinement of the instrumentation was therefore made, allowing direct electronic readout of this difference, resulting in satisfactory measurement of the gas temperature.

\section{Photography}

Injection of fuel particles into the furnace gases follows the predictable visual pattern: a dark area between the point of injection and the point of ignition corresponds to the pre-ignition heat-up time. Once ignited, each particle gives rise to a bright trajectory from ignition to burnout appearing as a bright streak in time-exposure photographs. Inasmuch as, in the work to date, the particle burning times have been small fractions of a second, each snapshot with photographic exposure times of 1 to 2 seconds is sufficient to capture records of many burning particles. Burning times of individual particles are obtained by means of a mechanical light-chopper interposed between the camera and the furnace window. This technique had been shown previously to give accurate time-resolved measurements on single burning particles ${ }^{12}$.

The useful light-chopping frequency range so far has been from 200 to $1000 \mathrm{~Hz}$. This range can be extended, if needed, up to $4000 \mathrm{~Hz}$ and down to arbitrarily low values. In reading the photographic records care must be taken to ascertain that the streaks modulated by the optical frequency represent the entire burning time of the particle; i.e. they must include both ignition and burnout, unaffected by the opening or the closing of the camera shutter.

\section{B. Elutriation Apparatus}

The cold-flow elutriation apparatus consists of a set of constant-area tubes ( $A, C, E$ ) and tapered transition sections ( $B, D, F$ ) with appropriately small angles to prevent flow separation, arranged in the sequence shown in Fig. 3. All sections are made of transparent plastic. Care was taken to have smooth internal surface (by buffing) and smooth transitions between sections.

During the operation a metered stream of air is passed through a flow straightener and introduced at the bottom of the apparatus. A removable particle collector is located at the top (exit) end of the apparatus. Particles are introduced before each run, and replenished during the run as needed, through the top by temporary removal and replacement of the collector.

Two modes of operation of the apparatus have been developed: one for prepared samples consisting of particles having the same size and shape (discs of paper or metal foil, blocks of wood, etc.); and the other for heterogeneous samples, such as RDF.

To determine the entrainment characteristics of controlled shapes and sizes the flow rate in the apparatus is increased until the particles stabilize first at Station I and then at Station II. At low Reynolds numbers this happens at two different mass flow rates, corresponding to the same linear flow velocity. This, by definition, is the settling 
velocity of the sample. In view of the fact, however, that the entrainment regimes of interest to this project extend into the range of high Reynolds numbers where vortex shedding and instability occur (see Section IV B), such simple determination is not always possible. Under conditions of unstable flow the particles, having reached a height in the apparatus, tumble to lower levels and rise again repeatedly. Under these conditions the flow is adjusted until the particles attain their peak position at Station I or II. Thus the minimum settling velocity of the sample is determined (which is the important parameter in characterizing the carryover in suspension combustion).

A modified procedure had to be developed to handle heterogeneous samples, where the size (sieve) fraction alone is insufficient for characterization of entrainment, because shape and density matter as well (see Section II). To characterize such samples the flow rate in the apparatus is first increased until the most entrainable fraction becomes suspended at Station I; this yields the first (lowest) settling velocity. The flow is then further increased until a "heavier" fraction is suspended at Station I; the lighter fraction moves to Station II or beyond to the collector at the exit. This procedure, which can be extended to several flow-rate increments, depending on the heterogeneity of the sample, gives two results: (a) settling velocities for direct use in both laboratoryscale and large-scale combustors; and (b) collection of actual samples at the exit for further use in the laboratory (examination and combustion).

\section{RESULTS TO DATE}

\section{A. Preliminary Coal Combustion}

The first combustion task in this project deals with pulverized coal as the fuel. The reason for including this task is twofold. First, an important objective of the project is to determine differences in suspension combustion of RDF relative to coal (both bituminous and 1ignites), so a "baseline" study of coal is necessary. Second, inasmuch as a substantial body of data exists with bituminous coal, obtained by different laboratory techniques, the comparison of our results on this fuel with the previously available information provides a good way of characterizing the performance of our furnace.

To characterize this performance samples of bituminous coal have been injected into furnace gases with varying compositions and at various temperatures. At any given gas temperature the particle brightness increased and the particle burning times decreased with the oxygen content in the furnace gas, which was thus found to be a major furnace variable determining the burning time, as expected. In fact, at gas temperatures around $1000 \mathrm{~K}$ the decrease of oxygen content below $10-12 \%$ by volume gave rise to long, low-luminosity particle trajectories, possibly indicating the transition from the diffusion-controlled to the slower kineticallycontrolled regimes.

In view of the facts that (a) there are indications that in our experiments at low oxygen content the observed burning times correspond to only partial combustion of carbon (combustible matter was collected in the cyclone) and (b) a priori calculations of particie burning rates in kinetic 
regimes are highly uncertain, we make a comparison of our observed data with the calculation for a specific case of combustion of a sample of pulverized bituminous coal in oxygen-rich gases (obtained by use of oxygen as the secondary diluent; see Section III A 1).

The data used for the comparison are as follows:

$\begin{array}{ll}\text { coal particle diameter } & 68 \mu \mathrm{m} \\ \text { gas temperature } & 1020 \mathrm{~K} \\ \mathrm{O}_{2} \text { in furnace gas } & 38 \% \\ \text { average burning time } & 14 \mathrm{msec}\end{array}$

The value of the particle diameter was adopted, because the sample was sieved between 200 Mesh $(74 \mu \mathrm{m})$ and 230 Mesh $(62 \mu \mathrm{m})$ screens; it is only a rough approximation to the equivalent sphere diameter. The other quantities are laboratory data determined as described in Section III A.

$\mathrm{be}^{1}$, The theoretical expression for the particle burning time was taken to

$$
\tau=\frac{\rho D}{16 \mathrm{I} R T P} \mathrm{~d}_{\mathrm{p}}^{2}
$$

This expression assumes that the combustion reaction at the surface of the particle is $\mathrm{C}+1 / 2 \mathrm{O}_{2} \rightarrow \mathrm{CO}$. The effective temperature in the diffusion field was taken to be $1750 \mathrm{~K}$, a rough average of the measured free-stream and estimated flame-front values. This calculation gives a theoretical burning time of $18 \mathrm{msec}$. In view of the crudeness of assumptions this close agreement with the experimental burning time must be considered fortuitous.

The above preliminary study shows that the laboratory combustion equipment and the experimental procedures described in this Section are suitable for attainment of the objective of this project, i.e., the determination of particle burning time, $\tau=f\left(d_{p}, T_{g}, o_{2}\right)$.

\section{B. Entrainment of Particles}

We are not aware of any data on RDF Particle entrainment in the form required for determination of two numbers required for application in combustors: the fraction of the fuel suspended by the gas stream and its residence time in the furnace. There 1 xxists a good data base for spherical particles, mostly at low temperatures $13,{ }^{14}$. There are also correlations 16 permitting estimation of entrainment data for non-spherical particles ${ }^{15,} 16$. However, the accuracy of such estimates is questionable.

We, therefore, present the entrainment information under two headings; (a) theoretical estimates for spherical particles, which are not realistic for $\mathrm{RDF}$, but are useful as baseline comparison with coal and (b) experimental daca on non-spherical particles obtained in our laboratory. 


\section{Spherical Particles}

It must first be noted that densities of RDF constituegt materials may vary by an order of magnitude. A few examples (in $\left.g r a m s / \mathrm{cm}^{2}\right)^{17}$,

wood (oven dry)
plastics
paper
glass

$$
\begin{aligned}
& 0.12-1.23 \\
& 1.05-2.09 \\
& 0.7-1.15 \\
& 2.4-5.9
\end{aligned}
$$

Entrainment velocities of such materials will now be estimated for typical boiler conditions: $T_{o}=1370 \mathrm{~K}\left(2000^{\circ} \mathrm{F}\right)$ and $\mathrm{U}_{\mathrm{g}}=750 \mathrm{~cm} / \mathrm{sec}(30$ $\mathrm{ft} / \mathrm{sec}$ ). The maximum sizes of (spherical) particles entrainable under these conditiogs are large enough to be in the Newton's law range: $750<\mathrm{Re}<$ $3.5 \times 10^{5}$. In this regime, the drag coefficient is almost constant, $C_{D}<0.445$, and the terminal velocity $U_{t}(\mathrm{~cm} / \mathrm{sec})$ of a particle of diameter $\mathrm{d}^{\mathrm{D}}(\mathrm{cm})$ is :

$$
U_{t} \simeq 1.73\left[\mathrm{gd}\left(\rho_{\mathrm{p}} / \rho_{\mathrm{g}}-1\right)\right]^{1 / 2}
$$

Thus the diameter of the largest particle entrainable in a combustor stream is

$$
d_{\max }=(U / 1.73)^{2} \cdot\left(\rho_{g} / \rho_{p} g\right)
$$

where $\mathrm{U}$ is the velocity of the gas stream.

The data for coal and for several materials which may be typical constituents of RDF, calculated by Equ. 5, are shown in Table I. It can be seen that the estimated entrainment characteristics of RDF constituents would not be grossly different from those of coal, if the particles were spherical. However, the consideration of the shape factor may change these numbers by orders of magnitude.

\section{Non-Spherical Particies}

Terminal velocities of a variety of particles have been measured in our cold-flow elutriation apparatus by the procedures described in Section III B. The performance of the apparatus was checked by determination of the suspension velocity of spherical glass beads, $1 \mathrm{~mm}$ in diameter. The experimentally found velocity is $670 \mathrm{~cm} / \mathrm{sec}$. The theory (Section IV B 1) predicts $780 \mathrm{~cm} / \mathrm{sec}$. In view of experimental uncertainties (the exact shape and density of the spheres, etc.) the agreement is satisfactory.

The experimental data for various controlled (non-spherical) shapes and for two screened RDF samples are collected in Table II. In a few relatively low-velocity cases the flow regime corresponded to $\operatorname{Re}<100$. However, in many cases the particles gave a clear appearance of insta bilities (tumbling, oscillation) as should be expected in the Newton regime (vortex shedding, etc.) 
regimes are highly uncertain, we make a comparison of our observed data with the calculation for a specific case of combustion of a sample of pulverized bituminous coal in oxygen-rich gases (obtained by use of oxygen as the secondary diluent; see Section III A 1).

The data used for the comparison are as follows:

$\begin{array}{ll}\text { coal particle diameter } & 68 \mu \mathrm{m} \\ \text { gas temperature } & 1020 \mathrm{~K} \\ 0_{2} \text { in furnace gas } & 38 \% \\ \text { average burning time } & 14 \mathrm{msec}\end{array}$

The value of the particle diameter was adopted, because the sample was sieved between 200 Mesh $(74 \mu \mathrm{m})$ and 230 Mesh $(62 \mu \mathrm{m})$ screens; it is only a rough approximation to the equivalent sphere diameter. The other quantities are laboratory data determined as described in Section III A. $b^{1}$, The theoretical expression for the particle burning time was taken to

$$
\tau=\frac{\rho R T}{16 \mathrm{MPP}} \mathrm{d}_{\mathrm{p}}^{2}
$$

This expression assumes that the combustion reaction at the surface of the particle is $\mathrm{C}+1 / 2 \mathrm{O}_{2} \rightarrow \mathrm{CO}$. The effective temperature in the diffusion field was taken to be $1750 \mathrm{~K}$, a rough average of the measured free-stream and estimated flame-front values. This calculation gives a theoretical burning time of $18 \mathrm{msec}$. In view of the crudeness of assumptions this close agreement with the experimental burning time must be considered fortuitous.

The above preliminary study shows that the laboratory combustion equipment and the experimental procedures described in this Section are suitable for attainment of the objective of this project, i.e., the determination of particle burning time, $\tau=f\left(d_{p}, T g, O_{2}\right)$.

\section{B. Entrainment of Particles}

We are not aware of any data on RDF particle entrainment in the form required for determination of two numbers required for application in combustors: the fraction of the fuel suspended by the gas stream and its

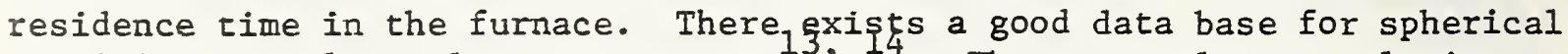
particles, mostly at low temperatures ${ }^{13}$. There are also correlations 16 However, the accuracy of such estimates is questionable.

We, therefore, present the entrainment information under two headings: (a) theoretical estimates for spherical particles, which are not realistic for RDF, but are useful as baseline comparison with coal and (b) experimental data on non-spherical particles obtained in our laboratory. 
It must first be noted that densities of $\mathrm{RD} \overrightarrow{\mathrm{r}}$ constituegt materials may vary by an order of magnitude. A few examples (in grams $/ \mathrm{cm}^{3}$ ) 17 , 18 :

$\begin{array}{ll}\text { wood (oven dry) } & 0.12-1.23 \\ \text { plastics } & 1.05-2.09 \\ \text { paper } & 0.7-1.15 \\ \text { glass } & 2.4-5.9\end{array}$

Entrainment velocities of such materials will now be estimated for typical boiler conditions: $\mathrm{T}_{\mathrm{f}}=1370 \mathrm{~K}\left(2000^{\circ} \mathrm{F}\right)$ and $\mathrm{U}_{\mathrm{g}}=900 \mathrm{~cm} / \mathrm{sec}(30$ $\mathrm{ft} / \mathrm{sec}$ ). The maximum sizes of (spherical) particles éntrainable under these conditions are large enough to be in the Newton's law range: $750<\mathrm{Re}<$ $3.5 \times 10^{5}$. In this regime, the drag coefficient is almost constant, $C_{D}<0.445$, and the terminal velocity $U_{t}(\mathrm{~cm} / \mathrm{sec})$ of a particle of diameter $\mathrm{d}^{\mathrm{D}}(\mathrm{cm})$ is:

$$
U_{t} \simeq 1.73\left[g d\left(p_{p} / \rho_{g}-1\right)\right]^{1 / 2}
$$

Thus, the diameter of the largest particie entrainable in a combustor stream is approximately

$$
d_{\max }=(U / 1.73)^{2} \cdot\left(\rho_{g} / \rho_{p} g\right)
$$

where $U$ is the velocity of the gas stream.

The data for coal and for several materials which may be typical constituents of RDF, calculated by Equ. 5, are shown in Table I. It can be seen that the estimated entrainment characteristics of RDF constituents would not be grossly different from those of coal, if the particles were spherical. However, the consideration of the shape factor may change these numbers by orders of magnitude.

\section{Non-Sphericai Particles}

Terminal velocities of a variety of particles have been measured in our cold-flow elutriation apparatus by the procedures described in Section III $B$. The performance of the apparatus was checked by determination of the suspension velocity of spherical glass beads, $1 \mathrm{~mm}$ in diameter. The experimentally found velocity is $670 \mathrm{~cm} / \mathrm{sec}$. The theory (Section IV B 1) predicts $780 \mathrm{~cm} / \mathrm{sec}$. In view of experimental uncertainties (the exact shape and density of the spheres, etc.) the agreement is satisfactory.

The experimental data for various controlled (non-spherical) shapes and for two screened RDF samples are collected in Table II. In a few relatively low-velocity cases the flow regime corresponded to $\operatorname{Re}<100$. However, in many cases the particles gave a clear appearance of instabilities (tumbling, oscillation) as should be expected in the Newton regime (vortex shedding, etc.). 
Clearly, the extremely wide range of elutriation velocities for the RDF sample cannot be ascribed to variation in size and density only: the shape is no doubt an important factor, as expected. A direct evidence of this is that, after elutriation and removal of the more entrainable fraction, the residue does not consist only of large, heavy particles, but also contains small elongated pieces.

The above results indicate the continued use of the elutriation apparatus for two purposes: physical separation of samples according to their entrainment characteristics for laboratory combustion studies; and development and/or confirmation of correlations (shape factors) for nonspherical particles. It is expected that the latter activity will lead to estimation of terminal velocities for $\mathrm{RDF}$ samples in applied combustion studies.

\section{ACKNOWLEDGEMENT}

Mr. C. Bulik set up the electronic instrumentation associated with temperature measurement and the time-resolved photography for recording the combustion of particles.

\section{GLOSSARY}

D diffusion coefficient

d diameter

$g$ acceleration due to gravity

$k$ thermal conductivity coefficient (gaseous)

$\mathrm{K}$ parameter defined by Equ. ( ${ }^{\prime}$ )

$M$ molecular weight of solid fuel (carbon)

$\mathrm{Nu}$ Nusselt number

$P$ pressure

$R$ gas constant

Re Reynolds number

T temperature

U velocity

$\varepsilon \quad$ radiant emissivity

$\eta$ parameter defined by Equ. (1)

0 density

$\sigma \quad$ Stefan-Boltzman constant

$\tau$ burning time

$$
\text { Subscripts }
$$

b thermocouple bead

g gas

P particle

1,2 denoting two different thermocouples 
Table I

Diameter of Largest Spherical Particles Entrainable in Hot Gas Stream Flowing at $900 \mathrm{~cm} / \mathrm{s}$ at $1370 \mathrm{~K}$

$\begin{array}{lcc}\text { Material } & \text { Density, } \mathrm{g} / \mathrm{cm}^{3} & \begin{array}{c}\text { Diameter of largest } \\ \text { spherical particle } \\ \text { entrainable, mm }\end{array} \\ \text { Newsprint } & 0.67 & 1.1 \\ \text { Wood } & 0.44 & 1.7 \\ \text { Plastics, Rubber } & 1.2 & 0.61 \\ \text { Coal } & 1.5 & 0.47\end{array}$

Table II

Measured Velocity for Particle Suspension

\begin{tabular}{|c|c|c|c|c|}
\hline \multicolumn{3}{|c|}{ Particle } & \multicolumn{2}{|r|}{ Velocity for } \\
\hline Material & $\begin{array}{c}\text { Density } \\
\mathrm{g} / \mathrm{cm}\end{array}$ & Shape & Size & $\begin{array}{c}\text { Suspension, } \\
\mathrm{cm} / \mathrm{s}\end{array}$ \\
\hline Newsprint & 0.66 & cir. disc & $0.635 \mathrm{~cm}$ dia. $\times 0.0076 \mathrm{~cm}$ & 90 \\
\hline Xerox Copy Paper & 0.75 & cir. disc & $0.635 \mathrm{~cm}$ dia. $\times 0.01 \mathrm{~cm}$ & 104 \\
\hline Aluminum foil & 2.7 & cir. disc & $0.635 \mathrm{~cm} \mathrm{dia.} \times 0.0038 \mathrm{~cm}$ & 126 \\
\hline Index Card & 0.78 & cir. disc & $0.635 \mathrm{~cm} \mathrm{dia.} \times 0.023 \mathrm{~cm}$ & 184 \\
\hline Wood & 0.44 & rect. plate & $0.6 \mathrm{~cm} \times 0.62 \mathrm{~cm} \times 0.16 \mathrm{~cm}$ & 357 \\
\hline Wood & 0.44 & sq. block & $0.7 \mathrm{~cm} \times 0.7 \mathrm{~cm} \times 0.64 \mathrm{~cm}$ & 476 \\
\hline $\mathrm{RDF}$ & ? & Irregular & $-20+35$ mesh & $13 / 546$ \\
\hline RDF & ? & Irregular & $-35+80$ mesh & $6 / 446$ \\
\hline
\end{tabular}




\section{REFERENCES}

1. M.A. Field, D.W. Gill, B.B. Morgan, and P.G.W. Hawksley, Combustion of Pulverised Coal, BCURA, Leatherhead, Surrey, England (1967).

2. R.H. Essenhigh: "Combustion and Propagation in Coal Systems", 16th Symposium (Internationa1) on Combustion, p. 389. The Combustion Institute (1977).

3. N.M. Laurendeau: "Heterogeneous Kinetics of Coal Char Gasification and Combustion", Prog. Energy Combust. Sci. 4, p. 221 (1978).

4. J.O.L. Wendt: "Fundamental Coal Combustion Mechanisms and Pollutant Formation in Furnaces", ibid. 6, 201 (1980).

5. P.M Chang and L. Carlson: "Vertical Combustor for Particulate Refuse", Numer. Heat Trans., 4, 101 (198I).

6. M. Liu: "Factors Affecting Hog Fuel Boiler Emissions", British Columbia Research Council, Rep. 2376, Vancouver, Canada (1976).

7. T.N. Adams: "Combustible Carryover Predictions for a Wood-Waste Boiler", Comb. and Flame, 34, 47 (1979).

8. M.F.R. Mulcahy and I.W. Smith: "Kinetics of Combustion of Pulverized Fue1", Kev. Pure App1. Chem. 19, 81 (1969).

9. R. Friedman and A. Maček: "Ignition and Combustion of Aluminum Particles in Hot Ambient Gases", Comb. and Flame, б́, 9 (1962).

10. R.J. Hamor and I.W. Smith: "Fluidizing Feeders for Providing Fine Particles at Low, Stable Flows", Fuel, 50, 394 (1971).

11. R.M. Fristrom and A.A. Westenberg, Flame Structure, p. 151, McGrawHill, New York (1965).

12. A. Maček and J.M. Semple: "Combustion of Boron Particles at Atmospheric Pressure", Comb. Sci. Tech., 1, 181 (1969).

13. H. Schlichting, Boundary Layer Theory, McGraw-Hill (1962).

14. R. Clift, J.R. Grace, and M.E. Weber, Bubbles, Drops, and Particles, Academic Press, New York (1978).

15. H. Wadell, J. Geol., 41, 310 (1933).

16. H. Heywood, Symp. Interaction Fluids and Particles, Inst. Chem. Eng., pp. 1-8, London (1962).

17. Handbook of Chemistry \& Physics, 30th ed., Chemical Publishing Co., Cleveland (1948).

18. Smithsonian Physical Tables, 9th ed., Smithsonian Institution, Washington, D.C. (1954). 


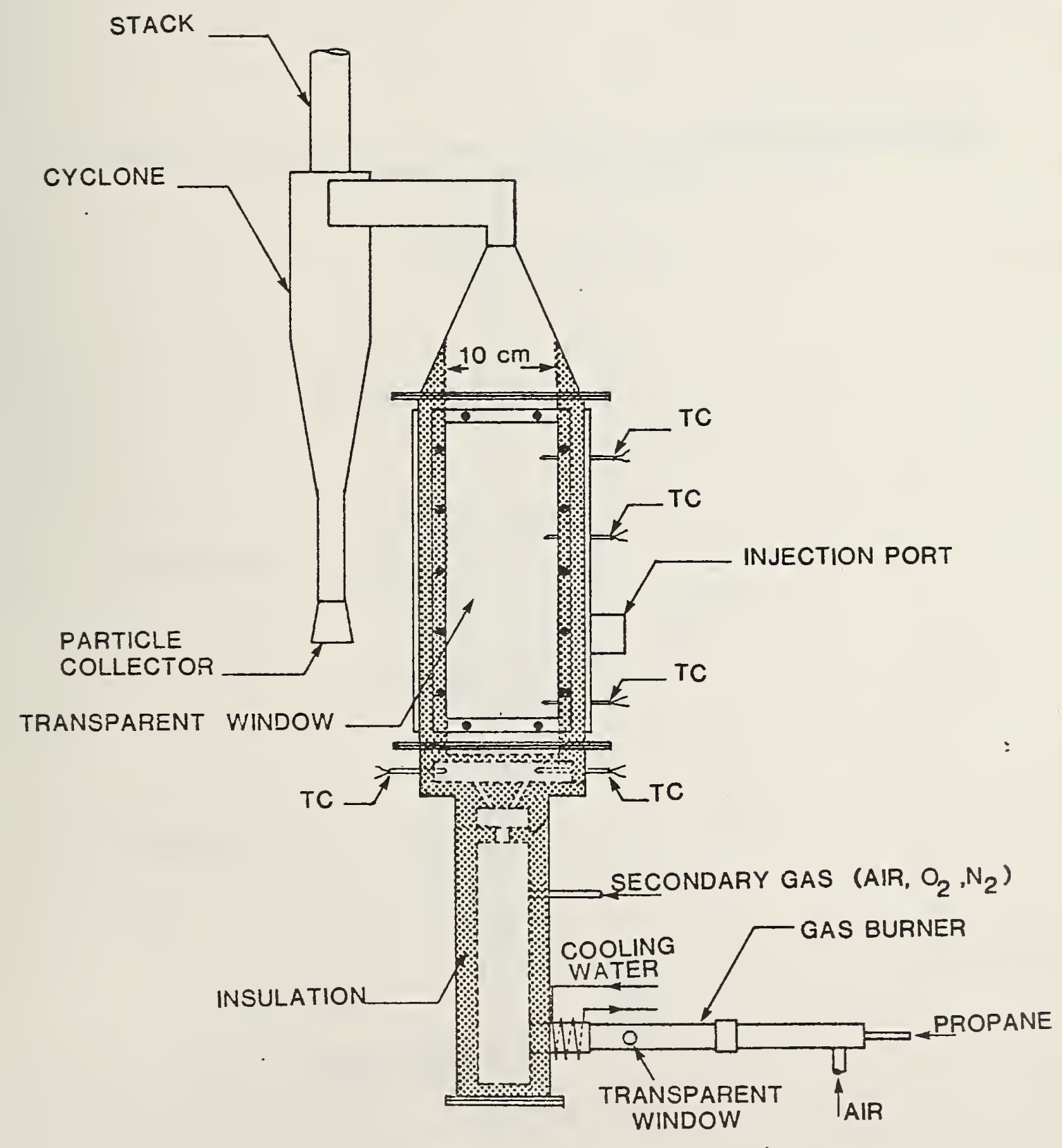

Fig 1: Laboratory furnace. TC - Thermocouple 
PARTICLE STREAM

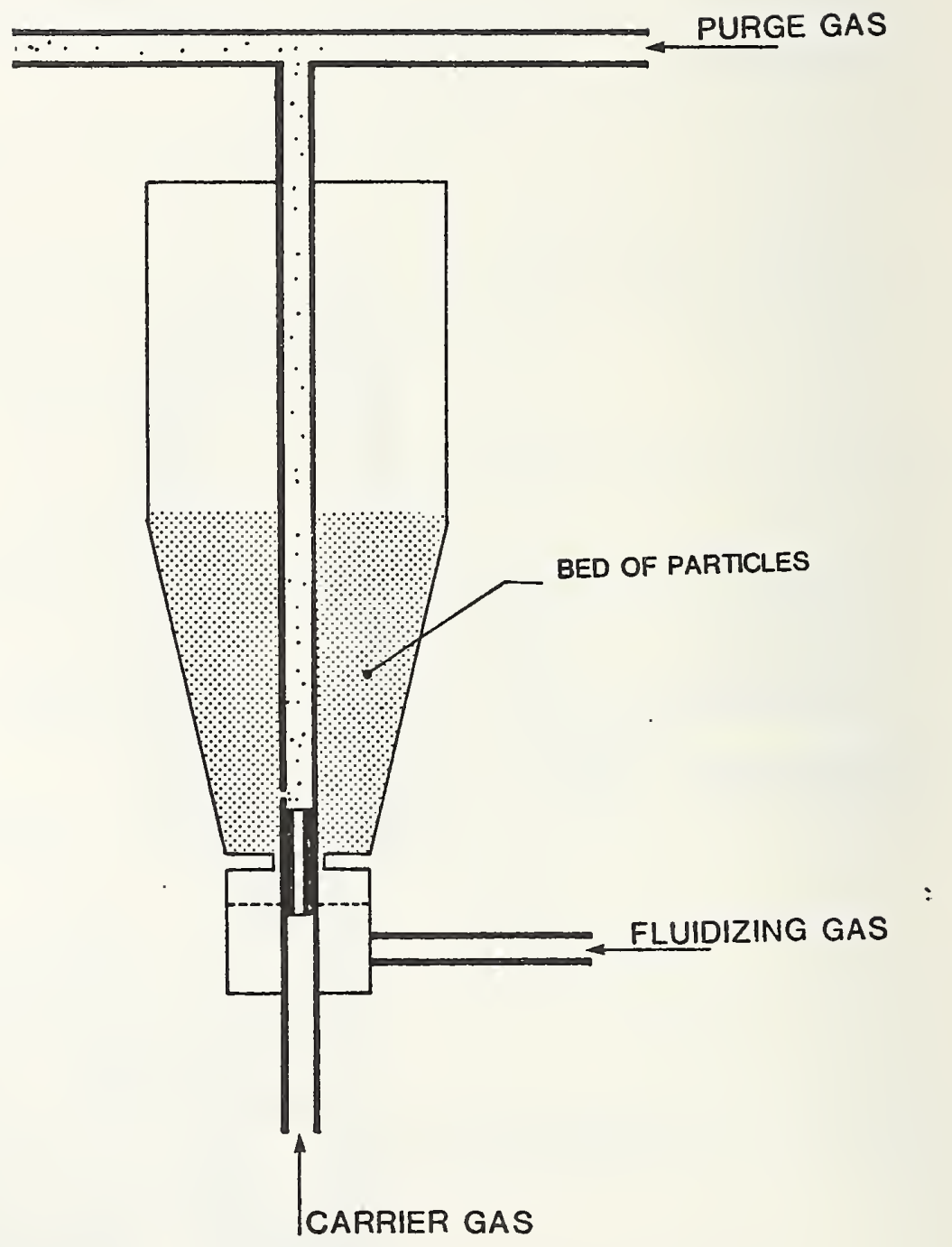

Fig. 2: Particle feeder 


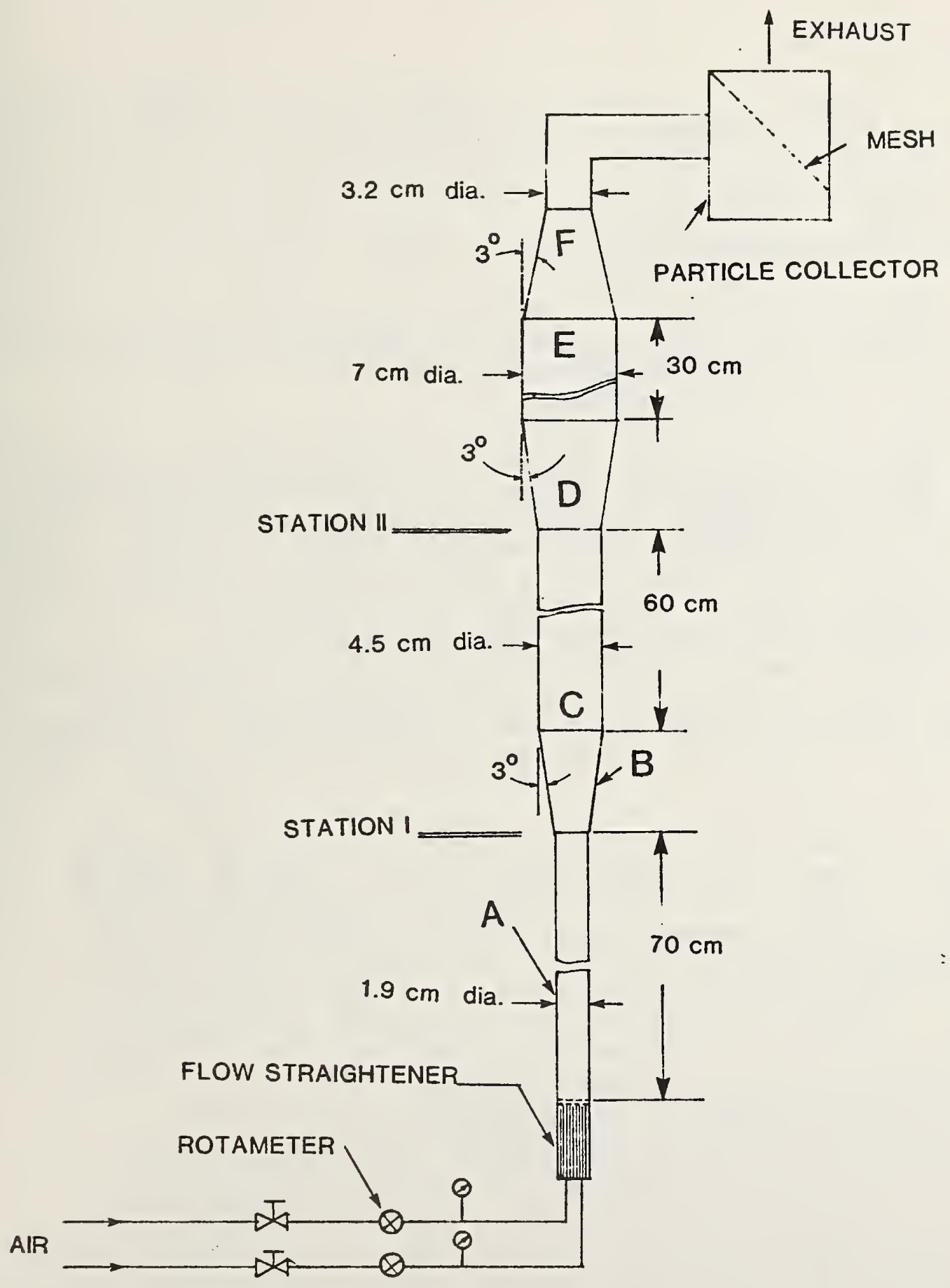

Fig. 3: Cold flow elutriation apparatus 


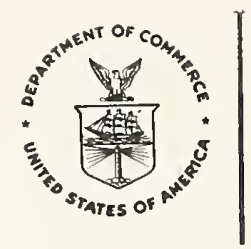

September 28, 1981

MEMORANDUM FOR The Record

From: Joseph G. Berke

Subject: Progress Report \#1 on IPA

This progress report covers the period of September 8 to 11 , and the several meetings in the area, prior to officially starting at the State Solid Waste Board on September 14.

On September 9 a meeting was held with the DoC-ITA trade specialists in the region 9 office. They were Mr. Francis Caffrey and Mr. George Dolan (addresses attached). The meeting was requested by Mr. Caffrey while I was still at NBS. The purpose was to learn of the IPA assignment and what I was to do. After reviewing the assignment the discussion moved on to a major problem they often encounter. Many of the companies they deal with often request standards and

specifications from the various countries to whom they wish to export their products. To date, they have tried many ways to get foreign product specs from various sources but with poor success. I informed them of the NBS Spec. library and inquiry service - they never heard about it.

Mr. Dolan in particular would like to learn about the NBS capability to identify, locate or recommend where to find, supply or reference various international or domestic standards. They need a point of contact and a phone number to call for assistance. Mr. Dolan also mentioned some companies come to him with ideas or products dealing with energy conservation and asking for help with marketing, and export. I mentioned the OERI at NBS which he had not heard about. He thought that some of his companies could use the service. He would like to receive several information packages and a name to contact so he could be of more service to the companies. In the area of recycting Mr. Dolan dealt with a company in Yuba City who has equipment for recycling plastics. He will look up the information on them and give it to me for follow-up. DoC sponsors many seminars around the area and we were offered the forum to talk about material recycling, recycled product directory currently being prepared for ORM by the State of Florida and procurement. We will discuss this more at a later date and see how it corresponds to the duties at SWMB. 
The next meeting was with Mr. Powell McDaniel, Deputy Regional Director - MBDA. He was briefed on the IPA assignment and specifically on the potential of Subtitle F of RCRA and how small a minority business could offer products with recoverd and recycled material. He suggested I meet with Ms. Jennifer Stanley of the State GSA. Ms. Staley has been supported by a continuing grant from MBDA to help minority business get into the procurement process with state. He would like to receive a copy of RCRA and at least the executive summary of the ORM seven state procurement study - I will send them. This material may be highlighted in the MBDA newsletter.

On September 10 an introductory meeting was held with several SWMB staff. Mr. John Hagerty and I discussed my areas of interest and how to best match them with the Board's areas. The three areas where there is a good match are the waste-to-energy projects under $\mathrm{Mr}$. Doug Strauch - Chief of the Waste Management Division and more directly under Mr. Armand Polansky. A second area is marketing of recovered materials and procurement of products containing recovered materials under Division Chief Herb Iwahiro and managers Regis Kunz and Chris Peck. The third area is with the Dept. of Health in the area of testing and measurement of hazardous and toxic waste under Dr. Harvey Collins and Dr. Robert Stephens. I will be visiting both Collins and Stephens to establish the specifics of our working relations. Dr. Stephens is working toward a state-wide quality assurance and lab calibration program and has expressed interest in NBS information and SRM's. More information will be developed when we meet at the Berkeley lab on September 22. Also met with Mr. Iwahiro and we talked about the marketing, waste reduction and procurement projects. I will "float" among the projects until a comfortable working system can be developed. The three areas cited are of utmost interest to the Board and $\mathrm{Mr}$. Trumbull the Chairman. These also complement the duties of the DOC Secretary under Subtitle E. Conversations with the area managers, Kunz and Peck, reaffirmed their interest in having NBS/DOC help.

On September 11 - met with Ms. Jennifer Stanley of the GSA - OMBDA office, at the suggestion of Mr. McDaniel of MBDA - DOC region 9. Ms. Stanley was interested in the idea of developing a program for minorities in the recycled product area. She serves on Governor's Small Business Advisory Council and they are looking for new project ideas to present to the Governor. I will arrange a meeting with SWMB staff to discuss how best to structure a joint program which will then be offered to the Governor for consideration. Should a program be initiated Ms. Stanley will publicize it in their newsletter and offer us a forum to present the program at various meetings. A meeting typical of the one we may be participants in will be held October 13 in Pasadena (information enclosed) sponsored by State Senator Diane E. Watson. DOC Secretary Baldridge is listed as a keynote luncheon 
speaker. Perhaps he may like to know of any program where NBS is partcipating - if it does happen. Will call or write in with more details as they develop. As of today it is uncertain if I will attend. Guidance from NBS would be appreciated.

Next meeting on the 11th was with Don Ekstedt - Chief of Specifications for the State Procurement Department. He received the seven state study and would be going over it. We talked about initiating a program with SWMB and OMBDA and he would support a program as long as it was carried out via normal procurement processes. State is already recycling and remanufacturing office furniture and Caltrans was evaluating recycled oils and greases. Procurement will probably be represented at the meeting with Ms. Stanley and SWMB. This project will be one that I may possibly carry out myself although I suggested someone from the Board staff take a lead role with my assistance. We will see what happens!

On September 14, the IPA begins and actual onsite project involvement will allow for the identification of needs.

A copy of the most current organizational structure is also attached. 
October 9, 1981

MEMORANDUM FOR The Record

From: Joseph G. Berke

Subject: IPA Progress Report No. 2 -- September 14 - October 1, 1981

On September 14, 1981, the IPA assignment officially started, and the process of getting acquainted with staff, projects, and procedures began. Opening meetings were held with Mr. Iwahiro and Mr. Strauch to review the job I was to do for NBS while in California and to get better acquainted with their respective program areas. Overviews of the major board program areas are shown in the organization chart submitted with report No. 1.

Additional general conversations were held with Dr. Robert Stevens of the Health Department Laboratory in Berkeley. This was a followup on a previous meeting with Dr. Stevens at NBS while he was attending a conference in May. The talks concerned the topics of developing some sort of voluntary/mandatory laboratory accreditation program for those labs in the State, public or private, who are doing hazardous waste analyses. A meeting was set for September 22 to discuss the matter further. Another call was to Harry Freeman of the Governor's Office of Appropriate Technology (OAT) to discuss their work on the disposal of hazardous wastes by incineration. OAT is reviewing various technologies and will select several--up to six--for possible demonstration. A report on the study will be issued soon, and we will get a copy. I informed him of the NBS work and interest in the subject, and we will meet in about two weeks to discuss details.

On this first day I also attended a meeting of the staff of the Office of Market Research and Development. Here I reviewed the IPA task and offered the services of NBS in appropriate areas. Projects in this area include a study of the export market for fibers collected in California. Specifically, the interest involves (1) export market and in-state mill capacity for waste paper in all categories, (2) influential factors governing the export of waste paper from California, (3) what products made from waste paper can be exported or sold in California, (4) information on future mill capacity, new construction, etc., and (5) a model or methods for projecting the supply and demand for waste paper. A call was placed to Jim Owens and Diana Friedman of BIE/DoC to see if the information was available on a state-specific basis. It was not. I also requested a copy of the ORM-funded study of waste paper markets in four southeastern states. The report cannot be released yet because it is still being reviewed at DoC. This report may be of help in the study here. A second area of interest of this Office is the procurement of products containing recovered material. The seven-state study is very helpful in showing what is happening around the country. The Florida projects on a directory of suppliers and the Colorado project on developing bid evaluation criteria for recycled products are going to be very helpful in California. I will continue to work with Cathy Hudson on these. I also prepared an outline for a joint project between SWMB 
and GSA on such procurements in California. We will be presenting the outline to the State purchasing director as soon as SWMB staffing of the project is settled. A draft copy of the procurement project is attached. This procurement project has the strong interest and support of the chairman, Mr. Trumbu11, and the Board members themselves. Mr. Trumbull mentioned the support and interest during a brief meeting with him. He also suggested that I attend, in his behalf, the meetings of the Toxic Substances Coordinating Council. I am trying to get in touch with proper people, but so far, no one representing the Council has returned the calls--I will keep trying.

Also attended the staff meeting of the Program Development Group and once again reviewed my IPA assignment. This group contains the $0 i 1$ recycling program. The people in this program are aware of the NBS work and are interested in meeting with Don Becker when he visits the Board on 0ctober 7 . The meetings have been arranged.

Another series of meetings were held with staff members of the Waste Management Section--under the direction of Mr. Strauch. Several ongoing projects in this. group are similar to several ongoing at NBS. The first of these involves the leaching of MSW, as received, ashing the MSW by ASTM methods, and leaching again by both the California method and the EPA extraction method. A different MSW sample from the same batch is used for the two leachings. EAL laboratories is under contract to perform the tests and report the results. Conversations with the EAL project director indicate that they are aware of NBS, the SRM materials, and that they are one of the commercial labs participating in the DoE/LETC Waste Characterization Program that NBS also participates in. They are interested in the NBS work in waste and would like to hear more about the IPA project and be made aware of waste related SRM's, data, research, etc. A further meeting was agreed to, but a time has not yet been set. It will probably be after their work on the state project is complete--about a month or two.

Another project, by Brown-Vence and Associates, is looking at the uses for fly ash. A meeting is scheduled for October 6 to discuss the project and inform them of the NBS work on the subject in CBT, CAC, and the literature search already performed. The Waste Management Section of the SWMB also monitors the ix major waste-to-energy projects being carried out around the state. It ppears that the actual technical needs reside with the cities and counties carrying out the work. More effort will be made to interact directly with the project directors to determine their technical needs. A new project that is in the planning stage addresses the problem of testing and monitoring the migration of landfill gas as well as to look at maximum recovery of the gas. Once the project gets going, the NBS participating role will be better defined. Attached is an article describing the problem and the project.

The first in-person meeting with the Health Department Lab in Berkeley took place September 22. Dr. Stevens was called out of town so the meeting was with Ms. Janice Nakao, a health chemist. We talked about my IPA and what programs NBS had that may be of help. One need was inorganics in water covering the elements and compounds cited in the Federal Register, Part III, December 3, 1979, and on page 64 of the August California Assessment Manual. 
Basically, SRM's are needed for various waste stream constituents in various matrices found in the environment. A copy of the manual is available in CAC, and the specific pages referred to are attached. The next major topic and area of measurement need revolve around a laboratory QA and Certification Program for public and private state laboratories. There is no legislation to establish a program, but it is being worked on. The program would be for labs doing hazardous waste analysis for cleanups after spills, for transporters, for enforcement and monitoring, and for the benefit of all interested parties. Currently, lab selection is done by "people knowing the good ones," by word of mouth, and from experience. In the absence of formal legislation, the thought ran to a voluntary accreditation program. This would include onsite inspections, reference sample analysis, equipment calibration, procedure review, and staff capability. NBS could be a participant in many of these areas. One thought was to hold a statewide conference on the subject of measurement needs and voluntary accreditation. This will have to be developed in more detail in subsequent meetings, but it is a thought.

Another major area of need involves training, information, and methods for use by county officials, who are generally first on the scene of a spill or other accident, to quickly determine what the material or mixtures of materials are and the treatment. Most labs are not well equipped, some even have activation analys is units--but not all. Most are one- to two-person operations, and yet they are the ones closest to the problem and who arrive at the scene first. Thus, rapid simple onsite screening tests are necessary along with proper data and training. The test, as a minimum, quickly identifies if a material is explosive, flammable, corrosive, etc., and how to treat the problem. One area of information and training is the effects of the surrounding matrix--dust, asphalt, concrete, etc.--on the material spilled and how the natural matrix can be quickly "subtracted out" of an analysis to isolate the material in question.

A brief conversation with a lab chemist indicated the need for SRM's of pure malathion and inaloxion. The material they buy from standard suppliers is commercial grade, and they need pure certified material. They also need stock solutions of organo-leads in a solvent that can be diluted to various concentrations. There was great interest in our synthetic leachates and the PCB in 0il SRM. It would be useful to prepare a brochure or a list of SRM's that have application to hazardous waste testing, even those older ones that when leached provide an interesting leachate--a new use for an old product. I have requested, through Steve Carpenter, samples of the leachates for Berkeley.

Another project at the Board involves a study to determine the feasibility of a "waste research institute." The firm of Gibbs ar $1 \mathrm{Hill}$ are doin $\mathrm{g}$ the std $:$.

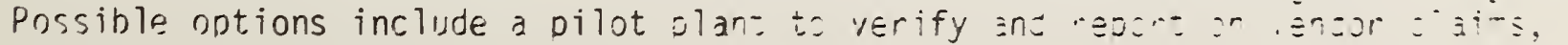
basic research laboratory, owner/operator training facilizy, technical evaluating and reporting center, economic research on MSW, or a combination of some of the above. The study is just getting started, and I will be following it closely. I provided the project person with contacts at NBS to discuss basic research in MSW as well as other information about ASTM, ASME, and other items of initial value to the study. The results should be useful to the NBS mission of technical assistance to the States. 
A meeting with Dr. Harvey Collins, Chief of the Environmental Health Branch-Department of Health Services, identified the need for critically analyzed compiled technical data on such items as treatment, disposal, analyses, sampling of hazardous and toxic wastes--whether from a fresh spill or an old abandoned site. There is a lot of new information coming out, some good but mostly poor, and someone needs to look at the material. Perhaps a focused program with in SRD, monitored by ORM, could be established. Dr. Collins also suggested visits to Dr. Storm in Hazardous Materials Management and to Dr. Heslep, Director of the Berkeley Lab, to brief them on the NBS program and my role in California. A copy of Dr. Collins' branch organization chart is attached.

This concludes report No. 2. It would be very helpful to me to hear from various NBS staff about the format and contents of this report, areas of interest that they want me to specifically pursue, and current NBS "products" or expertise that can be applied to the above subjects.

Attachments

CC:

C. Reimann

C. C. Gravatt

D. Johnson

ORM Staff 


\section{Conferences Sponsored}

November 20-21, 1980 -- Workshop on the Procurement of Products Containing Recovered Materials. Held at NBS.

May 18 - 20, 1981 -- DoE/NBS Workshop on Environmental Speciation and Monitoring Needs for Trace Metal-Containing Substances from Energy-Related Processes. Held at NBS.

September 28 -

October 1, 1981

-- 4th International Conference on Used 0il Recovery and Reuse Co-sponsored by U.S.D.O.E. and

U.S.N.B.S. Held at Caesars Palace, Las Vegas.

\section{Technical and Professional Committees}

Becker, Donald A.

Berke, Joseph B.

Matthews, R. T.

Yakowitz, $H$.
Voting Member, ASTM Committee D-2 Member, Technical Divisions

$$
\text { B, C, L, N, P }
$$

Member, ASTM Test Monitoring Board

Member, ASTM Committee D-38

ASTM E-38, Vice-Chairman, Awards

Member, ASTM Committee D-34

Member, ASTM D-34

Member, ASTM D-19

Vice Chairman, ASTM Committee D-34.02 


\section{Publications}

1. Berke, J. G. and Hudson, C. H., NBSIR 81-2316, "Procurement of

Products Containing Recovered Material: A Summary of Activities in Seven States", (July 1981).

2. Becker, D. A., "Re-refined Lube $0 i 1$ Consistency and Quality: The Ultimate Question," Proceedings, Second European Congress on the Recycling of Used 0ils, Syndicat National des Fabricants Raffineurs, Paris (October 1980). In Press.

3. Becker, D. A. and Hsu, S. H., "Status Report on the Characterization of Re-refined Lubricating Base 0ils," SAE Paper No. 801382, Society of Automotive Engineers, Warrendale, PA (October 1980).

4. Becker, D. A., "Research Methodology in Used $0 i 1$ Recycling," Proceedings, Conference on Atomic and Nuclear Methods in Fossil Energy Research, American Nuclear Society (December 1980). In Press.

5. Becker, D. A., Rook, H. L., and LaFleur, P. D., "High Purity Materials, Standards, and Reference Materials," Chapter 5, Section 4 in Nondestructive Activation Analysis, edited by S. Amiel, Elsevier Scientific PubT. Co., NYC (1981).

6. Becker, D. A., "Recycling-0il", Encyclopedia of Chemical Technology, John Wiley and Sons, Inc., NYC. T(In Preparation).

7. Domalski, E. S., Kirklin, D. R., and Mitchel1, D. J., "Determination of the Calorific Value of Refuse and Refuse-Derived-Fuels by Large Bomb Calorimetry. Summary of the 1978 Fiscal Year Results," NBSIR 801968, January 1980.

8. Domalski, E. S., Kirklin, D. R., Colbert, J., Decker, P.

Abramowitz, S., "Test Procedures for the Determination of Gross Calorific Value of Refuse and Refuse-Derived-Fuel by Conventional and Large Bomb Calorimetry. Summary of 1979 FY Results," NBSIR 81-2278, June 1981.

9. "Chemical Waste Incinerator Ships - The Interagency Program to Develop a Capacity in the United States," to the Society of Naval Architests and Marine Engineers, Washington, DC, September 23, 1981. Coauthors:Gerald 0. Chapmen, U.S.E.P.A., Daniel Leubecker, Maritime Administration, Lissa Martinez, Maritime Administration, Rosalie, Matthews, U.S.D.O.C., Donald A. Oberacher, U.S.E.P.A., and Frits Wybenga, U. S. Coast Guard. 
Becker, D. A., "Alternative Utilization: Recycled 0il Used As Fuel," Fourth International Conference on Used 0il Recovery and Reuse, Las Vegas (September 1981).

Becker, D. A., "NBS Research on Re-refined Engine 0il Tests," Fourth International Conference on Used $0 i l$ Recovery and Reuse, Las Vegas (September 1981).

Becker, D. A., "Re-refined Lube $0 i 1$ Consistency and Quality: The Ultimate Question," Second European Congress on the Recycling of Used 0ils, Paris (October 1980).

Becker, D. A., "Current Status of the NBS Recycled 0il Program," Third Annual Conference, National Association of $0 i 1$ Recovery Coordinators, Raleigh, N.C. (April 1981).

Becker, D. A., "Recycled 0il Burned for Fuel: Positive or Negative?", American Boiler Manufacturers Association Meeting, Chicago (April 1981).

Becker, D. A., "Activities in Recycled $0 i 1$ and Product Quality," Used 0il Recycling Seminar Series for State Programs; Orlando, FL (July 1981); Philadelphia (September 1981).

Berke, J. G., "Prepared 5 minute tape on Resource Recovery for the Department of Commerce Radio Feature Service.

Domalski, E. S., "Design Characteristics of the 2.5 Kilogram Capacity Flow Calorimeter," Subcommittee E38.01 on Energy, Philadelphia, PA, Apr. 1981.

Domalski, E. S., "Recent Developments in the Design and Construction of the 2.5 Kilogram Capacity Flow Calorimeter," ASME Research Committee on Industrial and Municipal Wastes, New York, NY, June 1981.

Matthews, R. .T., "National Conference of State Legislators' Annual Meeting, Atlanta, Georgia, July 3, 1981: Panel on "Garbage - The Resource of the 80 's."

Yakowitz, H., Address to Chief Executive Officers of member companies of the American Paper Industry (Phoenix, Arizona), October 1980.

Yakowitz, H., Presentation to the Eastern Regional Conference, National Association of Recycling Industries (New York, New York), December 1980.

Yakowitz, H., Presentation to the California State Solid Waste Management Board (Sacramento, California), "Federal Plans for Resource Recovery from Municipal Waste," January 1981. 
Yakowitz, H., Presentation as member of U.S. delegation at Waste Management Policy Group meeting, Organization for Economic Cooperation and Development (Paris, France), "National Bureau of Standards Activities in Recycled Materials," April 1981.

Yakowitz, H., Presentation to the Executive Board of the Association of State and Territorial Solid Waste Management Officials (Washington, DC), "Department of Commerce Program in Resource Recovery," 1981.

Yakowitz, H., Presentation to American Iron and Steel Institute Task Group (Pittsburgh, Pennsylvania), "Possibilities for the Recycling of Steel Mill Sludges," July 1981. 
NBS-114A (REV. 2-8C)

U.S. DEPT. OF COMM.

1. PUBLICATION OR REPORT NO.

BIBLIOGRAPHIC DATA

NBSIR $81-2417$

2. Performing Organ. Report No.

3. Publication Date

November 1981

SHEET (See instructions)

4. TITLE AND SUBTITLE

\section{Technical Activities of the Office of Recycled Materials}

\section{5. $A U T H O R(S)$}

Donald A. Becker, Joseph G. Berke, Eugene S. Domalski, Rosalie I. Matthews \& Yakowitz

6. PERFORMING ORGANIZATION (If joint or other than NBS, see instructions) $\quad$ 7. Contract/Grant No.

MATIONAL BUREAU OF STANDARDS

DEPARTMENT OF COMMERCE

WASHINGTON, D.C. 20234

8. Type of Report \& Period Covered

9. SPONSORING ORGANIZATION NAME AND COMPLETE ADDRESS (Street, City, State, ZIP)

10. SUPPLEMENTARY NOTES

Document describes a computer program; SF-185, FIPS Software Summary, is attached.

11. ABSTRACT (A 200-word or less factual summary of most significant information. If document includes a significant bibliography or literature survey. mention it here)

A review of recycled materials programs at NBS, for FY $T 98 T$ is presented in this annual report.

12. KEY WORDS (Six to twelve entries; alphabetical order; capitalize only proper names; and separate key words by semicolons)

Energy-from-was te; materials market; $0 i 1$ analysis; recycled materials; refused-derived-fuel; re-refined oil.

\section{AVAILABILITY}

Unlimited

[X] For Official Distribution. Do Not Release to NTIS

$\square$ Order From Superintendent of Documents, U.S. Government Printing Office, Washington, D.C. 20402.

Order From National Technical Information Service (NTIS), Springfield, VA. 22161
14. NO. OF

PRINTED PAGES 


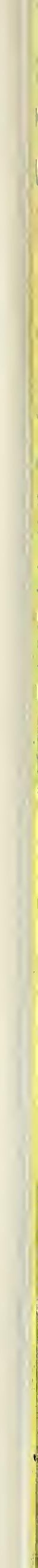



